University of Louisville

ThinkIR: The University of Louisville's Institutional Repository

Electronic Theses and Dissertations

$12-2012$

\title{
A novel high yield process for gold sulfide nanoparticle synthesis via shifting equilibrium of self-assembly reaction.
}

Dhruvinkumar Patel

University of Louisville

Follow this and additional works at: https://ir.library.louisville.edu/etd

\section{Recommended Citation}

Patel, Dhruvinkumar, "A novel high yield process for gold sulfide nanoparticle synthesis via shifting equilibrium of self-assembly reaction." (2012). Electronic Theses and Dissertations. Paper 1098. https://doi.org/10.18297/etd/1098

This Master's Thesis is brought to you for free and open access by ThinkIR: The University of Louisville's Institutional Repository. It has been accepted for inclusion in Electronic Theses and Dissertations by an authorized administrator of ThinkIR: The University of Louisville's Institutional Repository. This title appears here courtesy of the author, who has retained all other copyrights. For more information, please contact thinkir@louisville.edu. 


\title{
UNIVERSITY OF LOUISVILLE \\ A NOVEL HIGH YIELD PROCESS FOR GOLD SULFIDE NANOPARTICLE SYNTHESIS VIA SHIFTING EQUILIBRIUM OF SELF- ASSEMBLY REACTION
}

BY

\section{DHRUVINKUMAR PATEL}

\author{
A THESIS SUBMITTED \\ IN PARTIAL FULFILLMENT OF THE \\ REQUIREMENTS FOR THE DEGREE \\ Masters of Engineering
}

Approved, Thesis COMMITTEE:

Andre M. Gobin
Assistant Professor, Bioengineering

Committee Chair

Andrea S. Gobin

Associate Professor, Bioengineering

Stuart J. Williams

Assistant Professor, Mechanical engineering 


\section{ABSTRACT}

Gold nanoparticles (AuNPs) have attracted enormous attention in the field of nanotechnology for applications such as, immunoassay, drug delivery, contrast enhancement and tumor therapy. The typical range of gold nanoparticles varies from 1$150 \mathrm{~nm}$; there are many different subtypes of AuNPs mainly based on size, shape, and optical properties including: gold nanospheres, nanorods, nanocages, and nanoshells. The main advantage of using gold nanoparticles is the large surface-to-volume ratio; this will allow the particles to be functionalized with drugs and/or targeting agents to create many novel applications. Many AuNPs have another advantage as well, they can be fabricated to either absorb or scatter light in the visible to near-infrared (nIR) region of the spectrum. Current research, using gold nanoparticles, mainly focuses on taking advantage of the nIR window. In biomedical research the nIR window is very important; nIR light has minimal interference with tissue and only affects samples which absorb nIR light, which enables minimally invasive imaging and treatment.

Specifically, gold/gold sulfide nanoparticles (GGS) have been introduced for many applications compared to silica-gold nanoshells due to the smaller size of particles. This project is focused on a novel purification/high yield process of GGS nanoparticles using chloroauric acid $\left(\mathrm{HAuCl}_{4}\right)$ and sodium thiosulfate $\left(\mathrm{Na}_{2} \mathrm{~S}_{2} \mathrm{O}_{3}\right)$, with desired nIR peak that can be used for therapeutic applications. By combining the traditional published methods for 1-step self-assembly of GGS nanoparticles and dialysis techniques simultaneously, a new method for production of gold / gold-sulfide nanoparticles has been established in this research project which we call DiaSynth. In this process the equilibrium of the reaction is shifted to favor the formation of nIR absorbing particles. 
This technique minimizes production of gold nanoparticles with $530 \mathrm{~nm}$ resonance (colloidal gold), resulting in populations of nanoparticles that require minimum further processing for use as a therapeutic agent. The colloidal gold is considered a contaminant, formed during the self-assembly process, which are traditionally removed via multi-step centrifugation. We define a ratio of the absorbance of peaks, $\mathrm{R}^{\mathrm{nIR} / \mathrm{Au}}$; this is based on the peak absorbance in of the nIR region $(700-900 \mathrm{~nm})$ relative to the colloidal gold peak ( $\sim 530 \mathrm{~nm})$ as a relative measure of the quality of nIR particles. The current method for producing nIR GGS, based on a single step procedure, results in a poor ratio, $\mathrm{R}^{\mathrm{nIR} / \mathrm{Au}}=$ 0.7 - 1.0. The DiaSynth method utilizes a shift in kinetics via removal of smaller ions and other products during the reduction of gold and sulfur. This method has allowed us to increase the yield of as made product to have an $\mathrm{R}^{\mathrm{nIR} / \mathrm{Au}}=1.7-2.0$. In comparison, purification by centrifugation results in great loss of particles during each step to achieve similar ratios. At a ratio of $1.7-2.36$, no centrifugation is needed to separate out colloidal gold, resulting in reduced production costs and higher quality product. 


\section{TABLE OF CONTENT}

CHAPTER 1 - GOLD NANOPARTICLES.........................................12

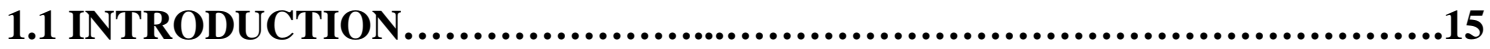

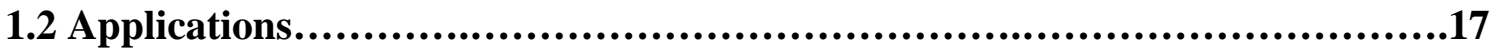

1.2.1 Nanoshells .....................................................................18

1.2.2 Nanorods.......................................................................19

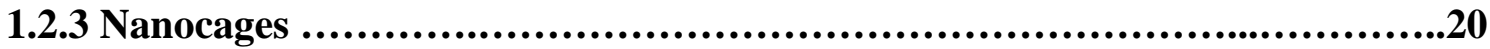

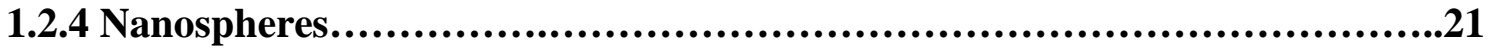

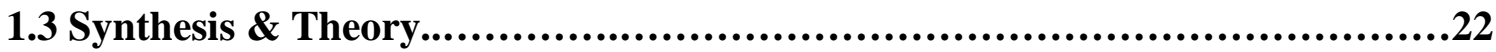

1.3.1 Models of Growth and Resonant Properties...................................25

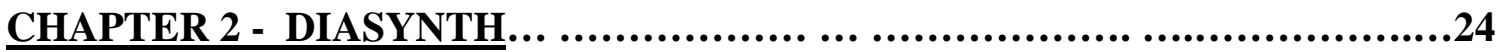

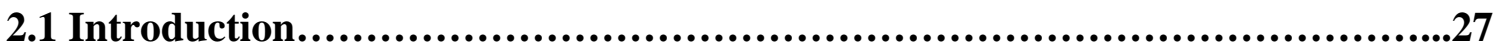

2.2 Current methods \& DiaSynth...............................................28

2.3 DiaSynth - optimized synthesis of gold / gold-sulfide nanoparticles ...............32

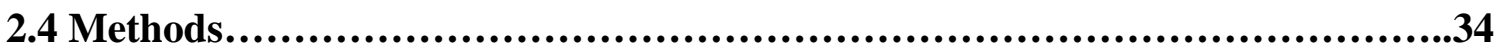

2.4.1 Traditional One-Step Method...................................................34

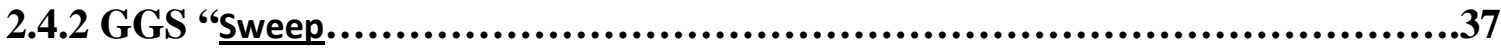


2.4.3 GGS Sweep on Oven Based Temperature Synthesis

2.4.4 GGS Synthesis in Water Bath \& Oven - Temperature Controlled Environment

2.4.5 GGS Synthesis in Water Bath - Temperature Controlled Environment...... 51

2.4.6 DiaSynth.................................................................59

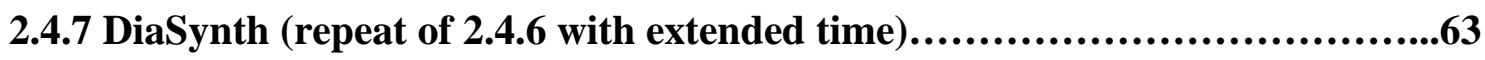

2.4.8 DiaSynth - with time and int. ratio variation...............................66

2.4.9 DiaSynth - using high temperature.........................................69

2.4.10 DiaSynth $-1,2$ step........................................................71

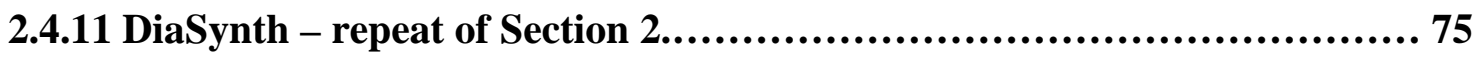

2.4.12 DiaSynth Sweep........................................................85

2.4.13 DiaSynth - using higher MWCO bags................................. 93

2.4.14 DiaSynth - 12 KDa MWCO Sweep........................................96

2.4.15 DiaSynth - Dialysate...................................................99

2.4.16 DiaSynth - Scale up..........................................................103

$\underline{\text { CHAPTER } 3}$ - DISCUSSION AND CONCLUSION $. . . \ldots \ldots \ldots \ldots \ldots \ldots \ldots \ldots \ldots \ldots . . . \ldots 106$

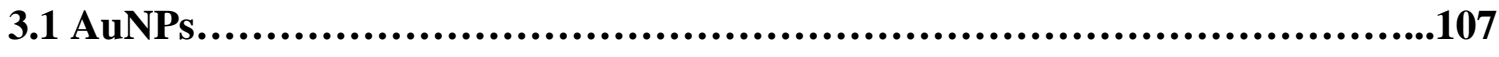

3.2 Temperature Effects............................................................108 
3.4 Future Direction

Appendix I - Provisional Patent Application. .115

Appendix II - Appointment of Members of the Examination Committee...........131

Appendix III - Oral Examination Request.....................................133

Appendix IV- Oral Examination Request........................................134 


\section{LIST OF FIGURES \& TABLES}

Figure 1: Spectral profile (A) image of the GNS that were fabricated with radius of $\sim 74$ $\mathrm{nm}$ and core of $\sim 60 \mathrm{~nm}$ and STEM image (B) to confirm the synthesis. 18

Figure 2: Spectral profiles of gold nanoparticles during the two-step synthesis. A, B, and C are different parameters that were used by Zhou et al for further understand the twostep self-assembly process (Zhou, Honma et al. 1994). 23

Figure 3: Spectral profile of the GGS nanoparticles with traditional single step selfassembly process, black line represents particles as made with $\mathrm{R}^{\mathrm{nIR} / \mathrm{Au}}=0.83$, while the red line is the particles after multi-step centrifugation with $\mathrm{R}^{\mathrm{nIR} / \mathrm{Au}}=1.95$. 31

Figure 4: Normalized absorbance of GGS nanoparticles with traditional single step selfassembly process, the black line represents nanoparticles as made with $\mathrm{R}^{\mathrm{nIR} / \mathrm{Au}}=0.83$ (As made), while the red line is the nanoparticles after multi-step centrifugation with $\mathrm{R}^{\mathrm{nIR} / \mathrm{Au}}=$ 1.95 (After 3X centrifugation). 35

Figure 5: GGS nanoparticle synthesis sweep using $11 \mathrm{~mL}$ of $2 \mathrm{mM} \mathrm{HAuCl} 4+\mathrm{X} \mathrm{mL}$ of 3 $\mathrm{mM} \mathrm{Na} 2 \mathrm{~S} 2 \mathrm{O} 3$ in $1 \mathrm{~mL}$ increments (from 1-7). 38

Figure 6: GGS nanoparticle synthesis sweep using $11 \mathrm{~mL}$ of $2 \mathrm{mM} \mathrm{HAuCl}_{4}+\mathrm{X} \mathrm{mL}$ of 3 $\mathrm{mM} \mathrm{Na}_{2} \mathrm{~S}_{2} \mathrm{O}_{3}$ in $0.5 \mathrm{~mL}$ increments (from 2.5-5). 39

Figure 7: GGS nanoparticle synthesis sweep using $11 \mathrm{~mL}$ of $2 \mathrm{mM} \mathrm{HAuCl}_{4}+\mathrm{X} \mathrm{mL}$ of 3 $\mathrm{mM} \mathrm{Na} \mathrm{S}_{2} \mathrm{O}_{3}$ in $0.5 \mathrm{~mL}$ increments (from $2.5-5$ ) at $37^{\circ} \mathrm{C}$ in an oven.

Figure 8: GGS nanoparticle synthesis sweep using $11 \mathrm{~mL}$ of $2 \mathrm{mM} \mathrm{HAuCl}_{4}+\mathrm{X} \mathrm{mL}$ of 3 $\mathrm{mM} \mathrm{Na} \mathrm{S}_{2} \mathrm{O}_{3}$ in $0.5 \mathrm{~mL}$ increments (from 2.5-5) at $65^{\circ} \mathrm{C}$ in an oven.............................. 42 Figure 9: Scatter plot (data from Table 4) of the initial ratio $\left(\mathrm{HAuCl}_{4}: \mathrm{Na}_{2} \mathrm{~S}_{2} \mathrm{O}_{3}\right)$ used vs the nIR peak at the end of the reaction is the given three controls. 44 
Figure 10: Scatter plot (data from Table 4) of the initial ratio $\left(\mathrm{HAuCl}_{4}: \mathrm{Na}_{2} \mathrm{~S}_{2} \mathrm{O}_{3}\right)$ used vs the $\mathrm{R}^{\mathrm{nIR} / \mathrm{Au}}$ at the end of the reaction is the given three controls..................................45

Figure 11: GGS nanoparticle synthesis using $11 \mathrm{~mL}$ of $2 \mathrm{mM} \mathrm{HAuCl}_{4}+2 \mathrm{~mL}$ of $3 \mathrm{mM}$ $\mathrm{Na}_{2} \mathrm{~S}_{2} \mathrm{O}_{3}$ in a water bath and an oven at $35^{\circ} \mathrm{C}$ or $65^{\circ} \mathrm{C}$. 48

Figure 12: GGS nanoparticle synthesis using $11 \mathrm{~mL}$ of $2 \mathrm{mM} \mathrm{HAuCl}_{4}+3 \mathrm{~mL}$ of $3 \mathrm{mM}$ $\mathrm{Na}_{2} \mathrm{~S}_{2} \mathrm{O}_{3}$ in a water bath and an oven at $35^{\circ} \mathrm{C}$ or $65^{\circ} \mathrm{C}$. 49

Figure 13: Spectral profile of the RT synthesis, using a mixture of $8 \mathrm{~mL}, 9 \mathrm{~mL}, 10 \mathrm{~mL}$, or $11 \mathrm{~mL}$ of $2 \mathrm{mM} \mathrm{HAuCl}_{4}$ and $3 \mathrm{~mL}$ of $3 \mathrm{mM} \mathrm{Na}_{2} \mathrm{~S}_{2} \mathrm{O}_{3}$. 52 Figure 14: Spectral profile of the $37^{\circ} \mathrm{C}$ water bath synthesis, using a mixture of $8 \mathrm{~mL}, 9$

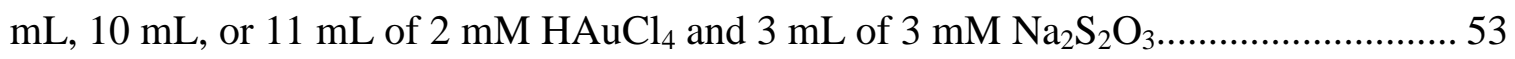
Figure 15: Spectral profile of the $100^{\circ} \mathrm{C}$ water bath synthesis, using a mixture of $8 \mathrm{~mL}, 9$

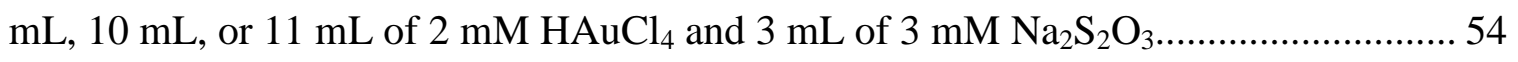
Figure 16: Scatter plot (data from Table 6) of the initial ratio $\left(\mathrm{HAuCl}_{4}: \mathrm{Na}_{2} \mathrm{~S}_{2} \mathrm{O}_{3}\right)$ used vs the $\mathrm{R}^{\mathrm{nIR} / \mathrm{Au}}$ at the end of the reaction is the given three controls. 56 Figure 17: Scatter plot (data from Table 6) of the initial ratio $\left(\mathrm{HAuCl}_{4}: \mathrm{Na}_{2} \mathrm{~S}_{2} \mathrm{O}_{3}\right)$ used vs the nIR peak at the end of the reaction is the given three controls.... 57 Figure 18: Normalized absorbance and spectral profile of GGS nanoparticles synthesized using various parameters. (Sample 1, black-square line) $11 \mathrm{~mL}$ of $2 \mathrm{mM} \mathrm{HAuCl} 4$ mixed with $3 \mathrm{~mL}$ of $3 \mathrm{mM} \mathrm{Na}_{2} \mathrm{~S}_{2} \mathrm{O}_{3}$ dialyzed against DI water with $\mathrm{R}^{\mathrm{nIR} / \mathrm{Au}}=1.4$. (Sample 2) 25 $\mathrm{mL}$ of $2 \mathrm{mM} \mathrm{HAuCl}_{4}$ dialyzed against $1 \mathrm{~L}$ of $\mathrm{Na}_{2} \mathrm{~S}_{2} \mathrm{O}_{3}$ for 2.5 hrs (blue-triangle line). (Sample 3, red-circle line) Non-dialyzed sample using $11 \mathrm{~mL}$ of $2 \mathrm{mM} \mathrm{HAuCl}{ }_{4}$ mixed with $3 \mathrm{~mL}$ of $3 \mathrm{mM} \mathrm{Na}_{2} \mathrm{~S}_{2} \mathrm{O}_{3}$ with $\mathrm{R}^{\mathrm{nIR} / \mathrm{Au}}=1.53$. 60 
Figure 19: Image of Non-Dialysis synthesis and dialyzed synthesis over $1 \mathrm{hr}$ time period. (A - D) Image of non-dialyzed sample at 30 secs, 5 mins, 30 mins, and 1 hr, respectfully. (E - F) Image of Dialyzed sample at 30 secs, 5 mins, 30 mins, and 1 hr, respectfully..... 61 Figure 20: Non-normalized absorbance and spectral profile of GGS nanoparticles synthesized using various parameters. (Sample 1, black-square line) $11 \mathrm{~mL}$ of $2 \mathrm{mM}$ $\mathrm{HAuCl}_{4}$ mixed with $3 \mathrm{~mL}$ of $3 \mathrm{mM} \mathrm{Na}_{2} \mathrm{~S}_{2} \mathrm{O}_{3}$ dialyzed against DI water with $\mathrm{R}^{\mathrm{nIR} / \mathrm{Au}}=1.4$. (Sample $2 \& 3$, respectively) $25 \mathrm{~mL}$ of $2 \mathrm{mM} \mathrm{HAuCl}_{4}$ dialyzed against $1 \mathrm{~L}$ of $\mathrm{Na}_{2} \mathrm{~S}_{2} \mathrm{O}_{3}$ for 2.5 hrs (blue-triangle line) and 5 hrs (pink line-triangle-down line), both with $\mathrm{R}^{\mathrm{nIR} / \mathrm{Au}}$ < 1. (Sample 4, red-circle line) Non-dialyzed sample using $11 \mathrm{~mL}$ of $2 \mathrm{mM} \mathrm{HAuCl} 4$

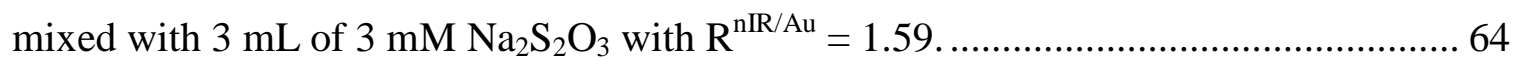
Figure 21: Normalized absorbance and spectral profile of GGS nanoparticles synthesized using various parameters. (Sample $1 \& 3$, red-circle \& blue-triangle line respectively) 11 $\mathrm{mL}$ of $2 \mathrm{mM} \mathrm{HAuCl}_{4}$ mixed with $2 \mathrm{~mL}$ of $3 \mathrm{mM} \mathrm{Na}_{2} \mathrm{~S}_{2} \mathrm{O}_{3}$ dialyzed against DI water for 1 \& 2 hrs, respectively, with $\mathrm{R}^{\mathrm{nIR} / \mathrm{Au}}=2.01 \& 1.65$, respectively. (Sample 5, black-square line) Non-dialyzed sample using $11 \mathrm{~mL}$ of $2 \mathrm{mM} \mathrm{HAuCl}_{4}$ mixed with $2 \mathrm{~mL}$ of $3 \mathrm{mM}$ $\mathrm{Na}_{2} \mathrm{~S}_{2} \mathrm{O}_{3}$ with $\mathrm{R}^{\mathrm{nIR} / \mathrm{Au}}=\mathrm{N} / \mathrm{A}$, due to the unknown nIR peak (out of range).....................67 67 Figure 22: Normalized absorbance and spectral profile of GGS nanoparticles synthesized using various parameters. (Sample $2 \& 4$, red-circle \& blue-triangle line respectively) 11 $\mathrm{mL}$ of $2 \mathrm{mM} \mathrm{HAuCl}_{4}$ mixed with $3 \mathrm{~mL}$ of $3 \mathrm{mM} \mathrm{Na}_{2} \mathrm{~S}_{2} \mathrm{O}_{3}$ dialyzed against DI water for 1 \& 2 hrs, respectively, with $\mathrm{R}^{\mathrm{nIR} / \mathrm{Au}}=1.58 \& 1.49$, respectively. (Sample 6, black-square line) Non-dialyzed sample using $11 \mathrm{~mL}$ of $2 \mathrm{mM} \mathrm{HAuCl}_{4}$ mixed with $3 \mathrm{~mL}$ of $3 \mathrm{mM}$

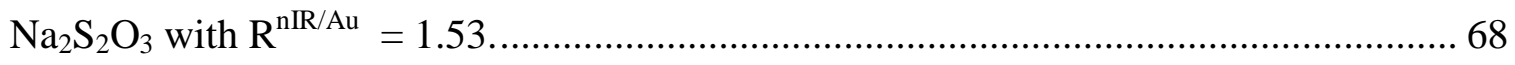


Figure 23: Normalized absorbance and spectral profile of GGS nanoparticles synthesized using DiaSynth method with various temperature of DI water. (Black-square line) Sample with RT DI water has highest $\mathrm{R}^{\mathrm{nIR} / \mathrm{Au}}=1.48$. The rest of the controls with high DI water

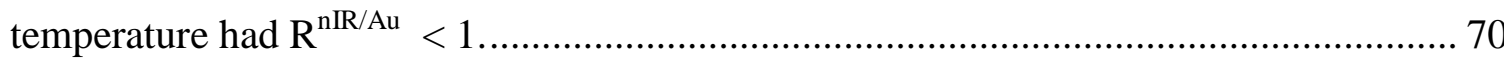
Figure 24: Normalized absorbance and spectral profile of GGS nanoparticles synthesized using DiaSynth method with one-step (Sample 1, blue-triangle line), two-step (Pinktriangle-down line), and Non-dialyzed samples, one step (Sample 3, black-square line) and two-step (red-circle line). The nIR peak and ratio are reported in Table 2............... 72 Figure 25: Normalized absorbance and spectral profile of GGS nanoparticles synthesized using DiaSynth method with one-step (Sample 1, blue-triangle line), two-step (Pinktriangle-down line), and Non-dialyzed samples, one step (Sample 3, black-square line) and two-step (red-circle line), after adding in the CS overnight. The nIR peak and quality

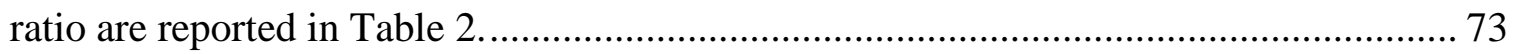
Figure 26: Normalized absorbance and spectral profile of GGS nanoparticles synthesized using DiaSynth method with 2000 MWCO Dialysis membrane, a mixture of $11 \mathrm{~mL}$ of 2 $\mathrm{mM} \mathrm{HAuCl}_{4}$ and $3 \mathrm{~mL}$ of $3 \mathrm{mM} \mathrm{Na}_{2} \mathrm{~S}_{2} \mathrm{O}_{3}$ is added. The sample were dialyze for 1 (redcircle line), 2 (blue-triangle line), and 4 (pink-triangle-down line). Non-dialyzed sample using $11 \mathrm{~mL}$ of $2 \mathrm{mM} \mathrm{HAuCl}_{4}$ mixed with $3 \mathrm{~mL}$ of $3 \mathrm{mM} \mathrm{Na} 2 \mathrm{~S}_{2} \mathrm{O}_{3}$ is used as a control (black-square line). nIR peak and quality ratio are reported in Table 8. 76 Figure 27: Normalized absorbance and spectral profile of GGS nanoparticles synthesized using DiaSynth method with 3500 MWCO Dialysis membrane, a mixture of $11 \mathrm{~mL}$ of 2 $\mathrm{mM} \mathrm{HAuCl}_{4}$ and $3 \mathrm{~mL}$ of $3 \mathrm{mM} \mathrm{Na}_{2} \mathrm{~S}_{2} \mathrm{O}_{3}$ is added. The sample were dialyze for 1 (redcircle line), 2 (blue-triangle line), and 4 (pink-triangle-down line). Non-dialyzed sample 
using $11 \mathrm{~mL}$ of $2 \mathrm{mM} \mathrm{HAuCl}_{4}$ mixed with $3 \mathrm{~mL}$ of $3 \mathrm{mM} \mathrm{Na}_{2} \mathrm{~S}_{2} \mathrm{O}_{3}$ is used as a control (black-square line). nIR peak and quality ratio are reported in Table 8. 77

Figure 28: Normalized absorbance and spectral profile of GGS nanoparticles synthesized using DiaSynth method with 2000 MWCO Dialysis membrane, a mixture of $11 \mathrm{~mL}$ of 2 $\mathrm{mM} \mathrm{HAuCl}_{4}$ and $2 \mathrm{~mL}$ of $3 \mathrm{mM} \mathrm{Na}_{2} \mathrm{~S}_{2} \mathrm{O}_{3}$ is added. The sample were dialyze for 1 (redcircle line), 2 (blue-triangle line), and 4 (pink-triangle-down line). Non-dialyzed sample using $11 \mathrm{~mL}$ of $2 \mathrm{mM} \mathrm{HAuCl}_{4}$ mixed with $2 \mathrm{~mL}$ of $3 \mathrm{mM} \mathrm{Na}_{2} \mathrm{~S}_{2} \mathrm{O}_{3}$ is used as a control (black-square line). nIR peak and quality ratio are reported in Table 9. 78

Figure 30: Graph of the nIR peak of samples from Tables 8 \& 9, X-axis is dialysis time (in hrs) for each control, Y-Axis is the initial ratio used to synthesize the AuNPs, and Zaxis nIR peak of the AuNPs after the synthesis

Figure 31: Graph of the quality ratio of samples from Tables $8 \& 9$, X-axis is dialysis time (in hrs) for each control, Y-Axis is the initial ratio used to synthesize the AuNPs, and Z-axis quality ratio of the AuNPs after the synthesis.. 82

Figure 32: TEM images of Dialyzed and non-dialyzed samples. Top row - Non-dialysis sample, Middle row - DiaSynth using 2000 MWCO Dialysis membrane, and Bottom row DiaSynth using 3500 MWCO Dialysis membrane. For column 1 \& 2 samples are at 100X, while column 3 samples are at 500X. 83

Figure 33: GGS nanoparticle sweep with DiaSynth method using $11 \mathrm{~mL}$ of $2 \mathrm{mM}$ $\mathrm{HAuCl}_{4}+\mathrm{X} \mathrm{mL}$ of $3 \mathrm{mM} \mathrm{Na}_{2} \mathrm{~S}_{2} \mathrm{O}_{3}$ in $0.5 \mathrm{~mL}$ increments (from 2.5-5) in a $2000 \mathrm{MWCO}$ Dialysis membrane. The Black-square, Red-circle, Blue-triangle, Pink-triangle-down, Green-square, and Purple-triangle-side line represents the spectral profile of the samples 
with $2.5,3,3.5,4,4.5$, and $5 \mathrm{~mL}$ of $3 \mathrm{mM} \mathrm{Na}_{2} \mathrm{~S}_{2} \mathrm{O}_{3}$. The nIR peak and quality ratio is reported in Table 11

Figure 34: GGS nanoparticle sweep with DiaSynth method using $11 \mathrm{~mL}$ of $2 \mathrm{mM}$ $\mathrm{HAuCl}_{4}+\mathrm{X} \mathrm{mL}$ of $3 \mathrm{mM} \mathrm{Na}_{2} \mathrm{~S}_{2} \mathrm{O}_{3}$ in $0.5 \mathrm{~mL}$ increments (from 2.5-5) in a $3500 \mathrm{MWCO}$ Dialysis membrane. The Black-square, Red-circle, Blue-triangle, Pink-triangle-down, Green-square, and Purple-triangle-side line represents the spectral profile of the samples with $2.5,3,3.5,4,4.5$, and $5 \mathrm{~mL}$ of $3 \mathrm{mM} \mathrm{Na}_{2} \mathrm{~S}_{2} \mathrm{O}_{3}$. The nIR peak and quality ratio is reported in Table 11 88

Figure 35: Scatter plot (data from Table 11) of the initial ratio $\left(\mathrm{HAuCl}_{4}: \mathrm{Na}_{2} \mathrm{~S}_{2} \mathrm{O}_{3}\right)$ used vs the nIR peak at the end of the reaction is the given three controls

Figure 36: Scatter plot (data from Table 11) of the initial ratio $\left(\mathrm{HAuCl}_{4}: \mathrm{Na}_{2} \mathrm{~S}_{2} \mathrm{O}_{3}\right)$ used vs the $\mathrm{R}^{\mathrm{nIR} / \mathrm{Au}}$ at the end of the reaction is the given three controls. 91

Figure 37: Normalized spectral profile of AuNPs synthesized using the DiaSynth method with 4 different MWCO bags. 94

Figure 38: Normalized spectral profile of AuNPs synthesized using DiaSynth method in a 12000 Da MWCO Dialysis membrane, using $11 \mathrm{~mL}$ of $2 \mathrm{mM} \mathrm{HAuCl} 4$ and various amount of $3 \mathrm{mM}$ Na2S2O3 (2.5, 3, and $3.5 \mathrm{~mL})$. 97

Figure 39: Normalized spectral profile of Non-Dialyzed, 12000 Da MWCO Dialysis membrane, and the rotovap sample. 100

Figure 41: Normalized spectral profile of the two different scale ups. 104 Figure 42: (A), (B), and (C) are non-dialyzed samples, while (D), (E), and (F) are from the $44+10$ scale up. 105 
Figure 43: Spectral profile of GGS nanoparticles synthesized using the ratio $11+2.5$, the

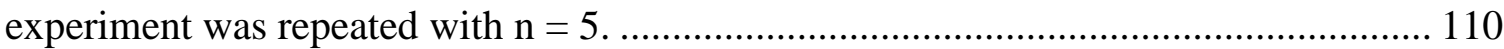


Table 1: Size and zeta (charge) measurement of the particles that were synthesized. ..... 35

Table 2: Represents the controls that will be used in the following experiment.............. 37

Table 3: Represents the controls that will be used in the following experiment............. 40

Table 5: nIR peak and the quality ratios of each sample from Figure 11 and $12 \ldots \ldots \ldots . . . .50$

Table 6: nIR peak and the quality ratios of each sample from Figure 13, 14 and 15...... 55

Table 7: nIR peak and the ratios of each sample before and after adding the CS. .......... 74

Table 8: nIR peak and the quality ratios of each sample from Figure 14 and $15 . \ldots \ldots \ldots . . . .80$

Table 9: nIR peak and the quality ratios of each sample from Figure 16 and $17 \ldots \ldots . . .74$

Table 10: Represents the controls that will be used in the following experiment.........80

Table 11: nIR peak and the quality ratios of each sample from Figure $31 \& 32 \ldots \ldots \ldots \ldots . .83$

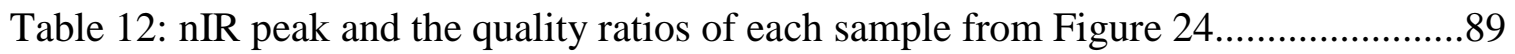

Table 13: Size and zeta measurements of the samples.............................................89

Table 14: nIR peak and the quality ratios of each sample from Figure 25.....................91

Table 15: Size and zeta measurements of the samples.............................92

Table 16: nIR spectral peak, quality ratio, size, and zeta measurements of the samples, a detailed explanation is given in the conclusion section...........................................96

Table 17: nIR spectral peak and quality ratio measurements of the scale up samples.....99

Table 18: nIR peak and the quality ratios of each sample from Figure 41. The average $\mathrm{nIR}$ peak is $813 \mathrm{~nm} \pm 27 \mathrm{~nm}$, and the average quality ratio is $1.88 \mathrm{~nm} \pm 0.07 \ldots \ldots \ldots \ldots . .105$

Table 19: Table 19: Results from the "As made" and DiaSynth method.......................106 


\section{CHAPTER 1 - Gold Nanoparticles}

\subsection{INTRODUCTION}

\section{Gold nanoparticles}

Biomedicine, involving the study of processes in biology, chemistry, and physics, has been one of the cores in nanotechnology (W. Cai 2008). Gold nanoparticles vary in size, typically in the range of 1-150 nm (Azzazy and Mansour 2009). However, there are many different subtypes of AuNPs based on their size, shape, and properties including: gold nanospheres, nanorods, nanocages, and nanoshells (W. Cai 2008). One important property of these nanoparticles is a large surface-to-volume ratio, though most of the nanoparticles have the size range of biomolecules and cellular organelles; not only does this give a possibility of interaction between the gold nanoparticles and biomolecules, but opens the field to various medical applications (Azzazy and Mansour 2009).

Nanoparticles can specifically be tuned as nano-platforms for an effective and targeted delivery of drugs, and imaging labels by reducing many biological, biophysical, and biomedical limitations for many application in vitro and ex vivo (W. Cai 2008). Due to the versatile properties gold nanoparticles (AuNPs), they have been introduced in the field of biomedical applications for drug delivery, ex/in-vivo imaging, in-vitro assays, and cancer therapy (theranostic applications) (W. Cai 2008). For many biological applications, gold nanoparticles must be conjugated with assorted biospecific recognition molecules, including antibodies, DNA probe molecules, biotin, and enzymes (Azzazy and Mansour 2009; Xie, Gao et al. 2009). By using different stabilizing molecules/agents gold nanoparticle properties can be altered. These biospecific molecules can be replaced 
by other macromolecules; not only can the surface of gold nanoparticles be modified either by coating or by grafting a macromolecule, but the properties of nanoparticles can be changed such as adsorption, size, zeta potential (charge), and hydrophobicity (Agbenyega 2008; Rai 2011).

Most of these applications are based on the advantage of using the unique optical properties of gold, such as surface plasmon resonance (SPR), luminescence, surfaceenhanced Raman scattering, catalytic effect, and amplification effect (Azzazy and Mansour 2009; Xie, Gao et al. 2009). In order to attach or coat the surface of gold nanoparticles with biospecific molecules, they are usually connected with ligands. Alkanethiols are the most common self-assembled monolayer (SAMs) used for passivating gold nanoparticles (Huo 2007; Rai 2011). Gold nanoparticles have been used as contrast agent for scanning electron and light microscopy in histology; they also have played an important role in advancing biosensor performance due to their large effective surface area and excellent biocompatibility (Huo 2007; Rai 2011).

AuNPs has been used in stained glass windows for centuries. However, recently, in the last decade or so, researchers have begun to understand the fundamental concepts that not only explain the optical properties at the nanoscale, but how these particles can be used in many different applications (Stone, Jackson et al. 2011). AuNPs can be fabricated to either absorb or scatter light in the visible to near-infrared (nIR) region of the spectrum (Lowery, Gobin et al. 2006; Gobin, Lee et al. 2007; Day, Bickford et al. 2010; Gobin, Watkins et al. 2010; Stone, Jackson et al. 2011). These unique optical properties are a result from the oscillations of electrons along the metal surface, which 
can be changed by modifying the particles' shape, size, or the medium that particles are suspended in (Pérez-Juste, Pastoriza-Santos et al. 2005; Stone, Jackson et al. 2011).

\subsection{Applications}

Theranostic applications have emerged as a technique to combine diagnosis, treatment, and imaging in cancer research, thus not only decreasing time, but improving efficacy of therapy. The ideal theranostic approach for cancer therapy has several tunable factors, which can range from imaging to treatment with a display of specifically targeting cancer cells (Young, Figueroa et al. 2012). Researchers have now begun to introduce multimodal nanoparticles for therapeutic and imaging contrast applications (Ren and Chow 2003; Park, Yang et al. 2008; Jelveh and Chithrani 2011; Sun, Eun et al. 2011). Specifically, gold/gold sulfide nanoparticles (GGS) has been developed for many of the same applications compared to silica-gold nanoshells because of the smaller size, higher absorptive properties, and easier to fabricate using the single-step self-assembly process described in the later parts of the chapter. (Gobin, Watkins et al. 2010). The theranostic effects of GGS are the result of surface plasmon oscillations to convert light into heat, causing increase in local temperature to ablate the specifically targeted cells, which occurs using frequency of light that matches the absorptive properties of GGS (Vladimir P. Zharov 2003; Song, Risco et al. 2008; Ghosh, Dutta et al. 2009; Lapotko 2011; Lukianova-Hleb, Koneva et al. 2011; Melancon, Zhou et al. 2011). 


\subsubsection{Nanoshells}

Gold nanoshells (GNS) are tunable spherical nanoparticles, composed of a dielectric core covered by a thin gold shell, with diameters ranging from 10 to $200 \mathrm{~nm}$
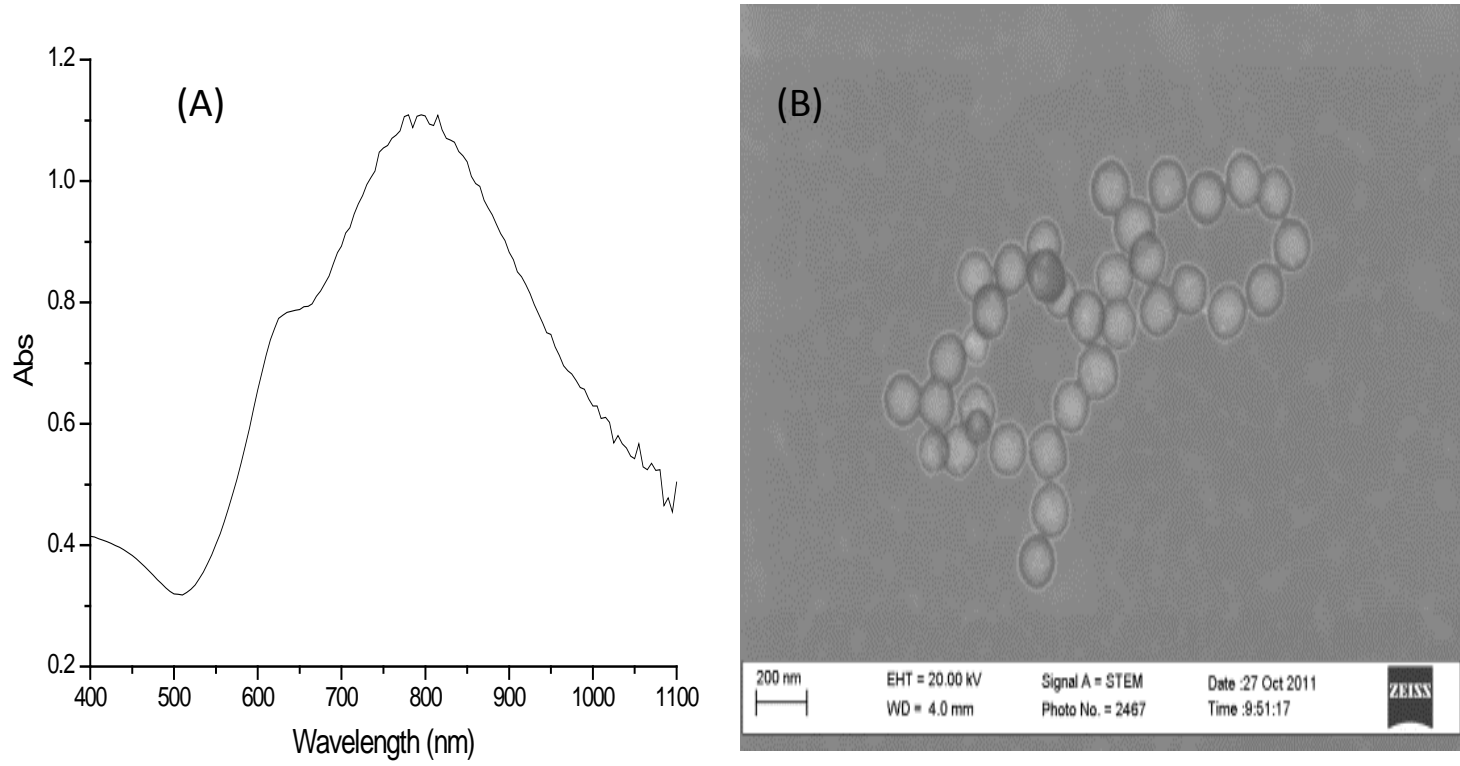

Figure 1: Spectral profile (A) image of the GNS that were fabricated with radius of $\sim 74 \mathrm{~nm}$ and core of $\sim 60 \mathrm{~nm}$ and STEM image (B) to confirm the synthesis.

(Erickson and Tunnell 2007). (Figure1) GNS have optical, chemical and physical properties, which make them an ideal candidate for enhancing cancer detection, cancer treatment, cellular imaging, and medical biosensing. Furthermore, gold affinity for thiol group with biocompatibility and it also simplifies conjugation to monoclonal antibodies or other biomolecules for both active tumor targeting and biosensing applications. Nanoshells can be fabricated with tunable optical properties, absorbing or scattering, from visible to infrared spectrum. 
GNS, due to their unique physical characteristics and benign toxicity profile, have been using in number of biomedical applications (Erickson and Tunnell 2007); however, they have shown the greatest potential for cancer targeting, imaging, and therapy agents. The use of GNS in contrast agents has been utilized to detect and image individual cancer cells in vitro and in vivo (Lowery, Gobin et al. 2006; Erickson and Tunnell 2007; Gobin, Lee et al. 2007). As a photothermal agent, GNS have successfully shown, in animal studies, to induce thermal necrosis of tumors. As biosensors, GNS have been used for the sensitive detection of biomarkers at the $\mathrm{ng} / \mathrm{ml}$ concentrations (Hirsch, Jackson et al. 2003; Erickson and Tunnell 2007).

\subsubsection{Nanorods}

AuNPs having a "rod-like" structure has been in interest due to their unique shape. The spectral profile of the gold nanorods includes two specific bands: one due to light absorbed along the short axis $(\sim 530 \mathrm{~nm})$ and the other due to absorption along the long axis ( 650-1000 nm) (Stone, Jackson et al. 2011). As the length of the nanorod increases, there is a red band shift, and because of this optical "control gold nanorods can be used for sensing, photothermal therapy, and imaging (Pérez-Juste, Pastoriza-Santos et al. 2005; Stone, Jackson et al. 2011).

The correlation between gold nanorod size, charge, shape, and spectral profile as a result of changes in dielectric and interparticle spacing, makes them acceptable as sensors (Yu and Irudayaraj 2006; Stone, Jackson et al. 2011). Yu and Irudayaraj et al. demonstrated a multiplex sensing system using gold nanorods with three different targeted IgGs. Yu and Irudayaraj et al. were able to measure the specificity and sensitivity caused by interactions between the IgGs and gold nanorods (Yu and Irudayaraj 
2006). This approach can be used in the development of optical biosensors for both in vivo and in vitro detection. However, Huang et al. demonstrated the potential usage of gold nanorods as a dual agent, molecular imaging and photothermal ablation therapy of cancer cells using a near-infrared laser. Hunag et al, conjugated anti-epidermal growth factor receptor (anti-EGFR) antibodies to the surface of gold nanorods to be used as for targeting (Huang, El-Sayed et al. 2006).

\subsubsection{Nanocages}

Gold nanocages represent a class of gold nanostructures with hollow interiors and porous walls (Chen, McLellan et al. 2006; Yavuz, Cheng et al. 2009). Gold nanocages has a strong absorption in the near-infrared region (Yavuz, Cheng et al. 2009). As mentioned by Yauvz et al., when the surface of a gold nanocage is covered with a "smart polymer", using a near-infrared laser to heat the polymer or the surface of the nanocage allows the release of a drug. Xai et al. functionalized the surface of gold nanocages with thermally responsive polymer, poly(Nisopropylacrylamide) (pNIPAAm) with a gold thiolate bonding, to control the release of a drug using near-infrared laser irradiation (Xia, Li et al. 2011). The pNIPAAm polymer chain has the ability to change conformation in response to temperature variation, and can be modified using different amounts of acrylamide. Once the gold nanocages undergo laser irradiation, the light is absorbed and converted into heat. Next, the polymer chains will collapse as the temperature increase, which ultimately leads to the opening of pores and thus releasing the drugs (Yavuz, Cheng et al. 2009; Xia, Li et al. 2011).

Chen et al. evaluated the use of PEGylated Au nanocages with passive targeting capabilities in a tumor mouse model (Chen, McLellan et al. 2006). The passive targeting 
depends on the aggregation of the nanoparticles in a tumor through leaky vasculature. However, active targeting, the second type of targeting system, takes advantage of the interaction between the ligand/IgG (targeting agent) immobilized on the surface of nanoparticles and the specific receptor, which is being targeted, overexpressed on the surface of tumor cells. It was observed that due to the enhanced permeability and retention effect, the nanocages had an increased circulation time, which meant that they could accumulate in the tumor site (Chen, McLellan et al. 2006).

\subsubsection{Nanospheres}

Chemotherapy, for different types of cancer treatment, can produce harmful side effects since it involves saturating the body with toxic drugs (Shah and Schwartz 2001). Using a unique drug delivery system offers advantages such as improved efficacy and reduced toxicity. Improvement in chemotherapy can be achieved through passive or active targeting using gold nanospheres (Kim, Ghosh et al. 2009). There are two different types of gold nanospheres (colloidal gold) separated by the fabrication methods, sodium citrate reduction and sulfur reduction. Both methods produce nanoparticles of different resonant properties (Brown, Nativo et al. 2010; Day, Bickford et al. 2010; Gobin, Watkins et al. 2010).

Kim et al had described using gold nanoparticles as multimodal drug delivery systems. Using the fabrication process to control the size of gold nanoparticles, which ultimately gives its high surface area to volume ratio, the gold nanoparticles can be loaded with multifunctional monolayers, which allows multiple functional moieties such as drugs and targeting agents to be functionalized on the surface (Kim, Ghosh et al. 2009). 
Day and Gobin et al developed a near-infrared resonant gold-gold sulfide nanoparticle system, not only as contrast agent, but therapeutic agents for breast cancer treatment using photoablation (Day, Bickford et al. 2010; Gobin, Watkins et al. 2010). The gold nanoparticles were functionalized with a conjugated anti-HER2 antibodies, this will allow the nanoparticles to specifically bind breast carcinoma cells which overexpress the HER2 receptor. Both reported that gold / gold-sulfide nanoparticles are a suitable material for multifunctional agent for cancer treatment.

\subsection{Synthesis \& Theory}

GGS nanoparticles are synthesized by reacting sodium sulfide $\left(\mathrm{Na}_{2} \mathrm{~S}\right)$ or sodium thiosulfate $\left(\mathrm{Na}_{2} \mathrm{~S}_{2} \mathrm{O}_{3}\right)$ with chloroauric acid $\left(\mathrm{HAuCl}_{4}\right)$, using the traditional single step method or a two-step method; although, according to published papers, this synthesis is surrounded by the issues over structure formation of the resulting product and other byproducts formed during the self-assembly process (Schwartzberg, Grant et al. 2007). The traditional one-step GGS reaction is carried out by mixing $2 \mathrm{mM}$ solution of $\mathrm{HAuCl}_{4}$ with $1 \mathrm{mM} \mathrm{Na} 2 \mathrm{~S}$ solution (after it has been aged), with a volumetric ratio of 1:2, while stirring at room temperature (RT) (Diao and Chen 2006). However, the two-step synthesis, discovered by Zhou et al (Figure 1), requires the $\mathrm{HAuCl}_{4}$ and $\mathrm{Na}_{2} \mathrm{~S}$ solutions to react for few minutes (first reduction) and then a second reduction, $\mathrm{Na}_{2} \mathrm{~S}$ solution, is added to formulate the metal-coatings on the nanoparticles (Zhou, Honma et al. 1994). Both self-assembly processes will result in formation of variety of particles: colloidal gold, GGS (circular/spherical), triangular plates, and rods (Diao and Chen 2006; Schwartzberg, Grant et al. 2007; Gobin, Watkins et al. 2010).

$$
\mathrm{HAuCl}_{4} * 4 \mathrm{H}_{2} \mathrm{O}+\mathrm{Na}_{2} \mathrm{~S} * 9 \mathrm{H}_{2} \mathrm{O}=\mathrm{Au}_{2} \mathrm{~S}+\mathrm{Au}+\mathrm{Au}_{2} \mathrm{~S} / \mathrm{Au} \text { (nanoshell) }+\mathrm{S}^{+}
$$



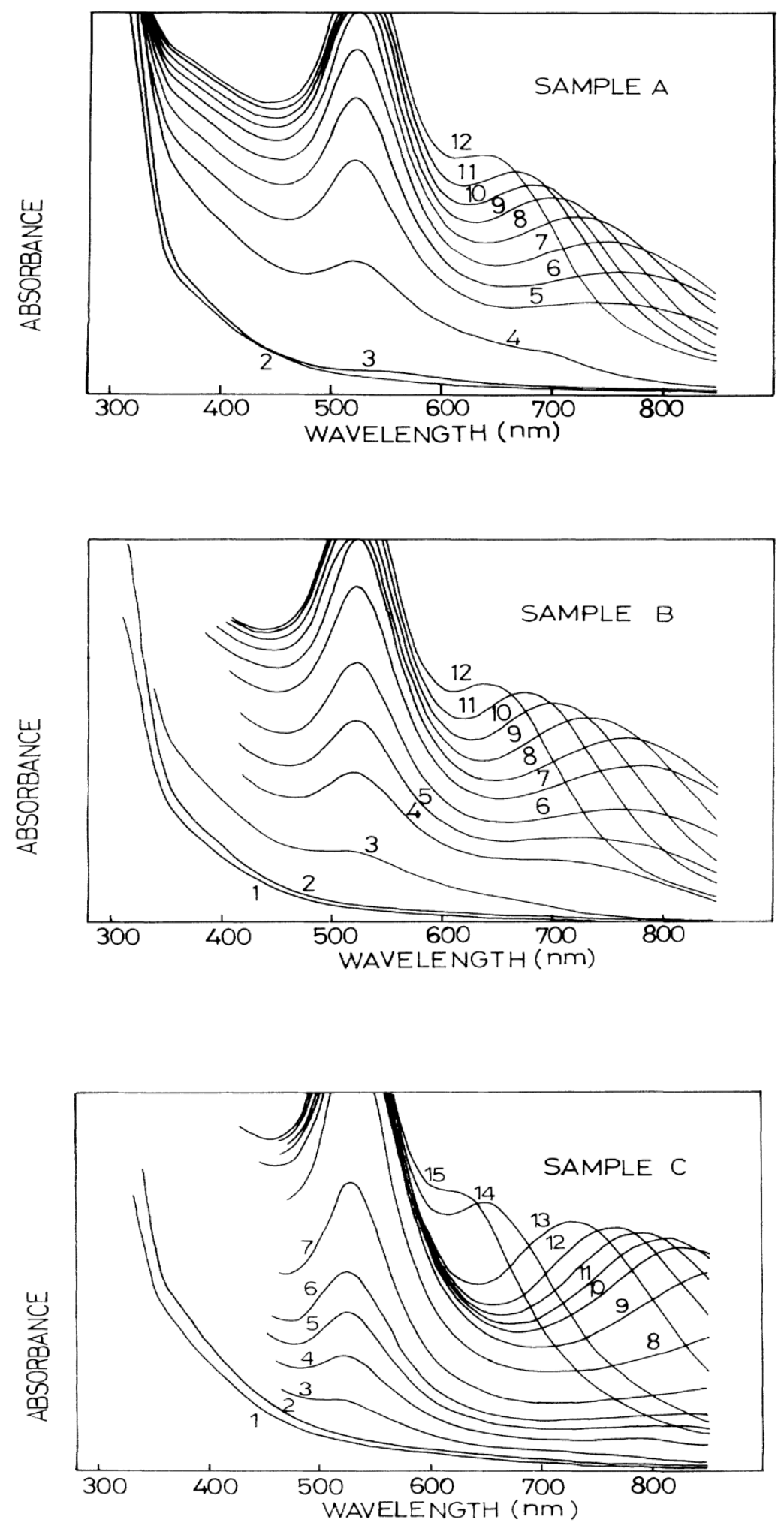

Figure 2: Spectral profiles of gold nanoparticles during the two-step synthesis. $A, B$, and $C$ are different parameters that were used by Zhou et al for further understand the two-step self-assembly process (Zhou, Honma et al. 1994). 
The spectral profile of the synthesized particles contains a plasmon resonance band at wavelengths of 520-540 nm (colloidal gold) and a near infrared peak (nIR) peak between 650-1000 nm (GGS, triangular plates, and rods) (Zhou, Honma et al. 1994; Averitt, Sarkar et al. 1997; Schwartzberg, Grant et al. 2007); however, positioning of the nIR peak can be changed by varying the synthesis conditions (Zhou, Honma et al. 1994; Diao and Chen 2006; Likhatskii and Mikhlin 2007; Schwartzberg, Grant et al. 2007; Gobin, Watkins et al. 2010). For the two-step method (Figure 1), the absorbance properties are strictly depended on the size of the initial particle growth before the second reduction step is continued (Zhou, Honma et al. 1994); also this would require more time and be difficult (Oldenburg, Averitt et al. 1998; Prodan, Nordlander et al. 2003), specifically during the timing for the second reduction step to make the gold nanoparticles for optimal tuning, compared to the one-step method. Two theories have been formulated to determine the nIR peak, surface plasmon resonance of $\mathrm{Au}_{2} \mathrm{~S} / \mathrm{Au}$ nanoshells and GGS aggregates (Zhou, Honma et al. 1994; Averitt, Sarkar et al. 1997; Diao and Chen 2001; Diao and Chen 2006). Although it is hard to determine the full mechanism of the nanoparticle growth, researchers have developed theories, equation (1) - unbalanced, on the synthesis (Raschke, Brogl et al. 2004; Diao and Chen 2006; Schwartzberg, Grant et al. 2007; Majimel, Bacinello et al. 2008). Schwartzberg et al. has reported formation dithionate, $\mathrm{S}_{2} \mathrm{O}_{6}{ }^{2-}$, due to oxidation of $\mathrm{Na}_{2} \mathrm{~S}$, and $\mathrm{SO}_{4}{ }^{2-}$ or $\mathrm{SO}_{3}{ }^{2-}$ species as well.

The current synthesis requires $\mathrm{Na}_{2} \mathrm{~S}$ to be aged for 2-3 days, and depending on how much of $\mathrm{Na}_{2} \mathrm{~S}$ has been added, concentration or further aging of sample, it could potentially change the nIR peak. Upon further understanding the reaction of $\mathrm{Na}_{2} \mathrm{~S}$ aging, Schwartzberg et al determined two things: (1) due to a chemical change during aging 
process of $\mathrm{Na}_{2} \mathrm{~S}$ solution there was an increase in nIR absorption, and (2) that $\mathrm{Na}_{2} \mathrm{~S}_{2} \mathrm{O}_{3}$ is the likely product from $\mathrm{Na}_{2} \mathrm{~S}$ aging because of oxygen exposure to form sulfur oxide species. It was also reported that $\mathrm{Na}_{2} \mathrm{~S}_{2} \mathrm{O}_{3}$ solution is more stable than $\mathrm{Na}_{2} \mathrm{~S}$ solution, and aging had no effect on the synthesis of the particles compared to $\mathrm{Na}_{2} \mathrm{~S}$ aging. Although, with the usage of $\mathrm{Na}_{2} \mathrm{~S}_{2} \mathrm{O}_{3}$, it still produces same results (colloidal gold, GGS, triangular plates, and rods), it is not known whether the same "species" are being formed or not (Schwartzberg, Grant et al. 2007).

\subsubsection{Models of Growth and Resonant Properties}

Over the last few decades, the development of optically controllable nanostructures came from Zhou et al. and later by Averitt et al., which reported nanostructure of an $\mathrm{Au}_{2} \mathrm{~S} / \mathrm{Au}$ core/shell using $\mathrm{HAuCl}_{4}$ and $\mathrm{Na}_{2} \mathrm{~S}$ (Zhou, Honma et al. 1994; Averitt, Sarkar et al. 1997). This reaction produced products with the optical signatures of two bands: (1) $520 \mathrm{~nm}$ and (2) near-IR band, which is similar to gold nanorods (Schwartzberg, Grant et al. 2007).

GGS nanoparticle synthesis has been considered due to their novel properties and device applications, though initially the focus of the formation of the nanoparticles, growth, is more important. Averitt et al. describes the properties of these particles as an Au-coated dielectric nanoparticles, or gold nanoshells; the theory relates to describing these particles as a dielectric core coated with a metal nanoshell, which occurs naturally, in the self-assembly process, during the growth of $\mathrm{Au} / \mathrm{Au} 2 \mathrm{~S}$ nanoparticles (Averitt, Sarkar et al. 1997). During the development of nanoparticle growth, while using $\mathrm{HAuCl}_{4}$ and $\mathrm{Na}_{2} \mathrm{~S}$, which takes place via reduction in solution, the plasmon absorption peak in the nIR region will shifts between 650 to $900 \mathrm{~nm}$ or beyond in extreme cases. 
This unique "red-shift" of the nanoparticle plasmon resonance to have a peak wavelength in the nIR regions of the spectrum has high importance for biomedical applications, as mentioned in the Application Section (1.2). Averitt et al. published results show that the plasmon shift is depended by the size and the dielectric properties of the $\mathrm{Au}_{2} \mathrm{~S}$ core with $\mathrm{Au}$ shell. Zhou et al. stated that during the later times in the synthesis, $\mathrm{S}^{2-}$ diffuses through the thin/thick gold shell and reduces the $\mathrm{Au}_{2} \mathrm{~S}$ core, further describing that this will result in an increase in the gold shell thickness while the core decreasing in size. Averitt et al. later described this kinetic scenario as highly unlikely due to $\mathrm{S}^{2-}$ bring not existence in aqueous solution at any $\mathrm{pH}$. Furthermore, this allowed improved understanding of some of the optical properties of Au nanoshells and helped model the growth kinetics of these nanoparticles. The results published by Averitt et al. indicate that the plasmon peak shift is in two-stage model of nanoparticle growth; first the Au2S core, and second then the Au shell formation on top growing linearly over time (Averitt, Sarkar et al. 1997).

Further studies, by Averitt et al., have demonstrated that $\mathrm{S}^{2-}$ is not a dominant aqueous species and when $\mathrm{Na}_{2} \mathrm{~S}$ is mixed, the $\mathrm{S}^{2-}$ reacts with the water to give $\mathrm{HS}^{-}$and $\mathrm{OH}^{-}$. From this, the growth of $\mathrm{Au}$ coated $\mathrm{Au}_{2} \mathrm{~S}$ nanoparticles were modeled as:

$$
2 \mathrm{AuCl}_{4}^{-}+3 \mathrm{HS}^{-} \leftrightarrows 2 \mathrm{Au}+3 \mathrm{~S}+3 \mathrm{H}^{+}+8 \mathrm{Cl}^{-}
$$

(2)(Averitt, Sarkar et al. 1997)

Both $\mathrm{Au}$ and $\mathrm{Au}$-coated $\mathrm{Au}_{2} \mathrm{~S}$ nanoparticles are grown, due to the $\mathrm{Au}$ and $\mathrm{S}$ being available for subsequent nucleation and growth. 


\section{CHAPTER 2: DIASYNTH}

\section{$2.1 \quad$ Introduction}

Chemistry can essentially be divided into three categories: the study of structures, equilibrium, and reaction rates (Conners 1990). According to Conners et al., chemical structures are described using quantum mechanics, equilibrium is studied by statistical mechanics and thermodynamics, and the study of rates relates with kinetics. Kinetics can be split into physical kinetics, which deals with physical phenomena, such as diffusion and viscosity; while the chemical kinetics deals with the rates of chemical reactions, including both covalent and covalent bond changes.

The rate of the reaction (Equation 2) is defined as how fast or slow a reaction proceeds to complete the reaction.

$$
\mathrm{aA}+\mathrm{bB} \leftrightarrows \mathrm{cC}+\mathrm{dD}
$$

There are several factors that can play an important role in affecting the rate of a reaction: concentration of reactants, physical state of the reactants, temperature at which the reaction takes occurs, and the use of a catalyst (Conners 1990; Silberberg 2006). 
- Concentration of reactants - The more molecules present in the system, the more frequently the molecules will collide; therefore, the reaction occurs at an accelerated speed (Silberberg 2006).

- Physical state - depending on the state of the sample, it can mix quickly, or require an outside source to aid in mixing (Silberberg 2006).

- Temperature - at higher temperatures samples are more likely to collide to each other by affecting the kinetic energy of the molecules (therefore the energy of collision) (Silberberg 2006).

- Catalyst - increases a reaction without being consumed by the reaction itself; the catalyst effects a lower activation energy and therefore increasing the reaction rate (Silberberg 2006).

\subsection{Current methods \& DiaSynth}

With the use of $\mathrm{Na}_{2} \mathrm{~S}_{2} \mathrm{O}_{3}$, GGS nanoparticles are more stable and can be used for different applications as mentioned above. However, in therapeutic applications such as nIR photothermal therapy (Gobin, Watkins et al. 2010) or drug delivery via nIR irradiation (Ren and Chow 2003), Gobin et al. reported that colloidal gold formation during the self-assembly process are considered a contaminant and must be removed. Not only does this reduce the total amount of beneficial particles available, but increase endothelial uptake of non-therapeutic particles, and can increase immune response (Raschke, Brogl et al. 2004; Gobin, Watkins et al. 2010). Traditionally, colloidal gold particles are removed via multistep centrifugation (Gobin, Watkins et al. 2010), which is not only time 
consuming but inefficient as well. This thesis is focused on a novel synthesis to produce high yield and manufacturing large quantities of nIR GGS nanoparticles with desired near infrared peak (nIR) that can be used for therapeutic applications. 
The importance of the nIR region in medicine, by using nanoparticle technology, is due to the high transmission and low absorption of light, between 650 and $900 \mathrm{~nm}$, by native tissue components such as water and hemoglobin (Gobin, Lee et al. 2007; Day, Bickford et al. 2010). The nIR light has minimal interference with tissue and only affects samples which absorb nIR light, which enables minimally invasive imaging and treatment (Lowery, Gobin et al. 2006; Huang, Jain et al. 2007; Gobin, Watkins et al. 2010; Sun, Zhang et al. 2012). AuNPs can be used to diagnose, specifically target, and photo-thermally treat tumors by localized hyperthermia using specific nIR lasers matching the peak 
resonance of the nanoparticles (Lowery, Gobin et al. 2006; Huang, Jain et al. 2007; Gobin, Watkins et al. 2010; Sun, Zhang et al. 2012).

The current method for producing nIR GGS nanoparticles using $\mathrm{Na}_{2} \mathrm{~S}_{2} \mathrm{O}_{3}$, which is based on a single step procedure, results in a low yield of nIR particles compared to colloidal gold. We define this as a ratio of the absorbance of peaks, $\mathrm{R}^{\mathrm{nIR} / \mathrm{Au}}$, of the nIR region $(700-900 \mathrm{~nm})$ relative to the colloidal gold peak $(\sim 530 \mathrm{~nm})$ as a relative measure

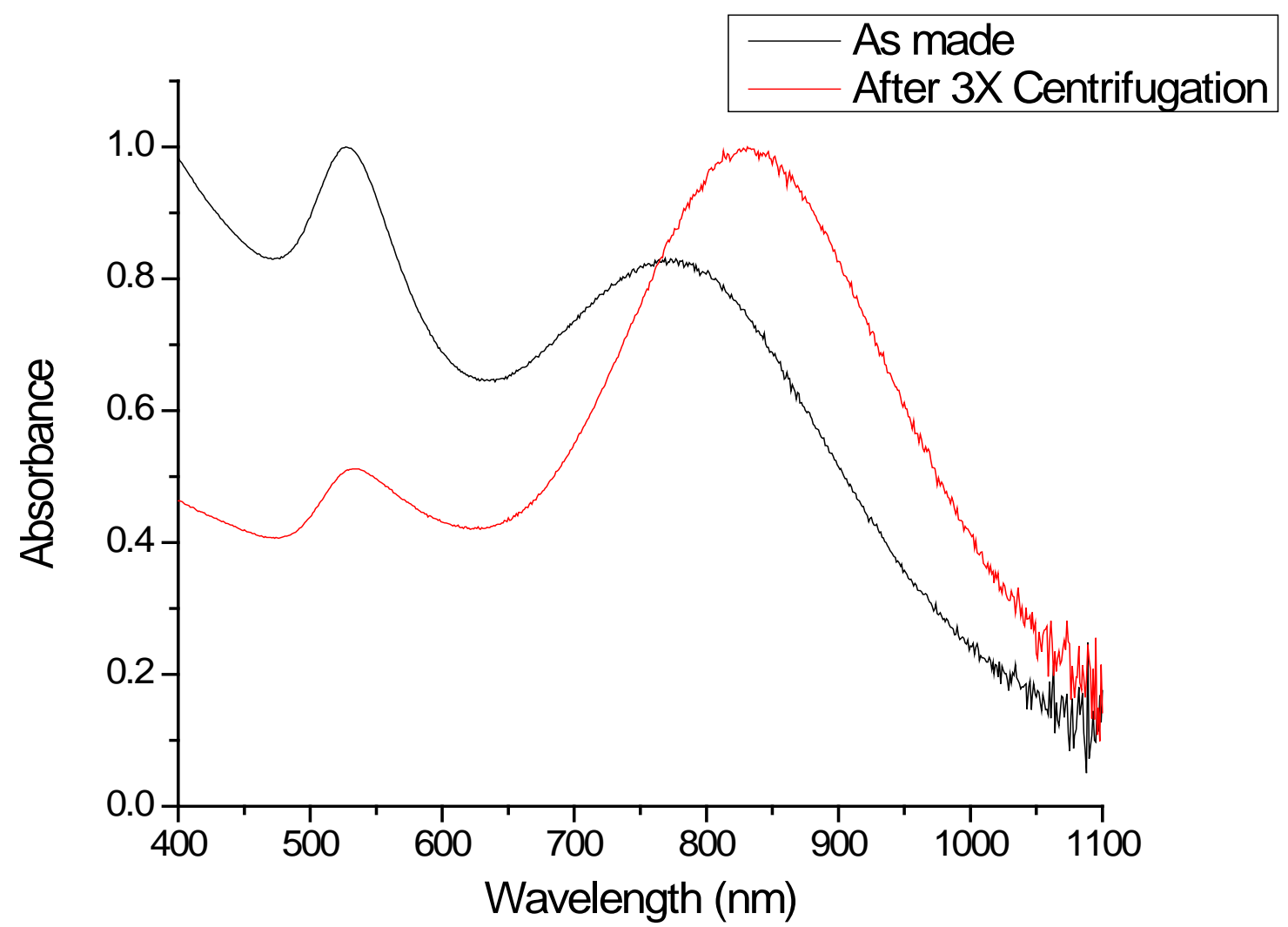

Figure 3: Spectral profile of the GGS nanoparticles with traditional single step self-assembly process, black line represents particles as made with $R^{\mathrm{nIR} / \mathrm{Au}}=\mathbf{0 . 8 3}$, while the red line is the particles after multi-step centrifugation with $R^{\mathrm{nIR} / A u}=1.95$.

of the yield of nIR particles. Once the GGS particles have been synthesized, colloidal gold is then removed via a multi-step centrifugation process (Figure 3), although this 
reduces the non-nIR fractions, the overall yield is reduced at each centrifugation step, in end dramatically reducing the yield. The multi-step centrifugation process starts with using $25 \mathrm{~mL}$ of GGS nanoparticles that are synthesized, and using in a $50 \mathrm{~mL}$ centrifugation tube, they are centrifuged at $1100 \mathrm{~g}$ for $20 \mathrm{~min}$. Next, the pellet was saved and the supernatant was re-spun at the same condition for two more times. The pellet from the second and third spin was combined with the first; this is to maximize the pellet collection and overall yield as depicted in Figure 3. Overall, three centrifugation steps (3X centrifugation) was necessary to reduce the colloid peak to a minimum. Also, it is important to note that using higher forces during centrifugation of the GGS nanoparticles can result in a solid pellet of the nanoparticles, this would reduce the overall yield.

\subsection{DiaSynth - optimized synthesis of gold / gold-sulfide nanoparticles}

By slight modification in synthesis of GGS nanoparticles, using $\mathrm{Na}_{2} \mathrm{~S}_{2} \mathrm{O}_{3}$ instead of $\mathrm{Na}_{2} \mathrm{~S}$, and including results published by Averitt, Sarkar, and Schwartzberg et al. with equations (1 \& 3), we have formulated equation (4) - unbalanced.

$$
\mathrm{HAuCl}_{4} * 3 \mathrm{H}_{2} \mathrm{O}+\mathrm{Na}_{2} \mathrm{~S}_{2} \mathrm{O}_{3} * 5 \mathrm{H}_{2} \mathrm{O}=
$$

$\mathrm{Au}_{2} \mathrm{~S}+\mathrm{Au}+\mathrm{Au}_{2} \mathrm{~S} / \mathrm{Au}$ (nanoshell) $+\mathrm{S}^{+}+\mathrm{SO}_{4}{ }^{2-}+\mathrm{NaCl}+\mathrm{SO}_{3}{ }^{2-}+\mathrm{H}^{+}+\mathrm{S}_{2} \mathrm{O}_{6}{ }^{2-}+\mathrm{Cl}^{-}+$ $\mathrm{Na}^{+}$

However, in order to shift the equilibrium or kinetics to this system, there are several available options. For example, the use of heat can increase the rate of reaction or the kinetics (as mentioned in Section 2.1), and by factoring heat into the reaction there is a possibility that the reaction would favor the formation of nIR absorbing particles and increasing the quality ratio. For this thesis, by combining published methods for single- 
step self-assembly of GGS nanoparticles, and dialysis simultaneously (DiaSynth), forcing ion-exchange (by removing reactants or products), the equilibrium of the reaction can be shifted to favor the formation of nIR absorbing particles. The DiaSynth technique will minimize production of AuNPs with $530 \mathrm{~nm}$ resonance (colloidal gold), resulting in an increase of yield of nIR particles and a population of nanoparticles that require minimum further processing for usage as a therapeutic agent. In addition, peak optical property shifts due to removal of some of the non-nIR resonant population. The DiaSynth method can increase the yield of the synthesis to have a ratio of $1.7-2.36$; thus, centrifugation process is not required or at minimal. 


\section{$2.4 \quad$ Methods}

\subsubsection{Traditional One-Step Method}

The purpose of this experiment is synthesis a batch of AuNPs using onestep self-assembly process with $\mathrm{HAuCl}_{4}$ and $\mathrm{Na}_{2} \mathrm{~S}_{2} \mathrm{O}_{3}$; followed by a $3 \mathrm{x}$ centrifugation to purify the sample.

\subsubsection{Protocol}

Hydrogen tetrachloroaurate (III) trihydrate (chloroauric acid, $\mathrm{HAuCl}_{4}{ }_{3} \mathrm{H}_{2} \mathrm{O}$ ) was purchased from Alfa Aesar and diluted to a concentration of $2 \mathrm{mM}\left(\mathrm{HAuCl}_{4}\right.$, gold solution). Sodium Thiosulfate $\left(\mathrm{Na}_{2} \mathrm{~S}_{2} \mathrm{O}_{3}\right)$ was prepared at a concentration of $3 \mathrm{mM}$. Next, at a volumetric ratio of 2.58 ( $\mathrm{HAuCl}_{4}{ }_{3} \mathrm{H}_{2} \mathrm{O}: \mathrm{Na}_{2} \mathrm{~S}_{2} \mathrm{O}_{3}$ ), $\mathrm{HAuCl}_{4}{ }_{3} \mathrm{H}_{2} \mathrm{O}$ and $\mathrm{Na}_{2} \mathrm{~S}_{2} \mathrm{O}_{3}$ are mixed and reacted at room temperature to allow for self-assembly of AuNPs. Next, spectral scans were obtained after an hour of the self-assembly synthesis at room temperature (RT), using a UV/Vis spectrophotometer (Carey 50 Varian). A Malvern Zetasizer (ZS90) was used to characterize the GGS nanoparticles surface charge and size. 


\subsubsection{Data/Analysis}

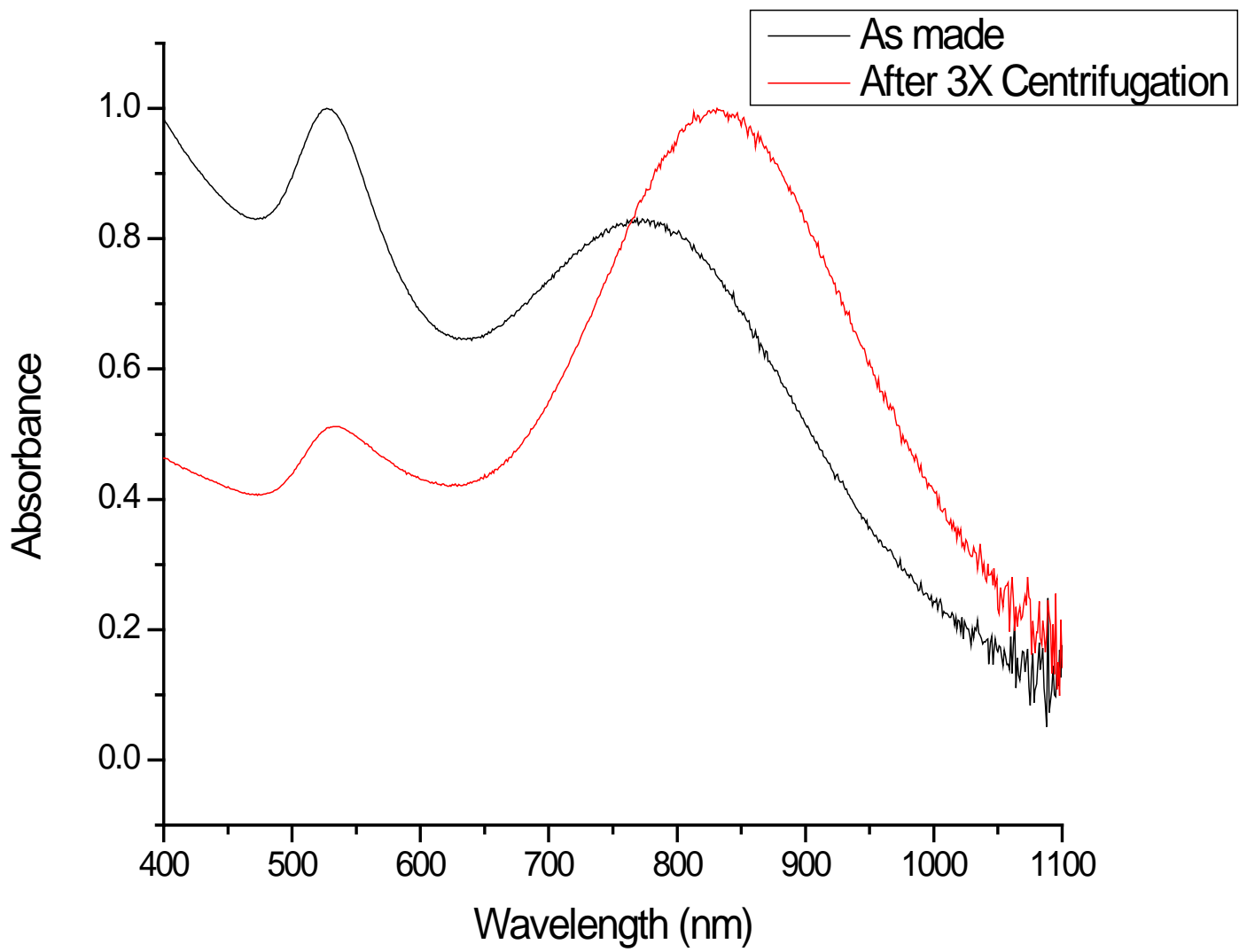

Figure 4: Normalized absorbance of GGS nanoparticles with traditional single step self-assembly process, the black line represents nanoparticles as made with $R^{\mathrm{nIR} / \mathrm{Au}}$ $=0.83$ (As made), while the red line is the nanoparticles after multi-step centrifugation with $R^{\mathrm{nIR} / \mathrm{Au}}=1.95$ (After $3 \mathrm{X}$ centrifugation).

\begin{tabular}{|c|c|c|}
\hline & As made & $\begin{array}{c}\text { After 3X } \\
\text { Centrifugation }\end{array}$ \\
\hline Size (nm) & 34.41 & 34.87 \\
\hline $\begin{array}{c}\text { Zeta } \\
\text { Potential } \\
\text { (mV) }\end{array}$ & -34.6 & -36.9 \\
\hline
\end{tabular}

Table 1: Size and zeta (charge) measurement of the particles that were synthesized. 


\subsubsection{Conclusion}

From the given data (Section 2.1.2) using the parameters described in Section 2.1.1, we can see that quality ratio, described in Chapter 1, of the as made sample (one-step self-assembly process) has a poor $\mathrm{R}^{\mathrm{nIR} / \mathrm{Au}}=.83$. Next, after the $3 \mathrm{X}$ centrifugation to purify the sample the $\mathrm{R}^{\mathrm{nIR} / \mathrm{Au}}$ increased to 1.95 , indicating that there was removal of colloidal particles. 


\subsubsection{GGS “Sweep"}

The purpose of this experiment is to run a "sweep" on GGS nanoparticle synthesis on small scale using one-step self-assembly process with $\mathrm{HAuCl}_{4}$ and $\mathrm{Na}_{2} \mathrm{~S}_{2} \mathrm{O}_{3}$ to see the difference the optimal peak of GGS nanoparticles for DiaSynth. A “sweep” is defined has a standard one-step self-assembly process, while changing the amount of $\mathrm{HAuCl}_{4}$ or $\mathrm{Na}_{2} \mathrm{~S}_{2} \mathrm{O}_{3}$ being added in an $\mathrm{X}$ increment.

\subsubsection{Protocol}

In 6 separate $50 \mathrm{~mL}$ centrifugation tubes, add $11 \mathrm{~mL}$ of $2 \mathrm{mM} \mathrm{HAuCl}_{4}$ and $3 \mathrm{mM} \mathrm{Na}_{2} \mathrm{~S}_{2} \mathrm{O}_{3}$ ranging from $1 \mathrm{~mL}$ to $7 \mathrm{~mL}$ in $1 \mathrm{~mL}$ increments in each tube separately. Next, spectral scans were obtained after an hour of the self-assembly synthesis at room temperature (RT), using a UV/Vis spectrophotometer (Carey 50 Varian).

\begin{tabular}{|c|c|c|}
\hline Sample & Samples $(\mathrm{Au}+\mathrm{Na2S2O3})$ & Int Ratios (Au/Na2S2O3) \\
\hline & $11+2.5$ & 4.40 \\
\hline \multirow{2}{*}{ RT } & $11+3$ & 3.67 \\
\hline & $11+3.5$ & 3.14 \\
\hline & $11+4$ & 2.75 \\
\hline & $11+4.5$ & 2.44 \\
\hline
\end{tabular}

Table 2: Represents the controls that will be used in the following experiment. 


\subsubsection{Data/Analysis}

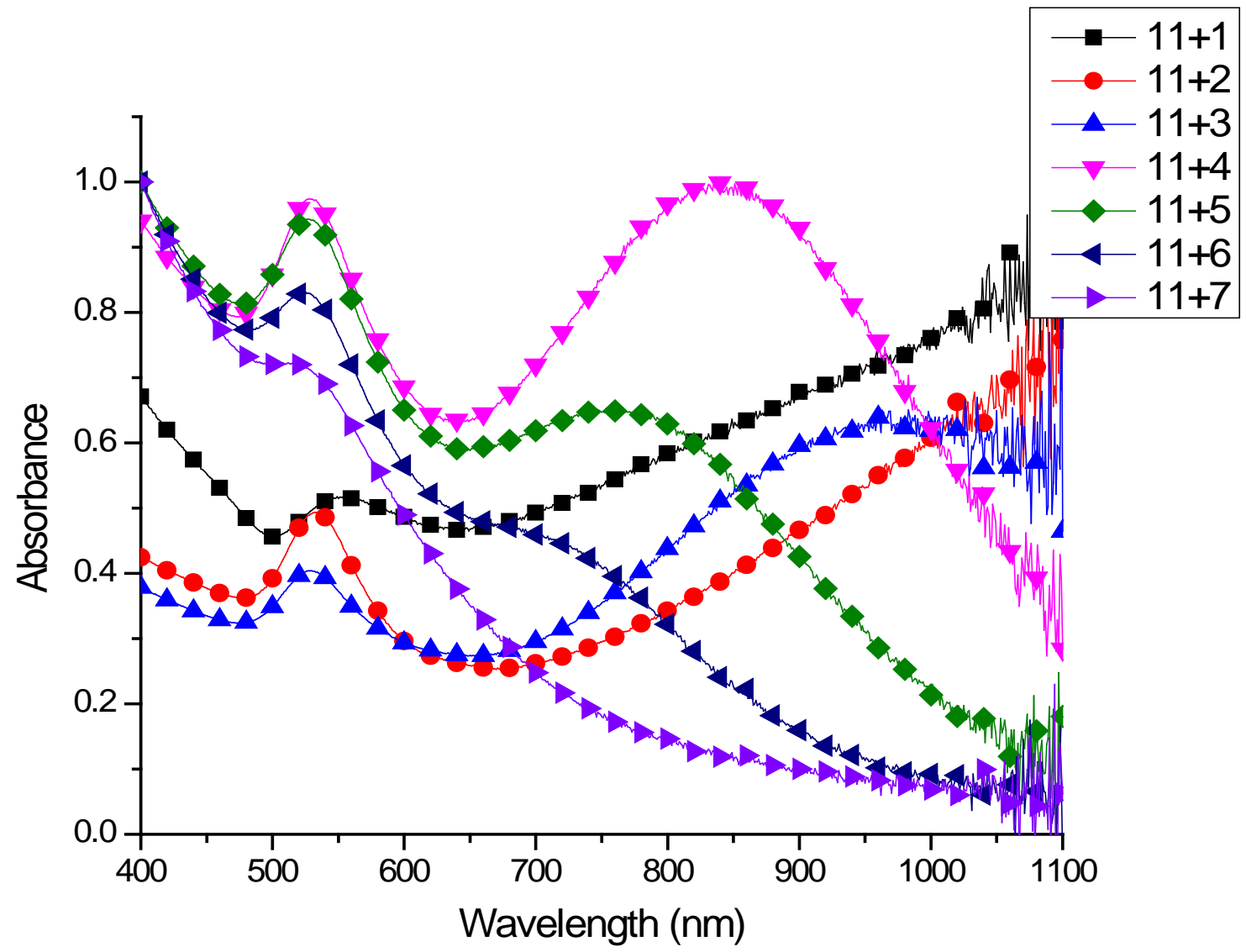

Figure 5: GGS nanoparticle synthesis sweep using $11 \mathrm{~mL}$ of $2 \mathrm{mM} \mathrm{HAuCl4}+\mathrm{X}$ $\mathrm{mL}$ of $3 \mathrm{mM}$ Na2S2O3 in $1 \mathrm{~mL}$ increments (from 1-7). 


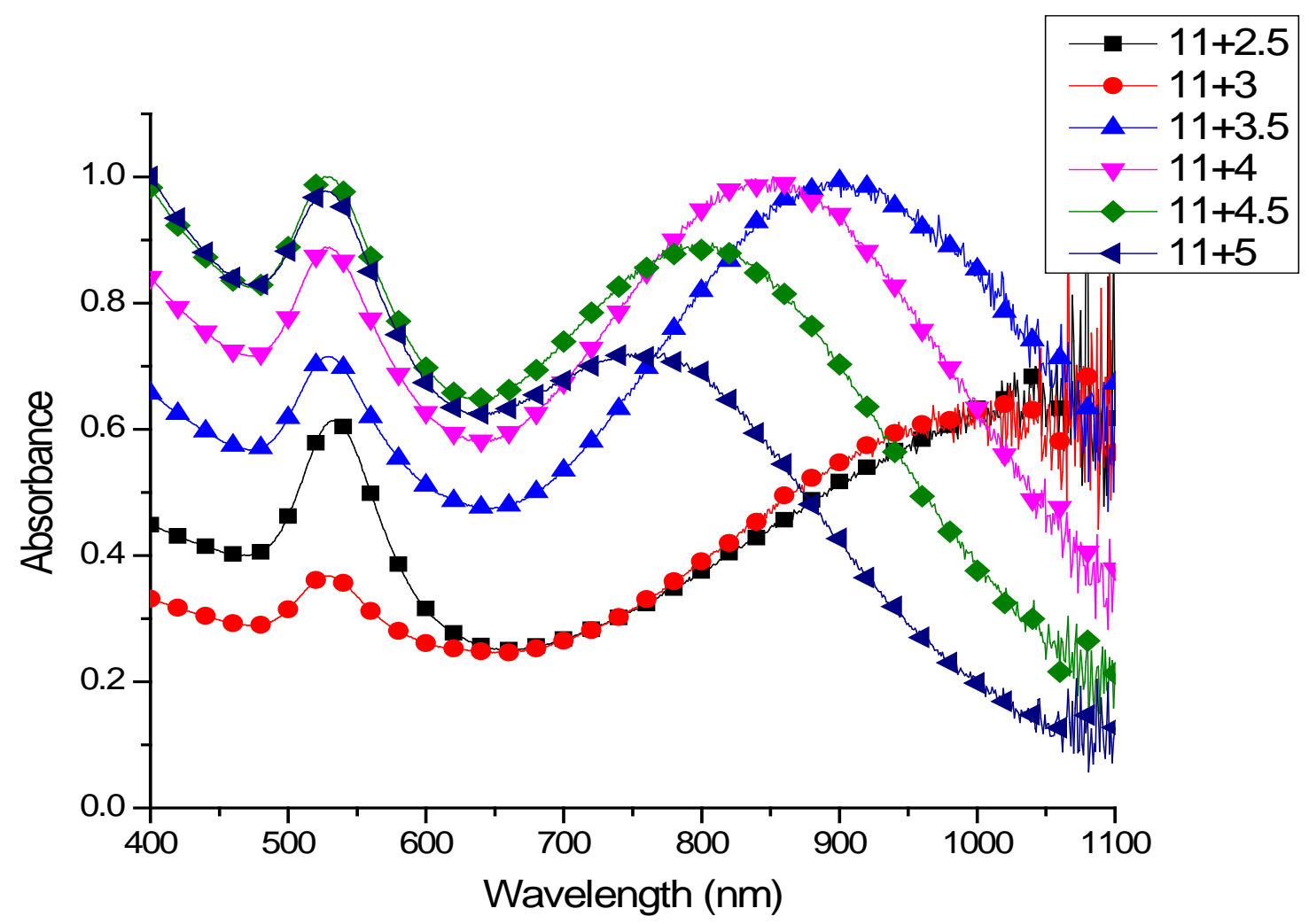

Figure 6: GGS nanoparticle synthesis sweep using $11 \mathrm{~mL}$ of $2 \mathrm{mM} \mathrm{HAuCl}_{4}+\mathrm{X}$ $\mathrm{mL}$ of $3 \mathrm{mM} \mathrm{Na} \mathrm{S}_{2} \mathrm{O}_{3}$ in $0.5 \mathrm{~mL}$ increments (from 2.5-5).

\subsubsection{Conclusion}

Once the sweep was complete, the spectral profile was taken for each of the samples. Figures $5 \& 6$ show the spectral profile on each sample; from that it was determined that it would be optimal to work in the range of $2 \mathrm{~mL}-4 \mathrm{~mL}$ of 3 $\mathrm{mM} \mathrm{Na}_{2} \mathrm{~S}_{2} \mathrm{O}_{3}$ to be mixed with $2 \mathrm{mM} \mathrm{HAuCl}_{4}$. 


\subsubsection{GGS Sweep on Oven Based Temperature Synthesis}

The purpose of this experiment is to run a sweep on GGS nanoparticle synthesis on small scale using one-step self-assembly process with $\mathrm{HAuCl}_{4}$ and $\mathrm{Na}_{2} \mathrm{~S}_{2} \mathrm{O}_{3}$; however, the samples were synthesized inside a temperature controlled oven. Increasing the temperature should drive the reaction faster, which ultimately would favor the formation of the nIR particles.

\subsubsection{Protocol}

In six separate $50 \mathrm{~mL}$ centrifugation tubes, add $11 \mathrm{~mL}$ of $2 \mathrm{mM} \mathrm{HAuCl}_{4}$ and $3 \mathrm{mM} \mathrm{Na} 2 \mathrm{~S}_{2} \mathrm{O}_{3}$ ranging from $2.5 \mathrm{~mL}$ to $5 \mathrm{~mL}$ in $0.5 \mathrm{~mL}$ increments in each tube separately. Once the samples were mixed, they were added to an oven at $37^{\circ} \mathrm{C}$ and reacted for $1 \mathrm{hr}$. The sweep was repeated again, except using an over at $65^{\circ} \mathrm{C}$. All the samples were compared to the sweep done in Section 2.4.2. Next, spectral scans were obtained after an hour after the self-assembly process using a UV/Vis spectrophotometer (Carey 50 Varian).

\begin{tabular}{|c|c|c|}
\hline Sample & Samples (Au + Na2S2O3) & Int Ratios (Au/Na2S2O3) \\
\hline & $11+2.5$ & 4.40 \\
\hline $37^{\circ} \mathrm{C}$ & $11+3$ & 3.67 \\
$\&$ & $11+3.5$ & 3.14 \\
\hline $65^{\circ} \mathrm{C}$ & $11+4$ & 2.75 \\
\hline & $11+4.5$ & 2.44 \\
\hline & $11+5$ & 2.20 \\
\hline
\end{tabular}

Table 3: Represents the controls that will be used in the following experiment. 


\subsubsection{Data/Analysis}

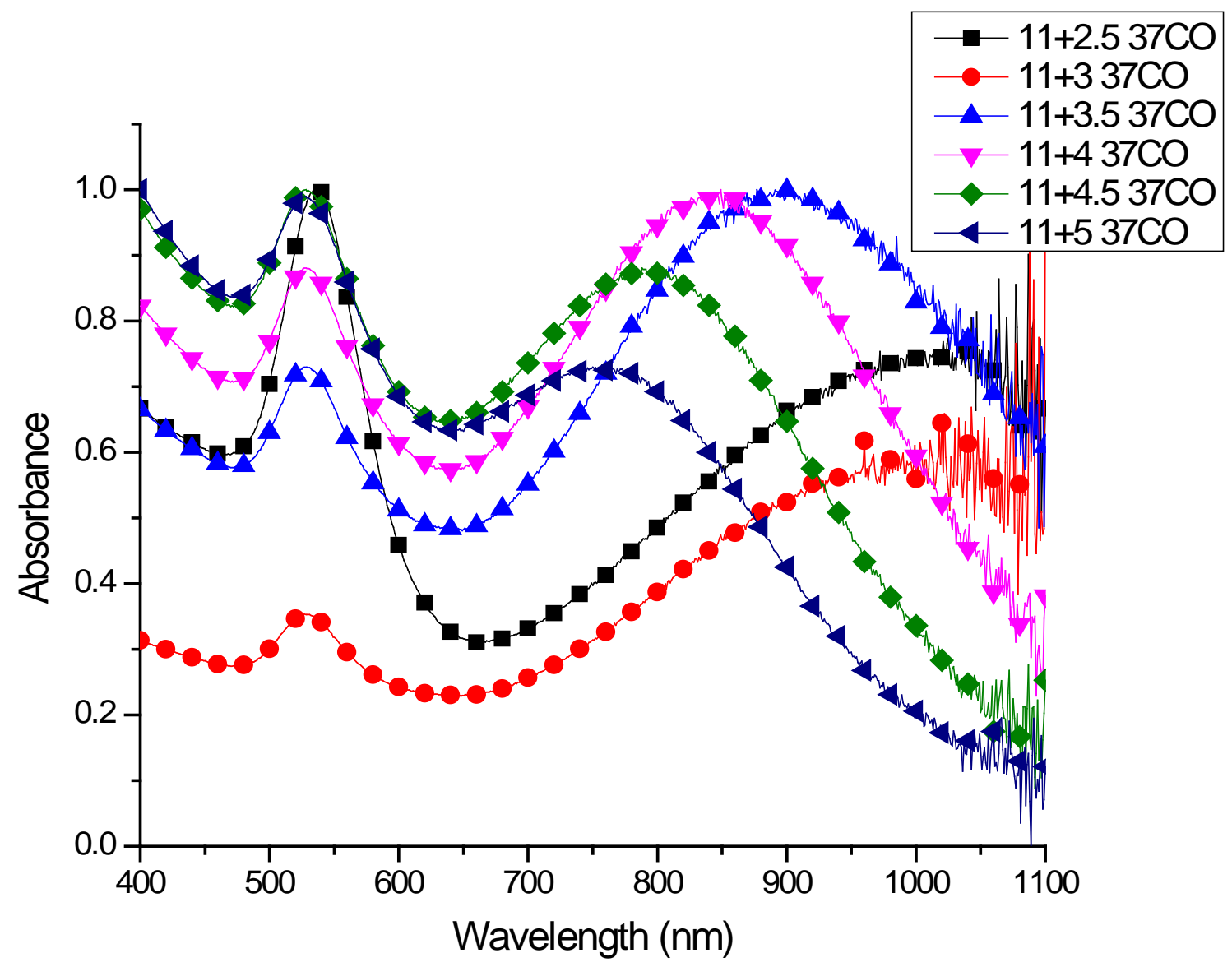

Figure 7: GGS nanoparticle synthesis sweep using $11 \mathrm{~mL}$ of $2 \mathrm{mM} \mathrm{HAuCl} 4+\mathrm{X}$ $\mathrm{mL}$ of $3 \mathrm{mM} \mathrm{Na} \mathrm{S}_{2} \mathrm{O}_{3}$ in $0.5 \mathrm{~mL}$ increments (from 2.5-5) at $37^{\circ} \mathrm{C}$ in an oven. 


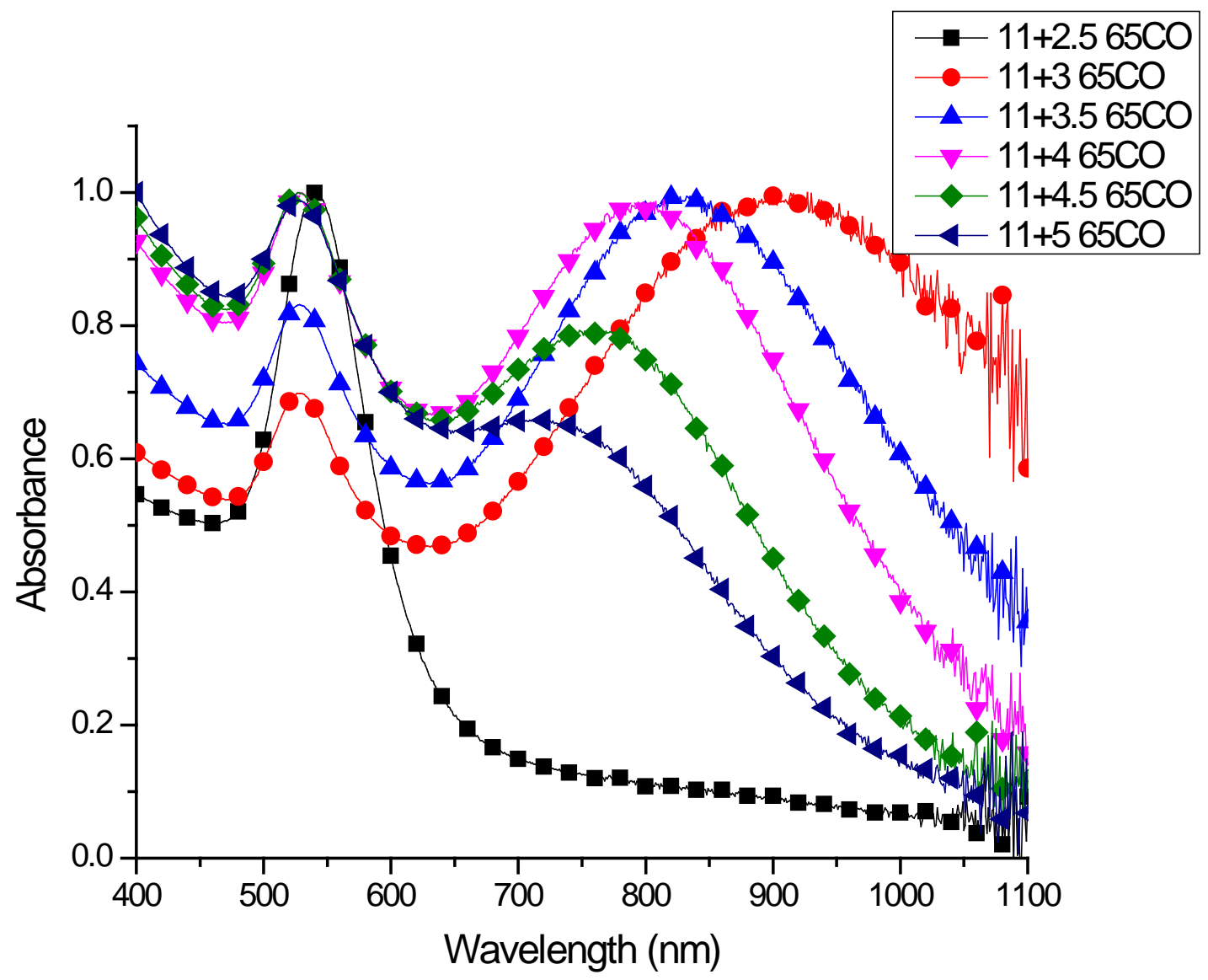

Figure 8: GGS nanoparticle synthesis sweep using $11 \mathrm{~mL}$ of $2 \mathrm{mM} \mathrm{HAuCl}_{4}+$ $\mathrm{X} \mathrm{mL}$ of $3 \mathrm{mM} \mathrm{Na} \mathrm{S}_{2} \mathrm{O}_{3}$ in $0.5 \mathrm{~mL}$ increments (from 2.5-5) at $65^{\circ} \mathrm{C}$ in an oven. 


\begin{tabular}{|c|c|c|c|}
\hline & $\begin{array}{c}\text { Int Ratios } \\
\text { (HAuCl4/Na2S203) }\end{array}$ & $\begin{array}{l}\text { nIR Wavelength } \\
\text { Peak }(\mathbf{n m})\end{array}$ & Quality Ratio \\
\hline \multirow{6}{*}{ RT } & 4.40 & N/A & N/A \\
\hline & 3.67 & 995 & 1.675 \\
\hline & 3.14 & 901 & 1.398 \\
\hline & 2.75 & 852 & 1.126 \\
\hline & 2.44 & 807 & 0.895 \\
\hline & 2.20 & 779 & 0.730 \\
\hline \multirow{6}{*}{37 CO } & 4.40 & 1025 & 0.773 \\
\hline & 3.67 & 987 & 1.665 \\
\hline & 3.14 & 901 & 1.370 \\
\hline & 2.75 & 859 & 1.135 \\
\hline & 2.44 & 801 & 0.885 \\
\hline & 2.20 & 785 & 0.713 \\
\hline \multirow{6}{*}{$65 \mathrm{CO}$} & 4.40 & N/A & N/A \\
\hline & 3.67 & 897 & 1.432 \\
\hline & 3.14 & 822 & 1.203 \\
\hline & 2.75 & 813 & 0.990 \\
\hline & 2.44 & 807 & 0.929 \\
\hline & 2.20 & 787 & 0.770 \\
\hline
\end{tabular}

Table 9: nIR peak and the quality ratios of each sample from Figure 6, 7, and 8. 


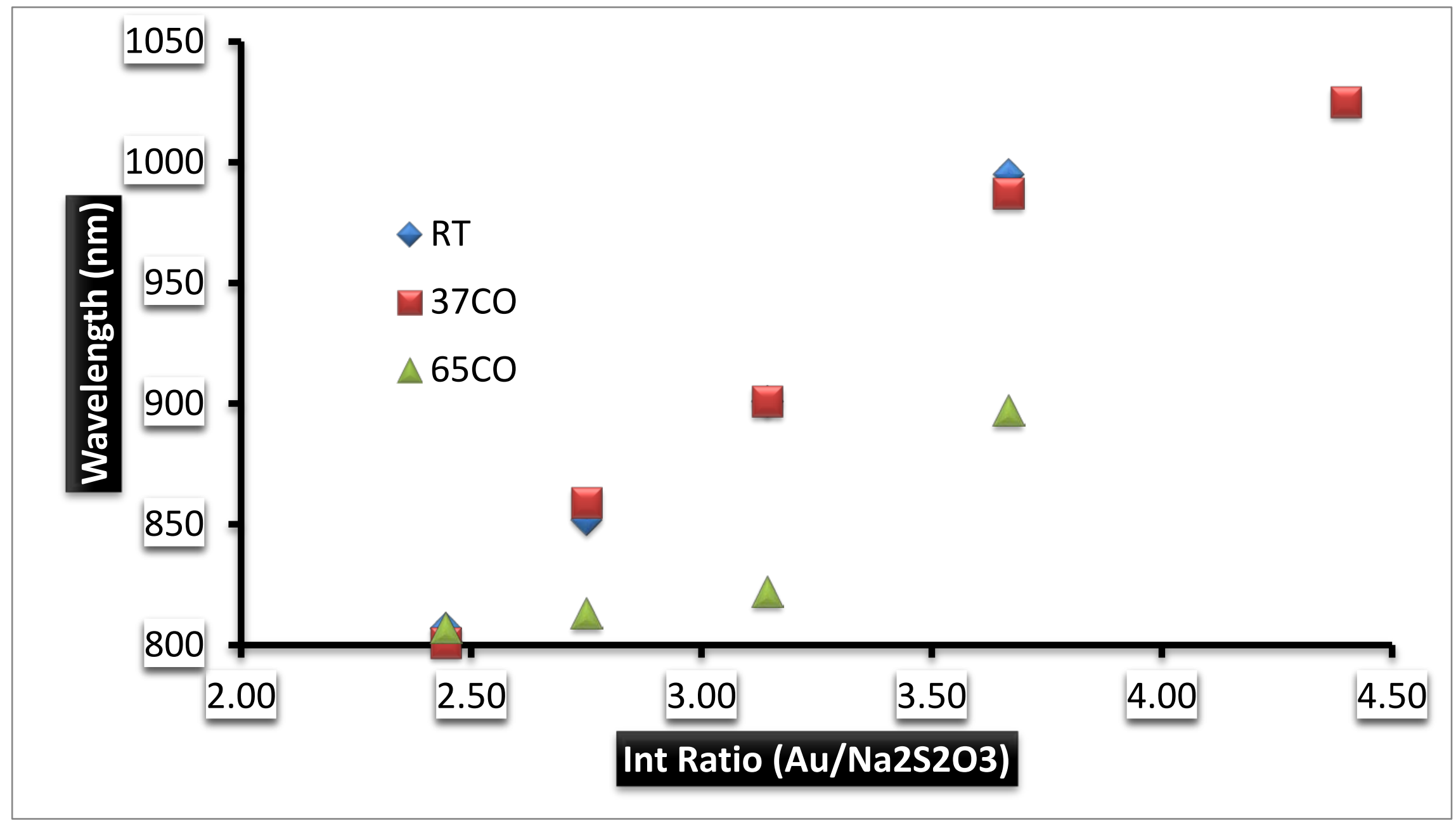

Figure 9: Scatter plot (data from Table 4) of the initial ratio $\left(\mathrm{HAuCl}_{4}: \mathrm{Na}_{2} \mathrm{~S}_{2} \mathrm{O}_{3}\right)$ used vs the nIR peak at the end of the reaction is the given three controls. 


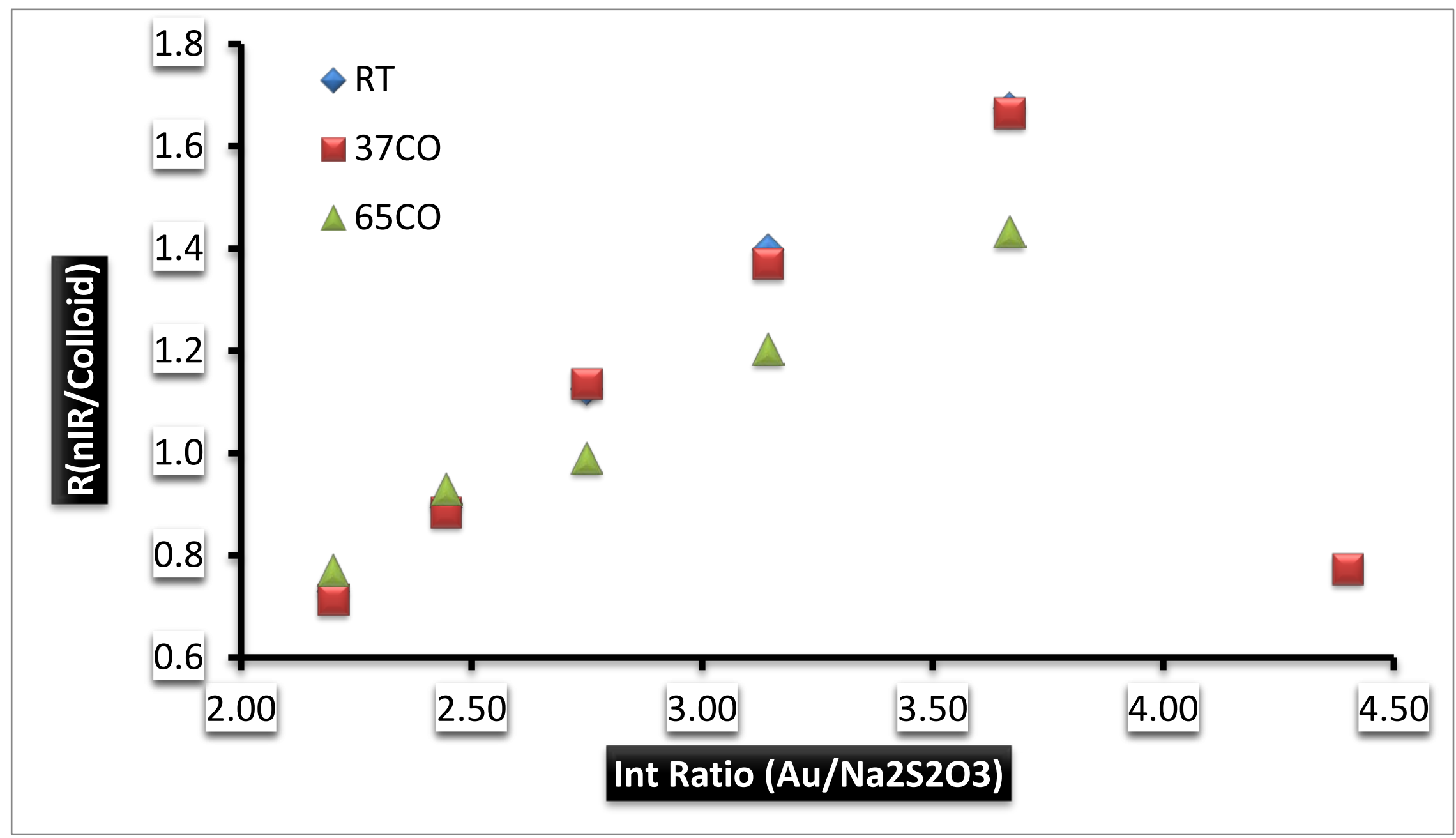

Figure 10: Scatter plot (data from Table 4) of the initial ratio ( $\left.\mathrm{HAuCl}_{4}: \mathrm{Na}_{2} \mathrm{~S}_{2} \mathrm{O}_{3}\right)$ used vs the $\mathrm{R}^{\mathrm{nIR} / \mathrm{Au}}$ at the end of the reaction is the given three controls. 


\subsubsection{Conclusion}

Once the sweep was complete, the spectral profile was taken for each of the samples. Figures $7 \& 8$ show the spectral profile on each sample; from that it was determined that it would be optimal to work in the range of $2 \mathrm{~mL}-4 \mathrm{~mL}$ of 3 $\mathrm{mM} \mathrm{Na} \mathrm{S}_{2} \mathrm{O}_{3}$ to be mixed with $2 \mathrm{mM} \mathrm{HAuCl}_{4}$, same as the data reported in Section 2.4.2. The sample will be tested in a water bath to see if it will aid in the reaction rate. 


\subsubsection{GGS Synthesis in Water Bath \& Oven - Temperature Controlled Environment}

The purpose of this experiment is to synthesize GGS nanoparticle on small scale using one-step self-assembly process with $\mathrm{HAuCl}_{4}$ and $\mathrm{Na}_{2} \mathrm{~S}_{2} \mathrm{O}_{3}$; however, the samples were synthesized inside a temperature controlled oven and water bath (repeat of experiment in Section 2.4.3).

\subsubsection{Protocol}

Fill a $1 \mathrm{~L}$ beaker with $800 \mathrm{~mL}$ of DI water and heat the water to $37^{\circ} \mathrm{C}$ or $65^{\circ} \mathrm{C}$. Next, using a $50 \mathrm{~mL}$ centrifugation tubes, add a mixture of $11 \mathrm{~mL}$ of $2 \mathrm{mM}$ $\mathrm{HAuCl}_{4}$ and 2 or $3 \mathrm{~mL}$ of $3 \mathrm{mM} \mathrm{Na}_{2} \mathrm{~S}_{2} \mathrm{O}_{3}$, and let the sample react for 1 hour at RT, $37^{\circ} \mathrm{C}$, and $65^{\circ} \mathrm{C}$. Next, spectral scans were obtained after an hour of the selfassembly synthesis at room temperature (RT), $37^{\circ} \mathrm{C}$, and $65^{\circ} \mathrm{C}$. Next, spectral scans were obtained after an hour after the self-assembly process using a UV/Vis spectrophotometer (Carey 50 Varian). 


\subsubsection{Data/Analysis}

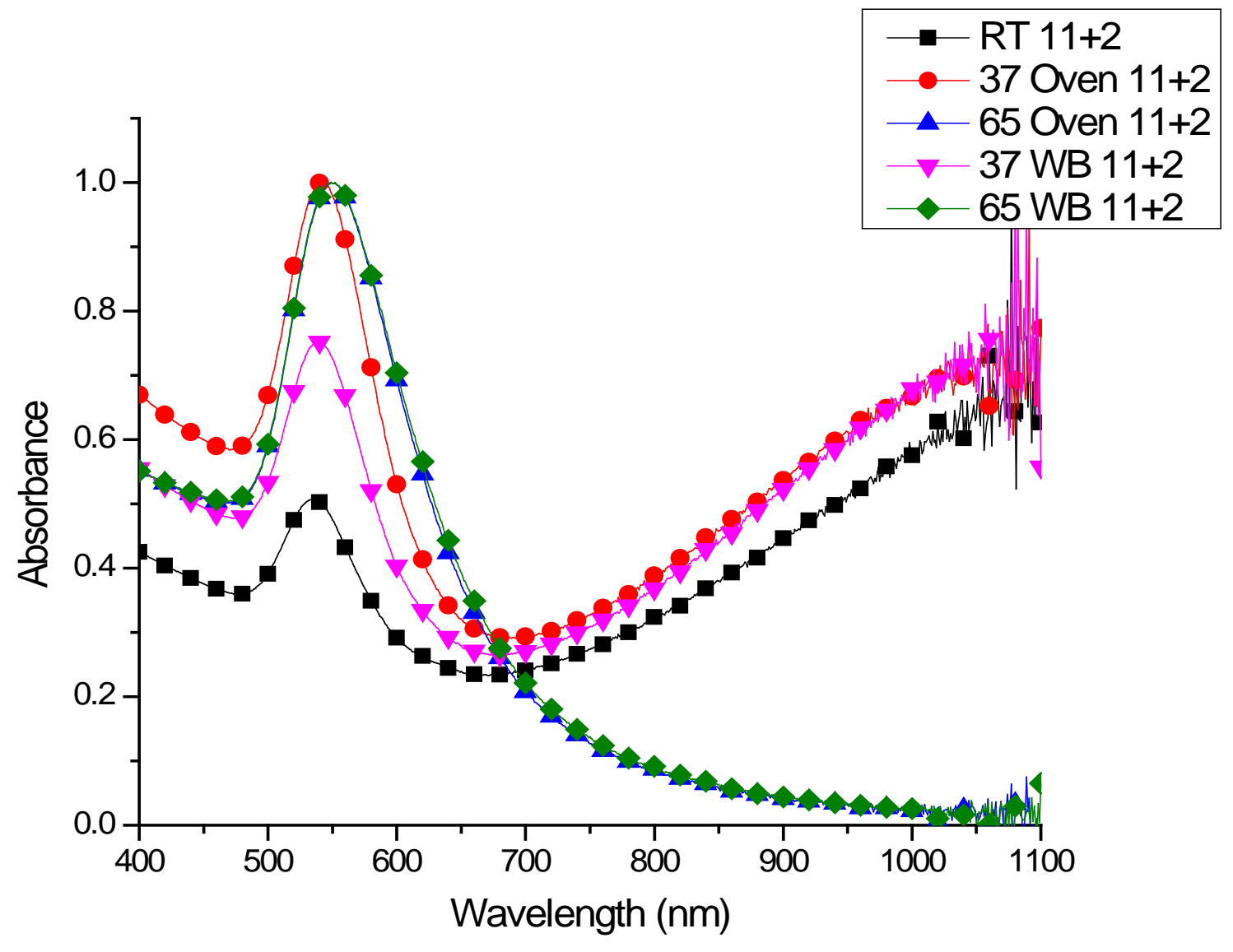

Figure 11: GGS nanoparticle synthesis using $11 \mathrm{~mL}$ of $2 \mathrm{mM} \mathrm{HAuCl}_{4}+2 \mathrm{~mL}$ of 3 $\mathrm{mM} \mathrm{Na} \mathrm{S}_{2} \mathrm{O}_{3}$ in a water bath and an oven at $35^{\circ} \mathrm{C}$ or $65^{\circ} \mathrm{C}$. 


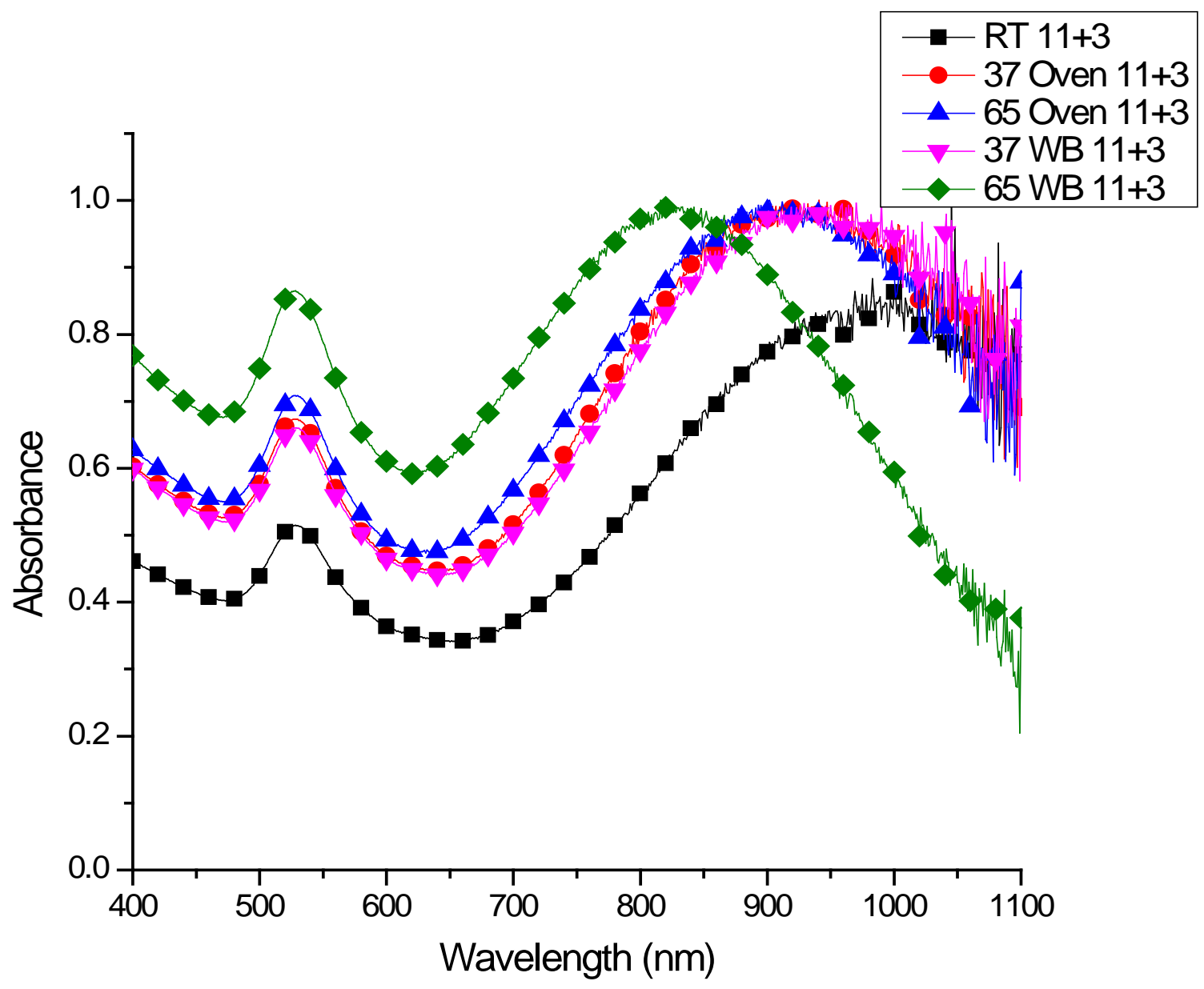

Figure 12: GGS nanoparticle synthesis using $11 \mathrm{~mL}$ of $2 \mathrm{mM} \mathrm{HAuCl}_{4}+3 \mathrm{~mL}$ of 3 $\mathrm{mM} \mathrm{Na} \mathrm{S}_{2} \mathrm{O}_{3}$ in a water bath and an oven at $35^{\circ} \mathrm{C}$ or $65^{\circ} \mathrm{C}$. 


\begin{tabular}{|c|c|c|c|}
\hline Samples & Int Ratio & $\begin{array}{l}\text { nIR Wavelength } \\
\text { Peak (nm) }\end{array}$ & Quality Ratio \\
\hline \multirow{2}{*}{ RT } & 5.5 & N/A & N/A \\
\hline & 3.67 & 990 & 1.663 \\
\hline \multirow{2}{*}{ 37C Oven } & 5.5 & N/A & N/A \\
\hline & 3.67 & 919 & 1.164 \\
\hline \multirow{2}{*}{ 65C Oven } & 5.5 & N/A & N/A \\
\hline & 3.67 & 902 & 1.271 \\
\hline \multirow{2}{*}{ 37C WB } & 5.5 & N/A & N/A \\
\hline & 3.67 & 930 & 1.496 \\
\hline \multirow{2}{*}{ 65C WB } & 5.5 & N/A & N/A \\
\hline & 3.67 & 826 & 1.270 \\
\hline
\end{tabular}

Table 4: nIR peak and the quality ratios of each sample from Figure 11 and 12.

\subsubsection{Conclusion}

Once the self-assembly process was complete, the spectral profile was taken for each of the samples. Figures 11 \& 12 show the spectral profile on each sample; from that it was determined that it using the water bath shows better results for $11+3$, and had better quality ratio. 


\subsubsection{GGS Synthesis in Water Bath - Temperature Controlled Environment}

The purpose of this experiment is to synthesize GGS nanoparticle on small scale using one-step self-assembly process with $\mathrm{HAuCl}_{4}$ and $\mathrm{Na}_{2} \mathrm{~S}_{2} \mathrm{O}_{3}$; however, the samples were synthesized inside a temperature controlled water bath (repeat of experiment in Section 2.4.3 and 2.4.4). However in those experiments the volume of $\mathrm{Na}_{2} \mathrm{~S}_{2} \mathrm{O}_{3}$ is changed, but instead for this experiment the $\mathrm{HAuCl}_{4}$ will be changed.

\subsubsection{Protocol}

Fill a $1 \mathrm{~L}$ beaker with $800 \mathrm{~mL}$ of $\mathrm{DI}$ water and heat the water to $37^{\circ} \mathrm{C}$ (WB) or $100^{\circ} \mathrm{C}(\mathrm{HB})$. Next, using a $50 \mathrm{~mL}$ centrifugation tubes, add a mixture of $8 \mathrm{~mL}, 9 \mathrm{~mL}, 10 \mathrm{~mL}$, or $11 \mathrm{~mL}$ of $2 \mathrm{mM} \mathrm{HAuCl}_{4}$ and $3 \mathrm{~mL}$ of $3 \mathrm{mM} \mathrm{Na}_{2} \mathrm{~S}_{2} \mathrm{O}_{3}$, and let the sample react for 1 hour at RT, $37^{\circ} \mathrm{C}$, and $100^{\circ} \mathrm{C}$. Next, spectral scans were obtained after an hour of the self-assembly synthesis at room temperature (RT), $37^{\circ} \mathrm{C}$, and $100^{\circ} \mathrm{C}$. 


\subsubsection{Data/Synthesis}

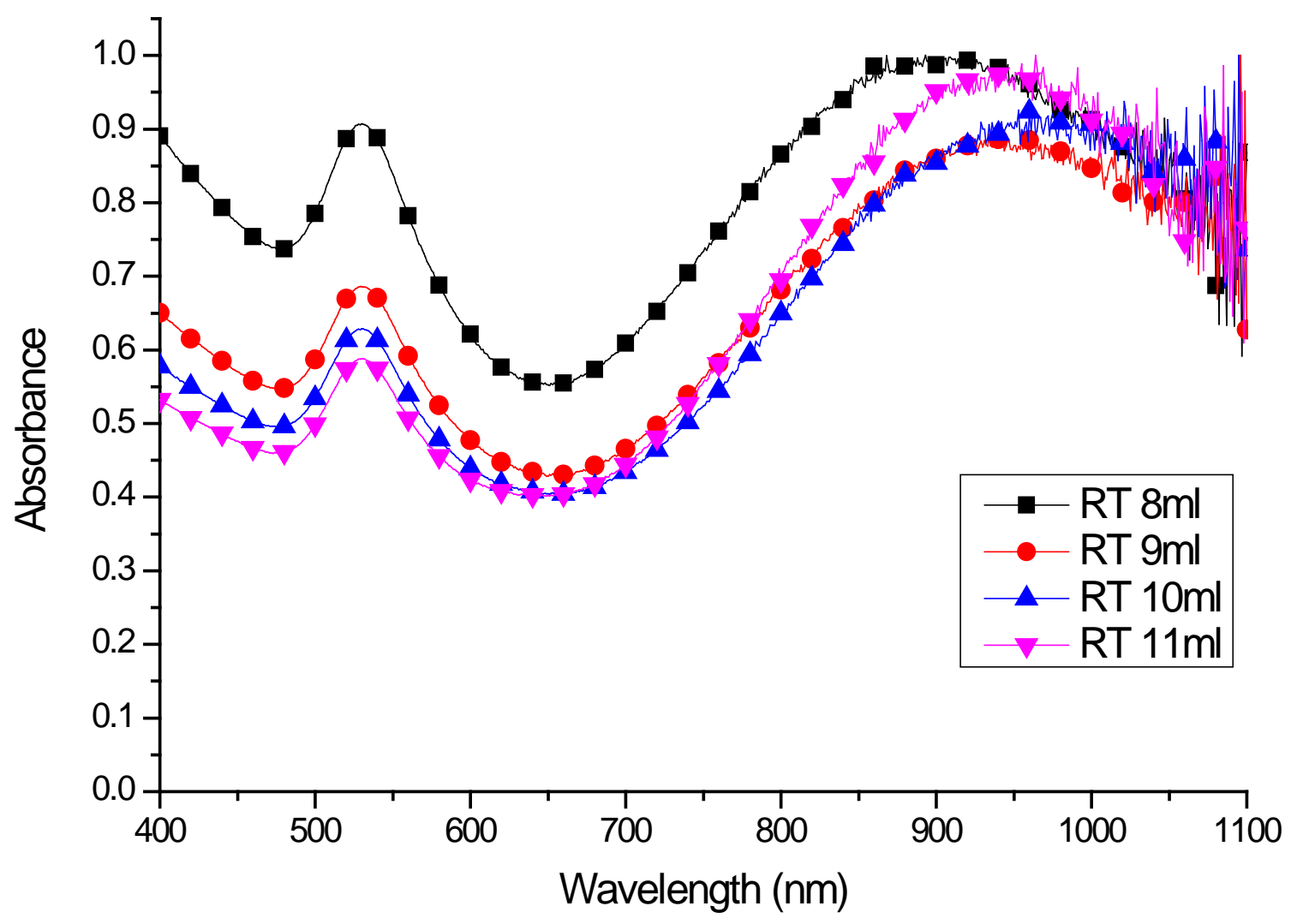

Figure 13: Spectral profile of the RT synthesis, using a mixture of $8 \mathrm{~mL}, 9 \mathrm{~mL}, 10$ $\mathrm{mL}$, or $11 \mathrm{~mL}$ of $2 \mathrm{mM} \mathrm{HAuCl}_{4}$ and $3 \mathrm{~mL}$ of $3 \mathrm{mM} \mathrm{Na}_{2} \mathrm{~S}_{2} \mathrm{O}_{3}$. 


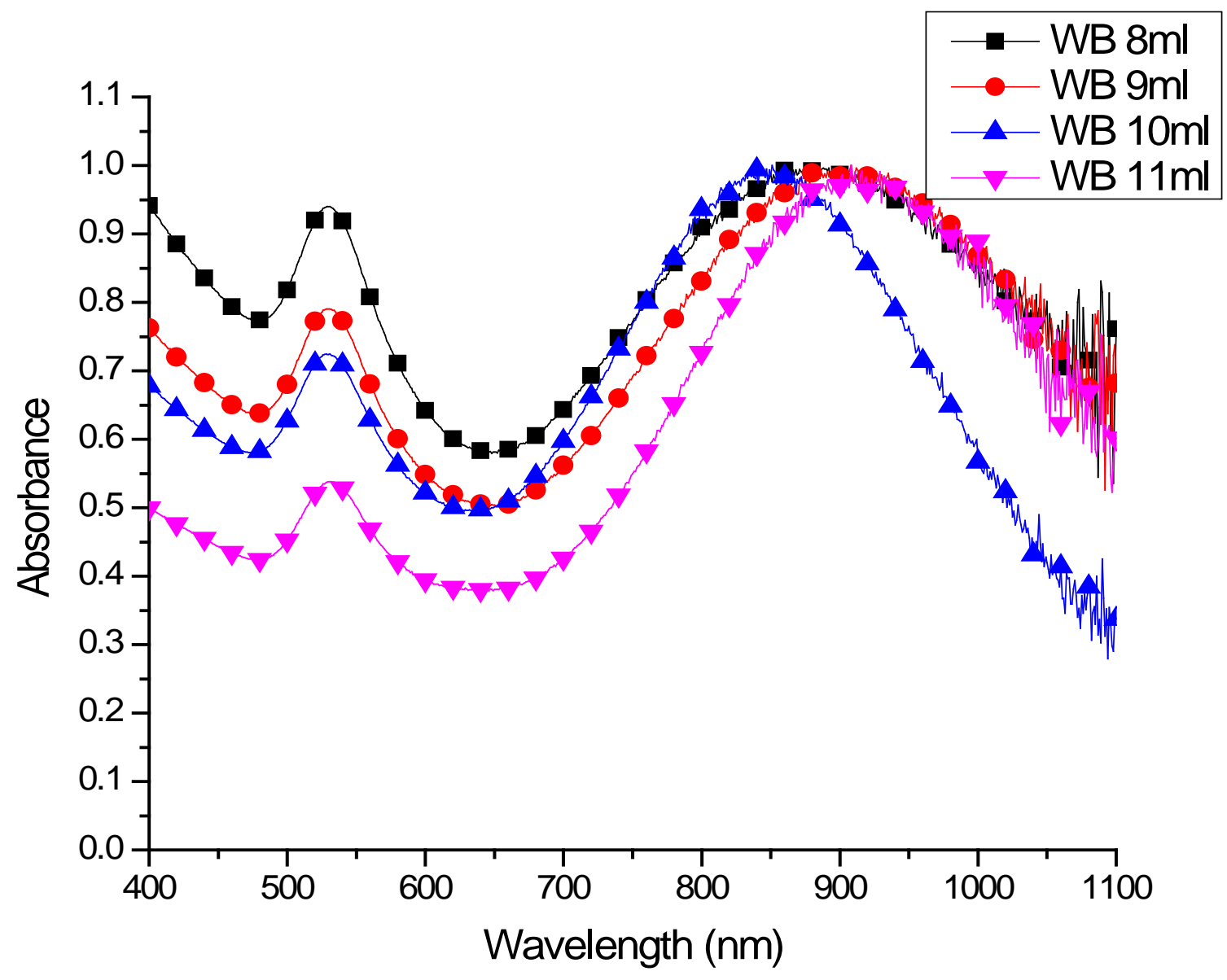

Figure 14: Spectral profile of the $37^{\circ} \mathrm{C}$ water bath synthesis, using a mixture of $8 \mathrm{~mL}, 9$ $\mathrm{mL}, 10 \mathrm{~mL}$, or $11 \mathrm{~mL}$ of $2 \mathrm{mM} \mathrm{HAuCl} \mathrm{H}_{4}$ and $3 \mathrm{~mL}$ of $3 \mathrm{mM} \mathrm{Na}_{2} \mathrm{~S}_{2} \mathrm{O}_{3}$. 


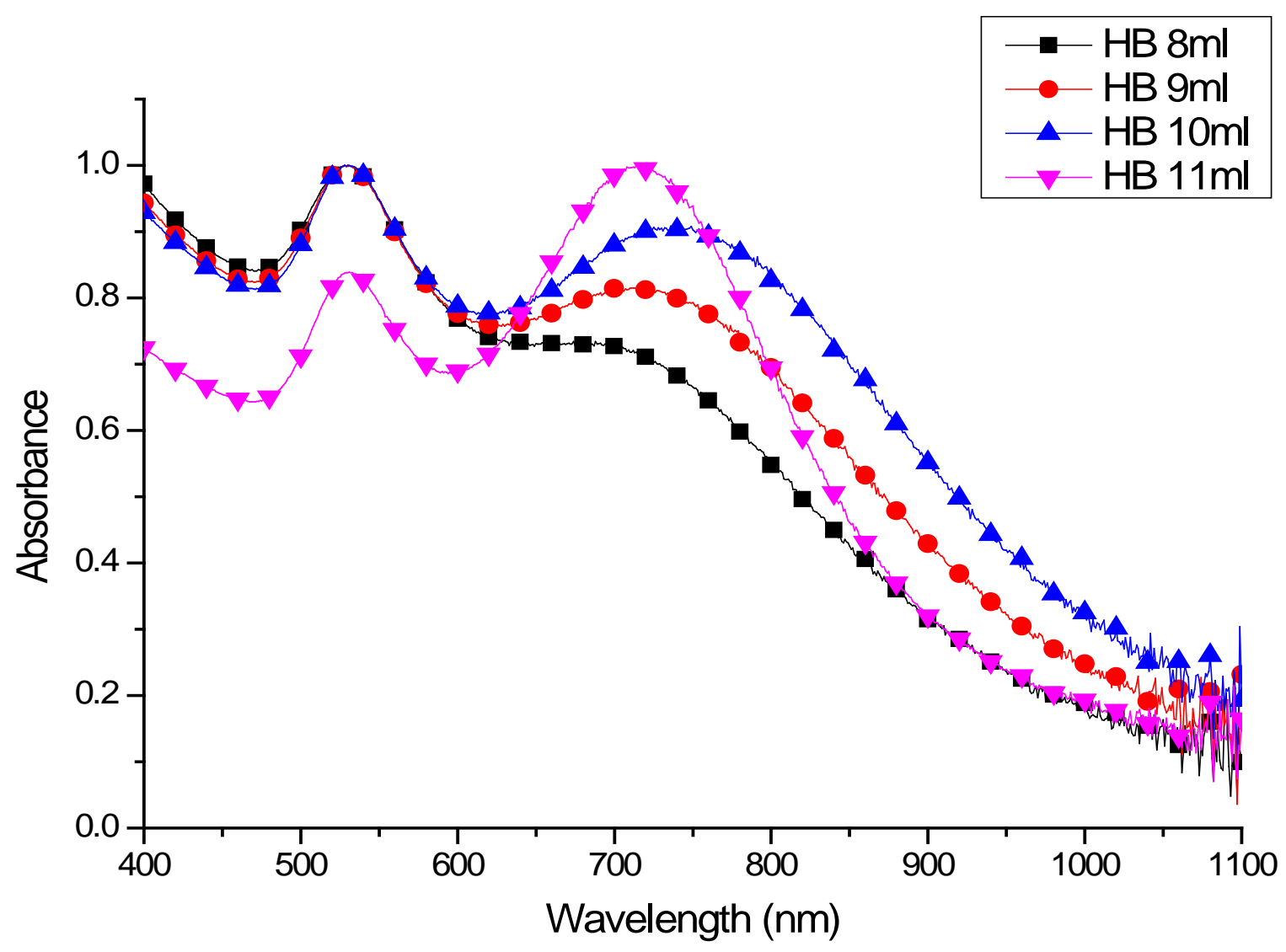

Figure 15: Spectral profile of the $100^{\circ} \mathrm{C}$ water bath synthesis, using a mixture of 8 $\mathrm{mL}, 9 \mathrm{~mL}, 10 \mathrm{~mL}$, or $11 \mathrm{~mL}$ of $2 \mathrm{mM} \mathrm{HAuCl}_{4}$ and $3 \mathrm{~mL}$ of $3 \mathrm{mM} \mathrm{Na} \mathrm{S}_{2} \mathrm{O}_{3}$. 


\begin{tabular}{|c|c|c|c|}
\hline & $\begin{array}{c}\text { Int Ratios } \\
\text { (Au/Na2S2O3) }\end{array}$ & $\begin{array}{l}\text { nIR Wavelength } \\
\text { Peak (nm) }\end{array}$ & Quality Ratio \\
\hline \multirow{4}{*}{ RT } & 2.67 & 912 & 1.103 \\
\hline & 3.00 & 955 & 1.458 \\
\hline & 3.33 & 953 & 1.591 \\
\hline & 3.67 & 964 & 1.700 \\
\hline \multirow{4}{*}{$37 \mathrm{C}$} & 2.67 & 863 & 1.064 \\
\hline & 3.00 & 908 & 1.265 \\
\hline & 3.33 & 851 & 1.380 \\
\hline & 3.67 & 908 & 1.858 \\
\hline \multirow{4}{*}{$100 \mathrm{C}$} & 2.67 & 716 & 0.789 \\
\hline & 3.00 & 736 & 0.817 \\
\hline & 3.33 & 749 & 0.908 \\
\hline & 3.67 & 720 & 1.193 \\
\hline
\end{tabular}

Table 5: nIR peak and the quality ratios of each sample from Figure 13, 14 and 15. 


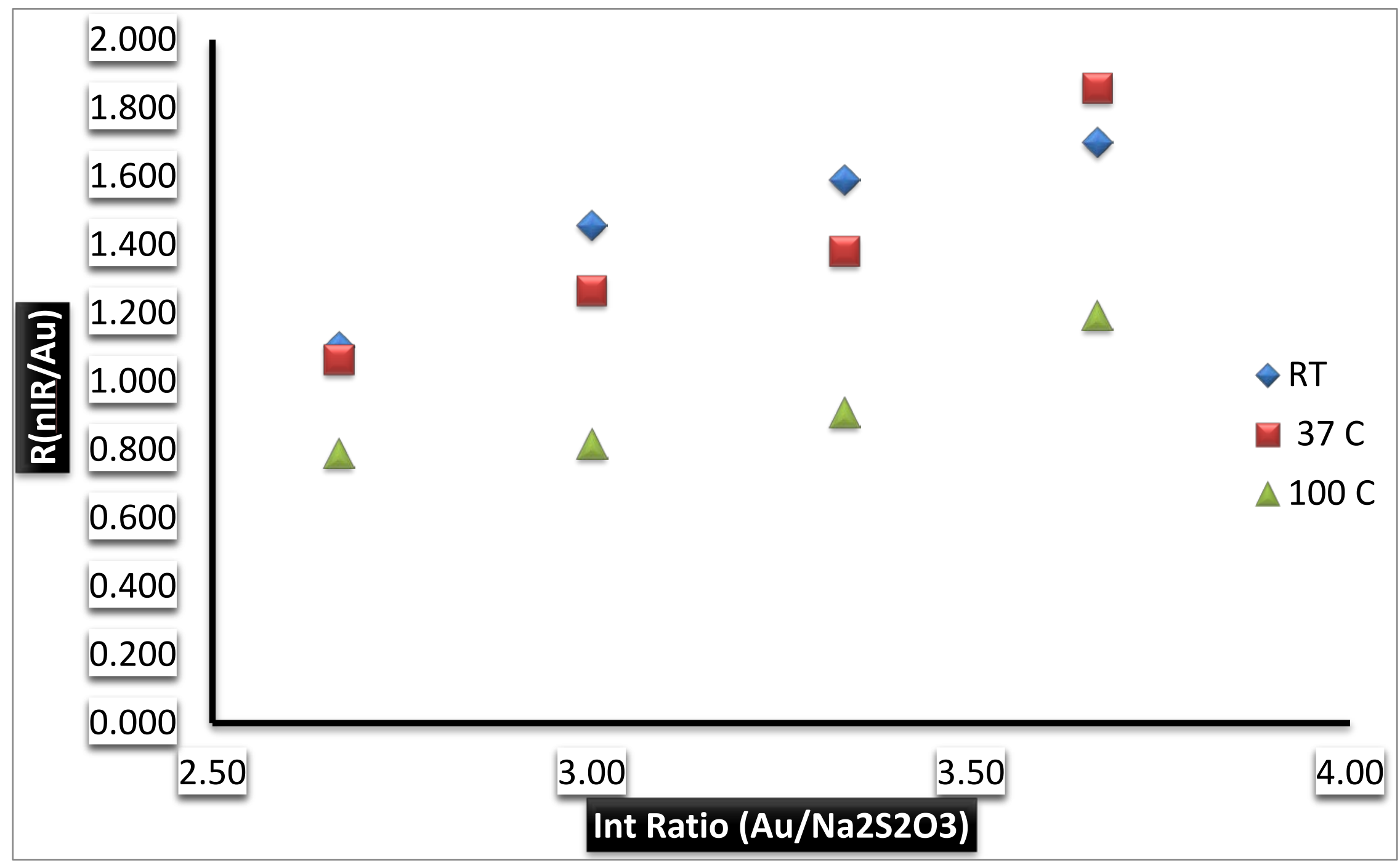

Figure 16: Scatter plot (data from Table 6) of the initial ratio ( $\mathrm{HAuCl}_{4}: \mathrm{Na}_{2} \mathrm{~S}_{2} \mathrm{O}_{3}$ ) used vs the $\mathrm{R}^{\mathrm{nIR} / \mathrm{Au}}$ at the end of the reaction is the given three controls.. 


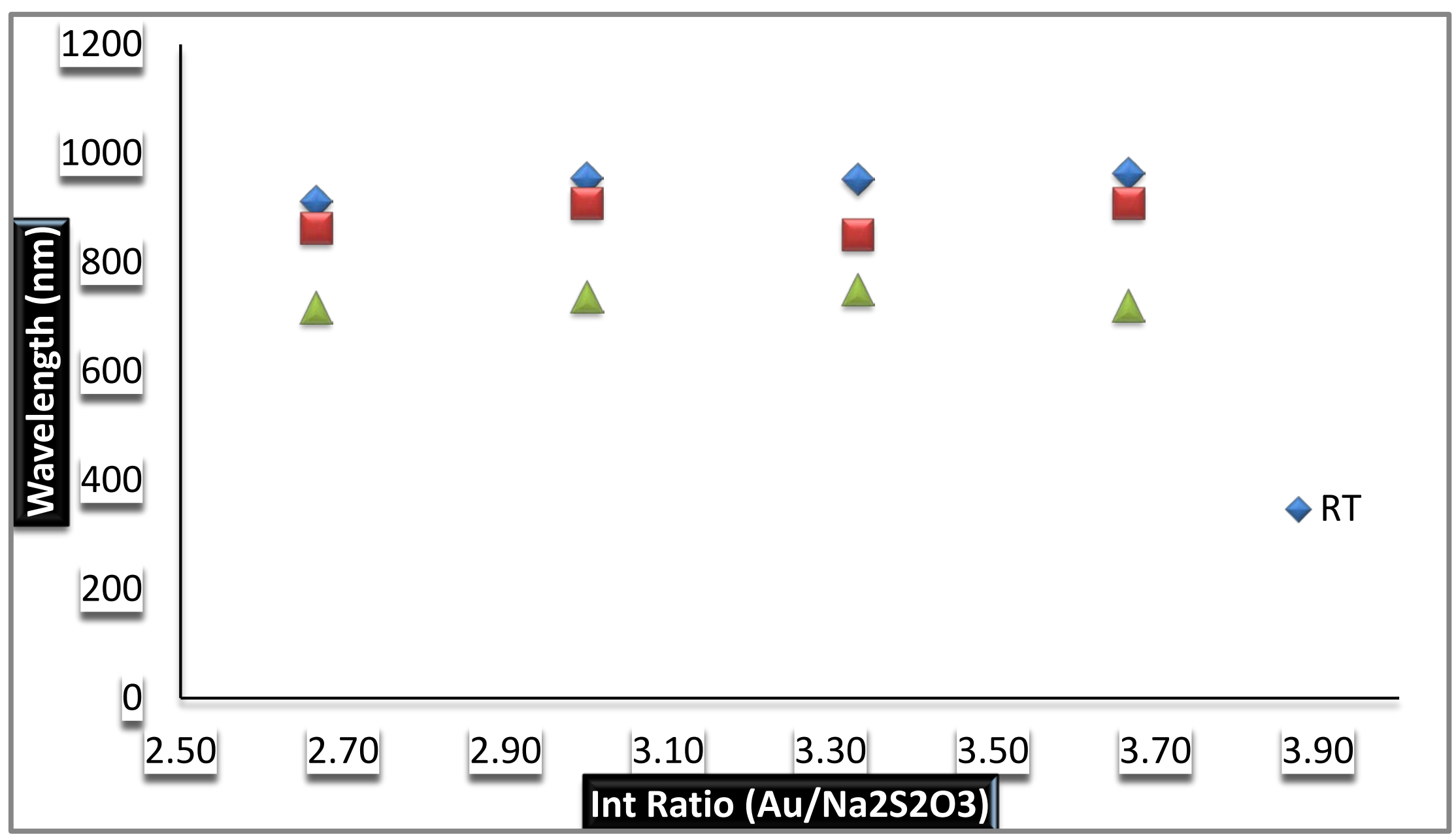

Figure 17: Scatter plot (data from Table 6) of the initial ratio $\left(\mathrm{HAuCl}_{4}: \mathrm{Na}_{2} \mathrm{~S}_{2} \mathrm{O}_{3}\right)$ used vs the nIR peak at the end of the reaction is the given three controls. 


\subsubsection{Conclusion}

Once the self-assembly process was complete, the spectral profile was taken for each of the samples. Figures $13,14, \& 15$, show the spectral profile on each sample. At higher temperatures samples are colliding faster to each other, which ultimately affecting the kinetic energy of the molecules, and driving the reaction. For the series of temperature studies, the kinetics was changed and shown to have an $\mathrm{R}^{\mathrm{nIR} / \mathrm{Au}}>1.2$. Most of the reaction show that using the $11+3$ samples has a better ratio, using the initial for the DiaSynth studies could be beneficial. 


\subsubsection{DiaSynth}

The purpose of this experiment is to synthesize a batch of AuNPs with $\mathrm{HAuCl}_{4}$ and $\mathrm{Na}_{2} \mathrm{~S}_{2} \mathrm{O}_{3}$ using the DiaSynth method, dialyzed against DI water at room temperature. Also, $\mathrm{HAuCl}_{4}$ dialyzed against $\mathrm{Na}_{2} \mathrm{~S}_{2} \mathrm{O}_{3}$ to see the kinetics and equilibrium shift of two different reactions.

\subsubsection{Protocol}

Fill a $1 \mathrm{~L}$ beaker with $800 \mathrm{~mL}$ of DI water and place stir bar inside. Next, using a 3500 Da MWCO Dialysis membrane, add a mixture of $11 \mathrm{~mL}$ of $2 \mathrm{mM}$ $\mathrm{HAuCl}_{4}$ (first in the bag) and $3 \mathrm{~mL}$ of $3 \mathrm{mM} \mathrm{Na}_{2} \mathrm{~S}_{2} \mathrm{O}_{3}$ (second after the gold solution had been added), and let the sample dialyze for 1 hour (Sample 1). Separately, fill a $1 \mathrm{~L}$ beaker with $3 \mathrm{mM} \mathrm{Na}_{2} \mathrm{~S}_{2} \mathrm{O}_{3}$. Next to that, add $25 \mathrm{~mL}$ of 2 mM HAuCl 4 in a 3500 Da MWCO Dialysis membrane and let it react for 2.5 hours (Sample 2). For a non-dialysis sample, $11 \mathrm{~mL}$ of $2 \mathrm{mM} \mathrm{HAuCl}_{4}$ and $3 \mathrm{~mL}$ of $3 \mathrm{mM} \mathrm{Na} \mathrm{S}_{2} \mathrm{O}_{3}$ are mixed in a $50 \mathrm{~mL}$ tube and reacted for $1 \mathrm{hr}$ as well (Sample 3). Next, spectral scans were obtained after an hour of the self-assembly synthesis at room temperature (RT), using a UV/Vis spectrophotometer (Carey 50 Varian). A Malvern Zetasizer (ZS90) was used to characterize the GGS nanoparticles surface charge and size. 


\subsubsection{Data/Analysis}

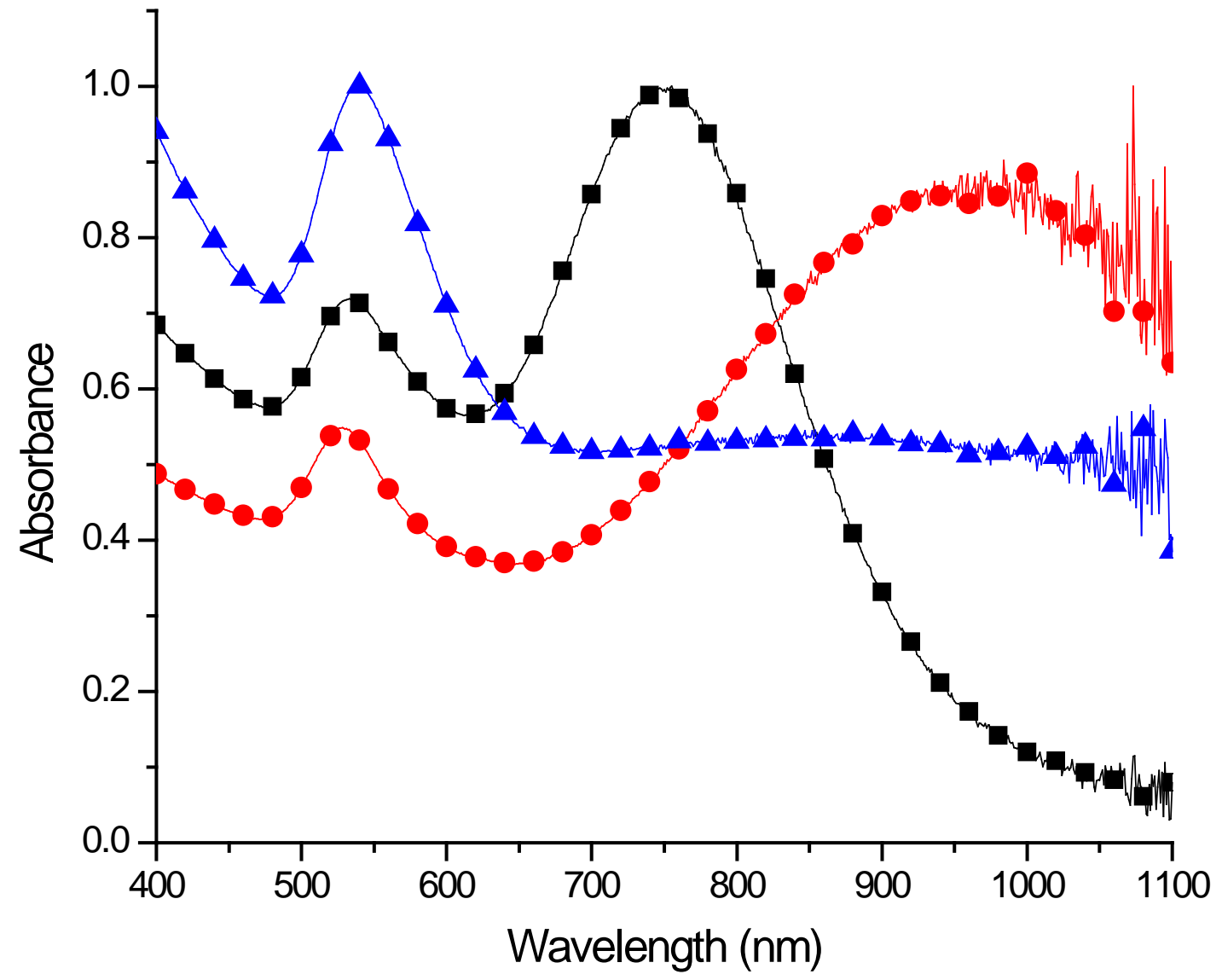

Figure 18: Normalized absorbance and spectral profile of GGS nanoparticles synthesized using various parameters. (Sample 1, black-square line) $11 \mathrm{~mL}$ of 2 $\mathrm{mM} \mathrm{HAuCl}_{4}$ mixed with $3 \mathrm{~mL}$ of $3 \mathrm{mM} \mathrm{Na}_{2} \mathrm{~S}_{2} \mathrm{O}_{3}$ dialyzed against DI water with $R^{\mathrm{nIR} / \mathrm{Au}}=1.4$. (Sample 2) $25 \mathrm{~mL}$ of $2 \mathrm{mM} \mathrm{HAuCl}{ }_{4}$ dialyzed against $1 \mathrm{~L}$ of $\mathrm{Na}_{2} \mathrm{~S}_{2} \mathrm{O}_{3}$ for 2.5 hrs (blue-triangle line). (Sample 3, red-circle line) Non-dialyzed sample using $11 \mathrm{~mL}$ of $2 \mathrm{mM} \mathrm{HAuCl}_{4}$ mixed with $3 \mathrm{~mL}$ of $3 \mathrm{mM} \mathrm{Na} \mathrm{S}_{2} \mathrm{O}_{3}$ with $\mathrm{R}^{\mathrm{nIR} / \mathrm{Au}}=$ 1.53. 


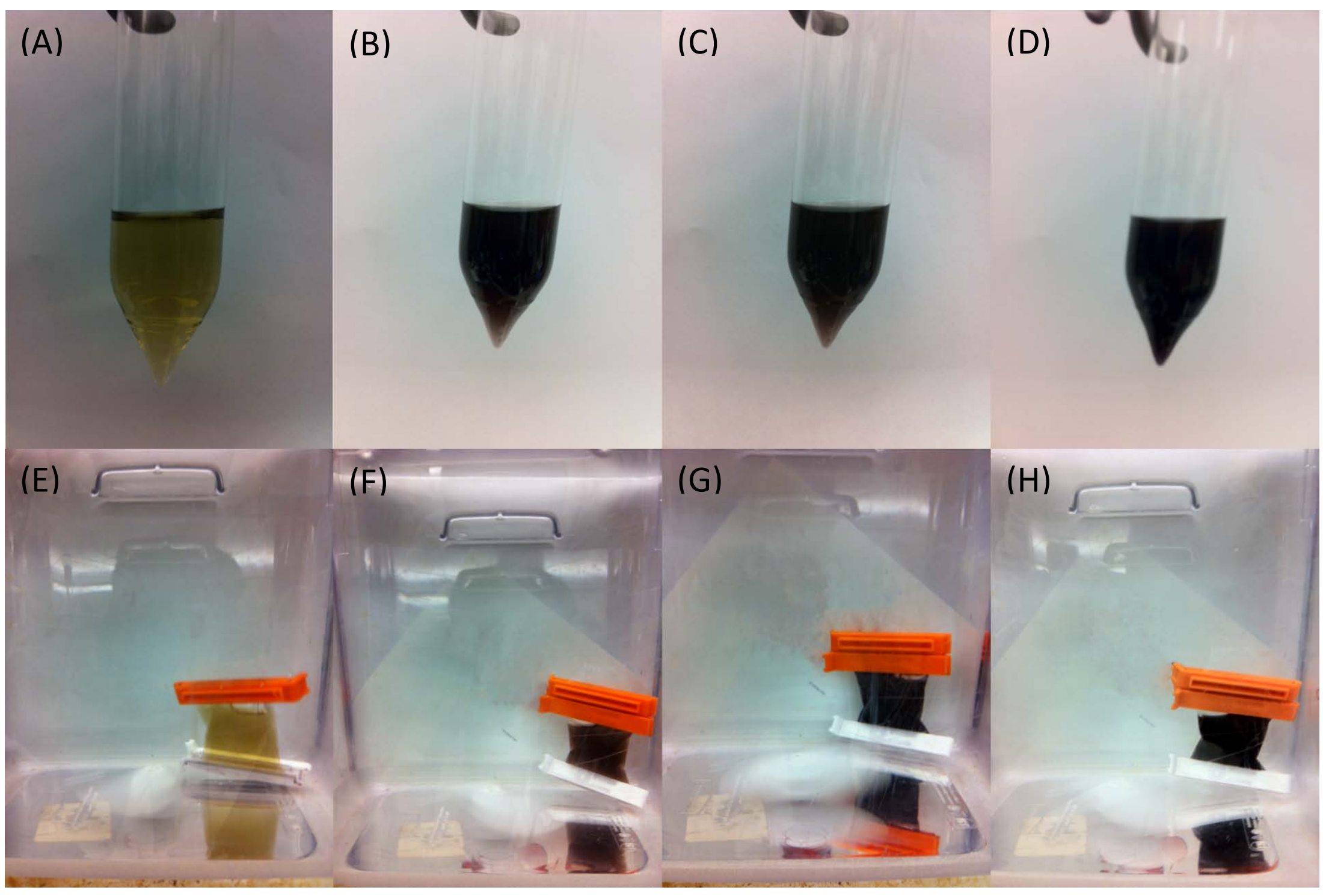

Figure 19: Image of Non-Dialysis synthesis and dialyzed synthesis over 1 hr time period. (A - D) Image of non-dialyzed sample at 30 secs, 5 mins, 30 mins, and 1 hr, respectfully. (E - F) Image of Dialyzed sample at 30 secs, 5 mins, $30 \mathrm{mins}$, and $1 \mathrm{hr}$, respectfully. 


\subsubsection{Conclusion}

From the given data, we can see that $11 \mathrm{~mL}$ of $2 \mathrm{mM} \mathrm{HAuCl}_{4}$ mixed with $3 \mathrm{~mL}$ of $3 \mathrm{mM} \mathrm{Na} \mathrm{S}_{2} \mathrm{O}_{3}$ in a 3500 Da MWCO Dialysis membrane, dialyzed against DI water has the best $n I R R^{n I R / A u}=1.4$; while the non-dialyzed sample had $\mathrm{R}^{\mathrm{nIR} / \mathrm{Au}}=1.53$. Sample dialyzed against $\mathrm{Na}_{2} \mathrm{~S}_{2} \mathrm{O}_{3}$ had pure colloid formation, and had $\mathrm{R}^{\mathrm{nIR} / \mathrm{Au}}<1$. 


\subsubsection{DiaSynth (repeat of 2.4.6 with extended time)}

The purpose of this experiment is to synthesize a batch of AuNPs with $\mathrm{HAuCl}_{4}$ and $\mathrm{Na}_{2} \mathrm{~S}_{2} \mathrm{O}_{3}$ using the DiaSynth method, dialyzed against DI water at room temperature. Also, $\mathrm{HAuCl}_{4}$ dialyzed against $\mathrm{Na}_{2} \mathrm{~S}_{2} \mathrm{O}_{3}$ for an extended period of time to see the kinetics and equilibrium shift of two different reactions.

\subsubsection{Protocol}

Fill a $1 \mathrm{~L}$ beaker with $800 \mathrm{~mL}$ of DI water and place stir bar inside. Next, using a 3500 Da MWCO Dialysis membrane, add a mixture of $11 \mathrm{~mL}$ of $2 \mathrm{mM}$ $\mathrm{HAuCl}_{4}$ (first in the bag) and $3 \mathrm{~mL}$ of $3 \mathrm{mM} \mathrm{Na}_{2} \mathrm{~S}_{2} \mathrm{O}_{3}$ (second after the gold solution had been added), and let the sample dialyze for 1 hour (Sample 1). Separately, fill a $1 \mathrm{~L}$ beaker with $3 \mathrm{mM} \mathrm{Na}_{2} \mathrm{~S}_{2} \mathrm{O}_{3}$. Next to that, add $25 \mathrm{~mL}$ of 2 $\mathrm{mM} \mathrm{HAuCl}_{4}$ in a 3500 Da MWCO Dialysis membrane and let it react for 5 hours (Sample 2 \& 3). For a non-dialysis sample, $11 \mathrm{~mL}$ of $2 \mathrm{mM} \mathrm{HAuCl}_{4}$ and $3 \mathrm{~mL}$ of $3 \mathrm{mM} \mathrm{Na} 2 \mathrm{~S}_{2} \mathrm{O}_{3}$ are mixed in a $50 \mathrm{~mL}$ tube and reacted for $1 \mathrm{hr}$ as well (Sample 4). Next, spectral scans were obtained after an hour of the self-assembly synthesis at room temperature (RT), using a UV/Vis spectrophotometer (Carey 50 Varian). A Malvern Zetasizer (ZS90) was used to characterize the GGS nanoparticles surface charge and size. 


\subsubsection{Data/Analysis}

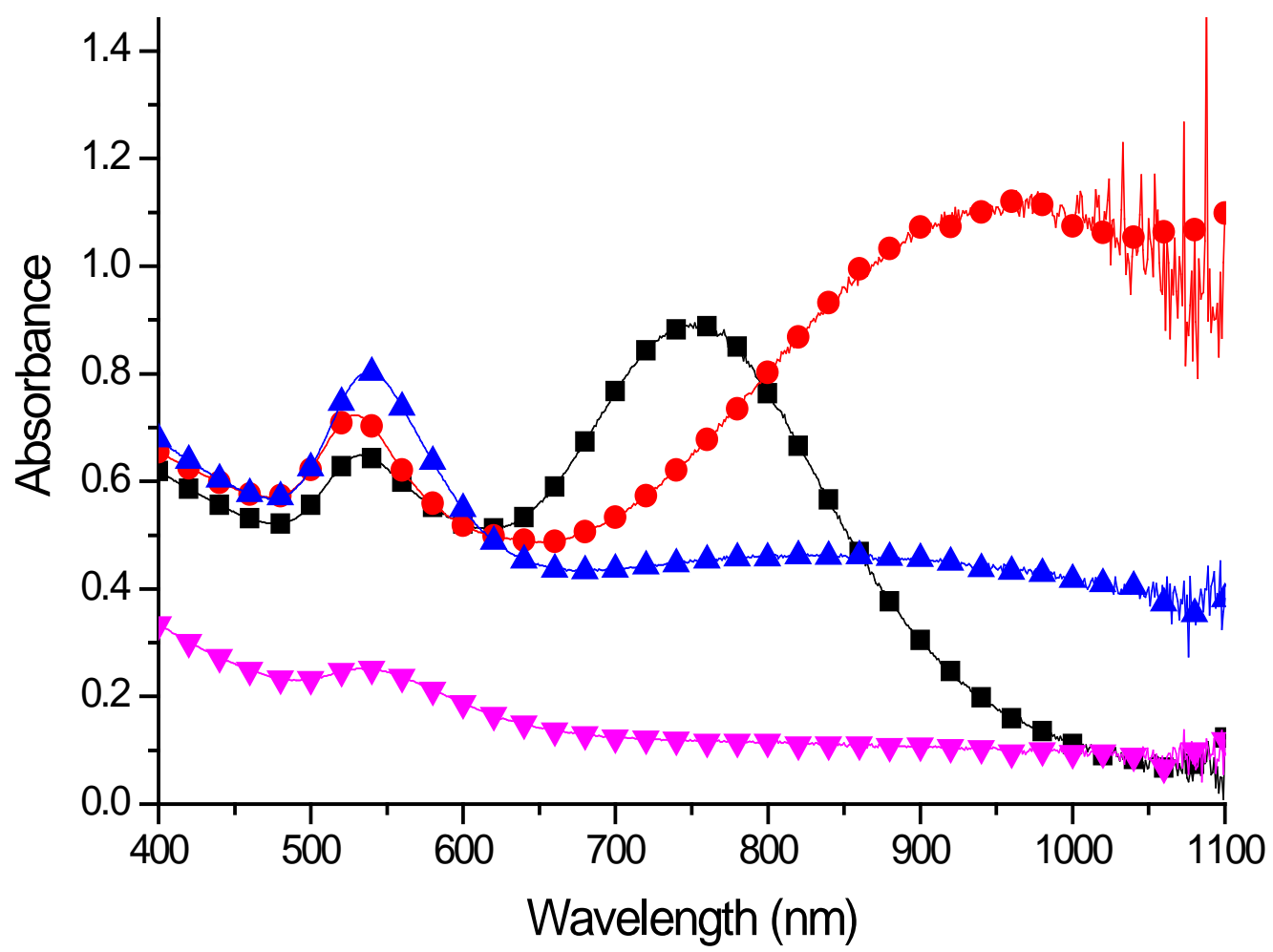

Figure 20: Non-normalized absorbance and spectral profile of GGS nanoparticles synthesized using various parameters. (Sample 1, black-square line) $11 \mathrm{~mL}$ of $2 \mathrm{mM} \mathrm{HAuCl}_{4}$ mixed with $3 \mathrm{~mL}$ of $3 \mathrm{mM} \mathrm{Na} \mathrm{S}_{2} \mathrm{O}_{3}$ dialyzed against DI water with $R^{\mathrm{nIR} / \mathrm{Au}}=1.4$. (Sample $2 \& 3$, respectively) $25 \mathrm{~mL}$ of $2 \mathrm{mM} \mathrm{HAuCl}_{4}$ dialyzed against $1 \mathrm{~L}$ of $\mathrm{Na}_{2} \mathrm{~S}_{2} \mathrm{O}_{3}$ for 2.5 hrs (blue-triangle line) and 5 hrs (pink line-triangle-down line), both with $R^{\text {nIR/Au }}<1$. (Sample 4 , red-circle line) Nondialyzed sample using $11 \mathrm{~mL}$ of $2 \mathrm{mM} \mathrm{HAuCl}_{4}$ mixed with $3 \mathrm{~mL}$ of $3 \mathrm{mM}$ $\mathrm{Na}_{2} \mathrm{~S}_{2} \mathrm{O}_{3}$ with $\mathrm{R}^{\mathrm{nIR} / \mathrm{Au}}=1.59$.

\subsubsection{Conclusion}

From the given data, we can see that $11 \mathrm{~mL}$ of $2 \mathrm{mM} \mathrm{HAuCl}_{4}$ mixed with $3 \mathrm{~mL}$ of $3 \mathrm{mM} \mathrm{Na} \mathrm{S}_{2} \mathrm{O}_{3}$ in a 3500 Da MWCO Dialysis membrane, dialyzed against DI water, has the best $\mathrm{nIR} \mathrm{R}^{\mathrm{nIR} / \mathrm{Au}}=1.4$; while the non-dialyzed sample 
had $\mathrm{R}^{\mathrm{nIR} / \mathrm{Au}}=1.59$. The extended dialysis sample dialyzed against $\mathrm{Na}_{2} \mathrm{~S}_{2} \mathrm{O}_{3}$ had pure colloid formation, and had $\mathrm{R}^{\mathrm{nIR} / \mathrm{Au}}<1$. 


\subsubsection{DiaSynth - with time and int. ratio variation}

The purpose of this experiment is to synthesize a batch of AuNPs with $\mathrm{HAuCl}_{4}$ and $\mathrm{Na}_{2} \mathrm{~S}_{2} \mathrm{O}_{3}$ using the DiaSynth method, dialyzed against DI water at room temperature. However, from the previous studies, Section 2.4.6 \& 2.4.7, samples with $11 \mathrm{~mL}$ of $2 \mathrm{mM} \mathrm{HAuCl}_{4}$ mixed with $3 \mathrm{~mL}$ of $3 \mathrm{mM} \mathrm{Na}_{2} \mathrm{~S}_{2} \mathrm{O}_{3}$ in a 3500 Da MWCO Dialysis membrane showed the best result. The experiment will use the sample initial ratio $\left(11+3,11 \mathrm{~mL}\right.$ of $2 \mathrm{mM} \mathrm{HAuCl}_{4}$ mixed with $3 \mathrm{~mL}$ of 3 $\mathrm{mM} \mathrm{Na} \mathrm{Na}_{2} \mathrm{O}_{3}$ or $\mathrm{HAuCl}_{4}: \mathrm{Na}_{2} \mathrm{~S}_{2} \mathrm{O}_{3}$, used for dialysis) as well as $11+2$, while extending the dialysis time to 2 hrs and including non-dialysis controls.

\subsubsection{Protocol}

Fill 4 - $1 \mathrm{~L}$ beaker with $800 \mathrm{~mL}$ of DI water and place stir bar inside. Next, using a 3500 Da MWCO Dialysis membrane, add a mixture of $11 \mathrm{~mL}$ of $2 \mathrm{mM}$ $\mathrm{HAuCl}_{4}$ (first in the bag) and 2 (Sample 1) or 3 (Sample 2) $\mathrm{mL}$ of $3 \mathrm{mM} \mathrm{Na}{ }_{2} \mathrm{~S}_{2} \mathrm{O}_{3}$ (second after the gold solution had been added), and let the sample dialyze for 1 (Sample $1 \&$ 2) hr \& 2 hrs (Sample $3 \& 4$ ). For a non-dialysis sample, $11 \mathrm{~mL}$ of 2 mM HAuCl 4 and 2 (Sample 5) or 3 (Sample 6) $\mathrm{mL}$ of $3 \mathrm{mM} \mathrm{Na}_{2} \mathrm{~S}_{2} \mathrm{O}_{3}$ are mixed in a $50 \mathrm{~mL}$ tubes and reacted for $1 \mathrm{hr}$. Next, spectral scans were obtained after an hour of the self-assembly synthesis at room temperature (RT), using a UV/Vis spectrophotometer (Carey 50 Varian). A Malvern Zetasizer (ZS90) was used to characterize the GGS nanoparticles surface charge and size. 


\subsubsection{Data/Analysis}

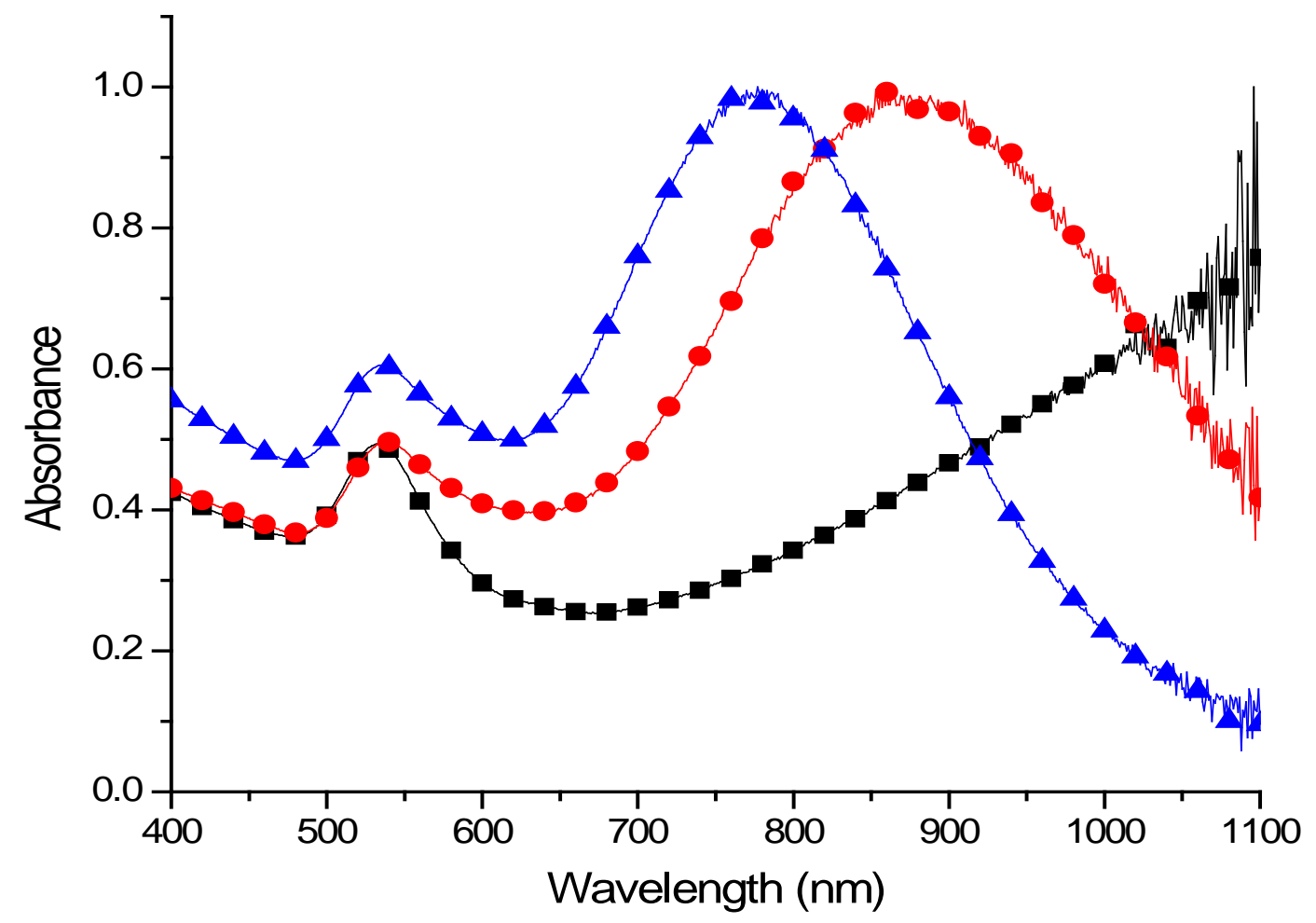

Figure 21: Normalized absorbance and spectral profile of GGS nanoparticles synthesized using various parameters. (Sample 1 \& 3, red-circle \& blue-triangle line respectively) $11 \mathrm{~mL}$ of $2 \mathrm{mM} \mathrm{HAuCl}_{4}$ mixed with $2 \mathrm{~mL}$ of $3 \mathrm{mM} \mathrm{Na} \mathrm{S}_{2} \mathrm{O}_{3}$ dialyzed against DI water for $1 \& 2$ hrs, respectively, with $R^{\text {nIR/Au }}=2.01 \& 1.65$, respectively. (Sample 5, black-square line) Non-dialyzed sample using $11 \mathrm{~mL}$ of 2 $\mathrm{mM} \mathrm{HAuCl}_{4}$ mixed with $2 \mathrm{~mL}$ of $3 \mathrm{mM} \mathrm{Na} \mathrm{S}_{2} \mathrm{O}_{3}$ with $\mathrm{R}^{\mathrm{nIR} / \mathrm{Au}}=\mathrm{N} / \mathrm{A}$, due to the unknown nIR peak (out of range). 


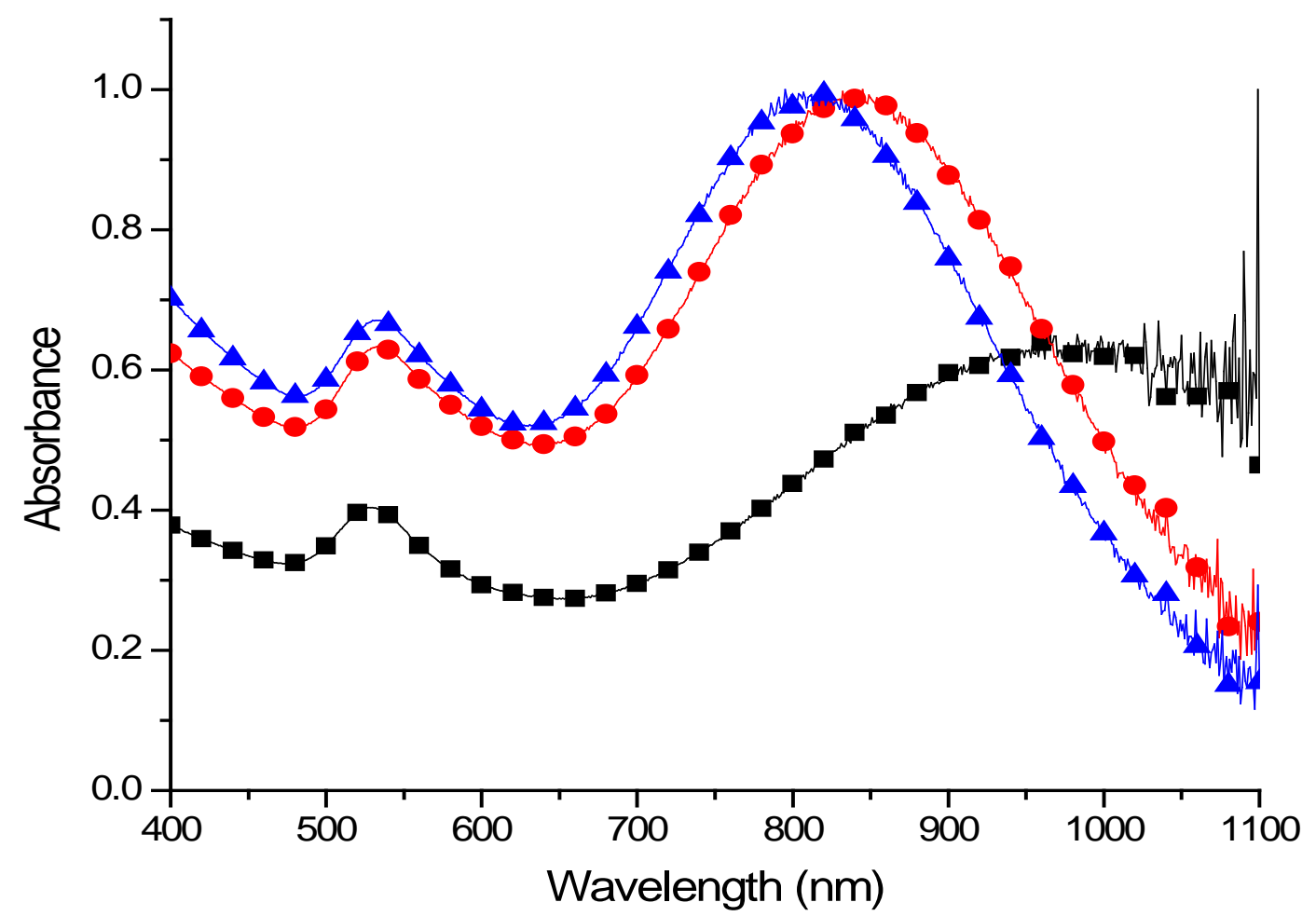

Figure 22: Normalized absorbance and spectral profile of GGS nanoparticles synthesized using various parameters. (Sample 2 \& 4, red-circle \& blue-triangle line respectively) $11 \mathrm{~mL}$ of $2 \mathrm{mM} \mathrm{HAuCl}_{4}$ mixed with $3 \mathrm{~mL}$ of $3 \mathrm{mM} \mathrm{Na} \mathrm{H}_{2} \mathrm{O}_{3}$ dialyzed against DI water for $1 \& 2$ hrs, respectively, with $R^{\mathrm{nIR} / \mathrm{Au}}=1.58 \& 1.49$, respectively. (Sample 6, black-square line) Non-dialyzed sample using $11 \mathrm{~mL}$ of 2 $\mathrm{mM} \mathrm{HAuCl}_{4}$ mixed with $3 \mathrm{~mL}$ of $3 \mathrm{mM} \mathrm{Na}_{2} \mathrm{~S}_{2} \mathrm{O}_{3}$ with $\mathrm{R}^{\mathrm{nIR} / \mathrm{Au}}=1.53$.

\subsubsection{Conclusion}

Using the $11 \mathrm{~mL}$ of $2 \mathrm{mM}$ HAuCl4 and $2 \mathrm{~mL}$ of $3 \mathrm{mM} \mathrm{Na2S2O} 3$ dialyzed against DI Water for 2 hrs has a $\mathrm{R}^{\mathrm{nIR} / \mathrm{Au}}=1.65$, not only does this show that dialyzing for $1 \mathrm{hr}$ shifts the equilibrium of the synthesis, but further (extended time) dialysis shifts the equilibrium even more on the 2000 Da MWCO Dialysis membrane. The initial ratios that are being using should be used 


\subsubsection{DiaSynth - using high temperature}

The purpose of this experiment is to synthesize a batch of AuNPs with $\mathrm{HAuCl}_{4}$ and $\mathrm{Na}_{2} \mathrm{~S}_{2} \mathrm{O}_{3}$ using the DiaSynth method, dialyzed against DI water at various temperatures including room temperature as a control.

\subsubsection{Protocol}

Fill 4 - 1 L beaker with $800 \mathrm{~mL}$ of DI water, two with DI water at $100^{\circ} \mathrm{C}$, one with DI water at $65^{\circ} \mathrm{C}$, and one with room temperature (RT) DI water, and place stir bar inside. Next, using a 3500 Da MWCO Dialysis membrane, add a mixture of $11 \mathrm{~mL}$ of $2 \mathrm{mM} \mathrm{HAuCl}_{4}$ (first in the bag) and $3 \mathrm{~mL}$ of $3 \mathrm{mM} \mathrm{Na} \mathrm{S}_{2} \mathrm{O}_{3}$ (second after the gold solution had been added), and let the sample dialyze for 1 hour. 


\subsubsection{Data/Analysis}

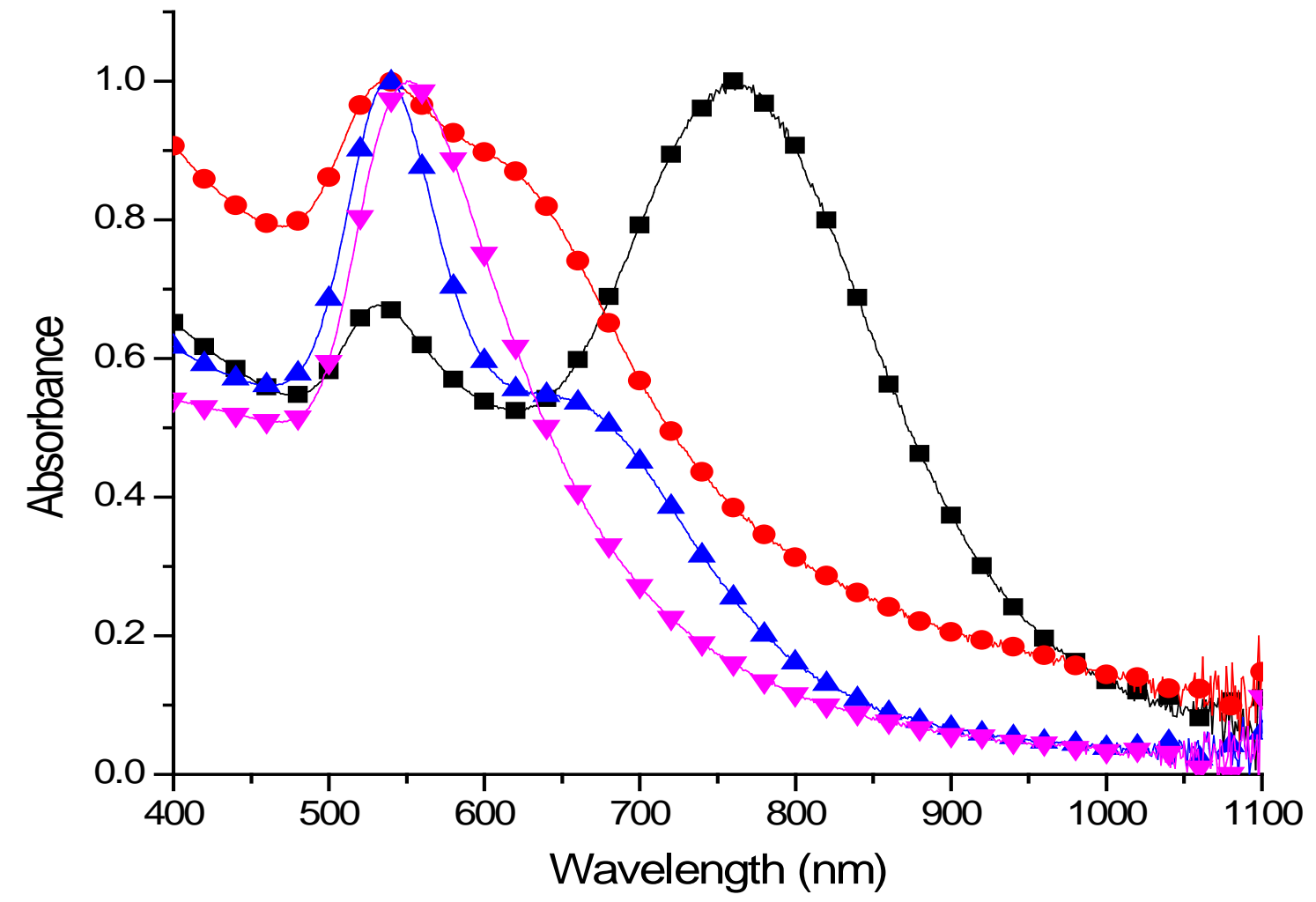

Figure 23: Normalized absorbance and spectral profile of GGS nanoparticles synthesized using DiaSynth method with various temperature of DI water. (Black-square line) Sample with RT DI water has highest $R^{\mathrm{nIR} / \mathrm{Au}}=1.48$. The rest of the controls with high DI water temperature had $\mathbf{R}^{\mathrm{nIR} / \mathrm{Au}}<1$.

\subsubsection{Conclusion}

When placing the dialysis membrane in the DI water at $100^{\circ} \mathrm{C}$, the sample started to react very fast and changed colors, therefore one sample ran for 5 mins (blue line) and the other for 15 mins (pink line). From the spectral profile, overtime samples had just pure colloid formation. Compared to the RT sample, this is relative close to what was previously synthesized; also the sample with DI water at $65^{\circ} \mathrm{C}$ (reacted for the full $1 \mathrm{hr}$ ) had similar results to the $100^{\circ} \mathrm{C}$ sample. 


\subsubsection{DiaSynth - 1,2 step}

The purpose of this experiment is to synthesize a batch of AuNPs with $\mathrm{HAuCl}_{4}$ and $\mathrm{Na}_{2} \mathrm{~S}_{2} \mathrm{O}_{3}$ using the DiaSynth method, dialyzed against DI water with the one-step and two-step techniques described in the introduction section, except instead of using a $1 \mathrm{~L}$ beaker, the experiment will use an $8 \mathrm{~L}$ bucket. Also, from the previous experiments the AuNPs are aggregating, indicating that the particles are not stable, therefore once the experiment is finished chitosan (CS) will be added to stabilize the AuNPs.

\subsubsection{Protocol}

Fill 2 - 8 L beaker with 7.5 - 8 L of DI water and place stir bar inside. Next, using a 3500 Da MWCO Dialysis membrane, add a mixture of $11 \mathrm{~mL}$ of 2 $\mathrm{mM} \mathrm{HAuCl}_{4}$ (first in the bag) and $3 \mathrm{~mL}$ of $3 \mathrm{mM} \mathrm{Na}_{2} \mathrm{~S}_{2} \mathrm{O}_{3}$ (second after the gold solution had been added), and let the sample dialyze for 1 hour (Sample 1). Next for the two-step reaction, $4 \mathrm{~mL}$ of $2 \mathrm{mM} \mathrm{HAuCl}_{4}$ and $3 \mathrm{~mL}$ of $3 \mathrm{mM} \mathrm{Na}_{2} \mathrm{~S}_{2} \mathrm{O}_{3}$ is reacted for 30 secs, in a 3500 Da MWCO Dialysis membrane, and $7 \mathrm{~mL}$ of $2 \mathrm{mM}$ $\mathrm{HAuCl}_{4}$ is additionally added in the 3500 Da MWCO Dialysis membrane and allow reaction for an hour (Sample 2). For the non-dialyzed samples, $11 \mathrm{~mL}$ of 2 $\mathrm{mM} \mathrm{HAuCl}_{4}$ and $3 \mathrm{~mL}$ of $3 \mathrm{mM} \mathrm{Na}_{2} \mathrm{~S}_{2} \mathrm{O}_{3}$ are mixed in a $50 \mathrm{~mL}$ tube and reacted for $1 \mathrm{hr}$ for the one-step process (Sample 3); additionally, a two-step process is done in the similar fashion as described above (Sample 4). Next, once the reaction is complete CS is added to stabilize the particles. 


\subsubsection{Data/Analysis}

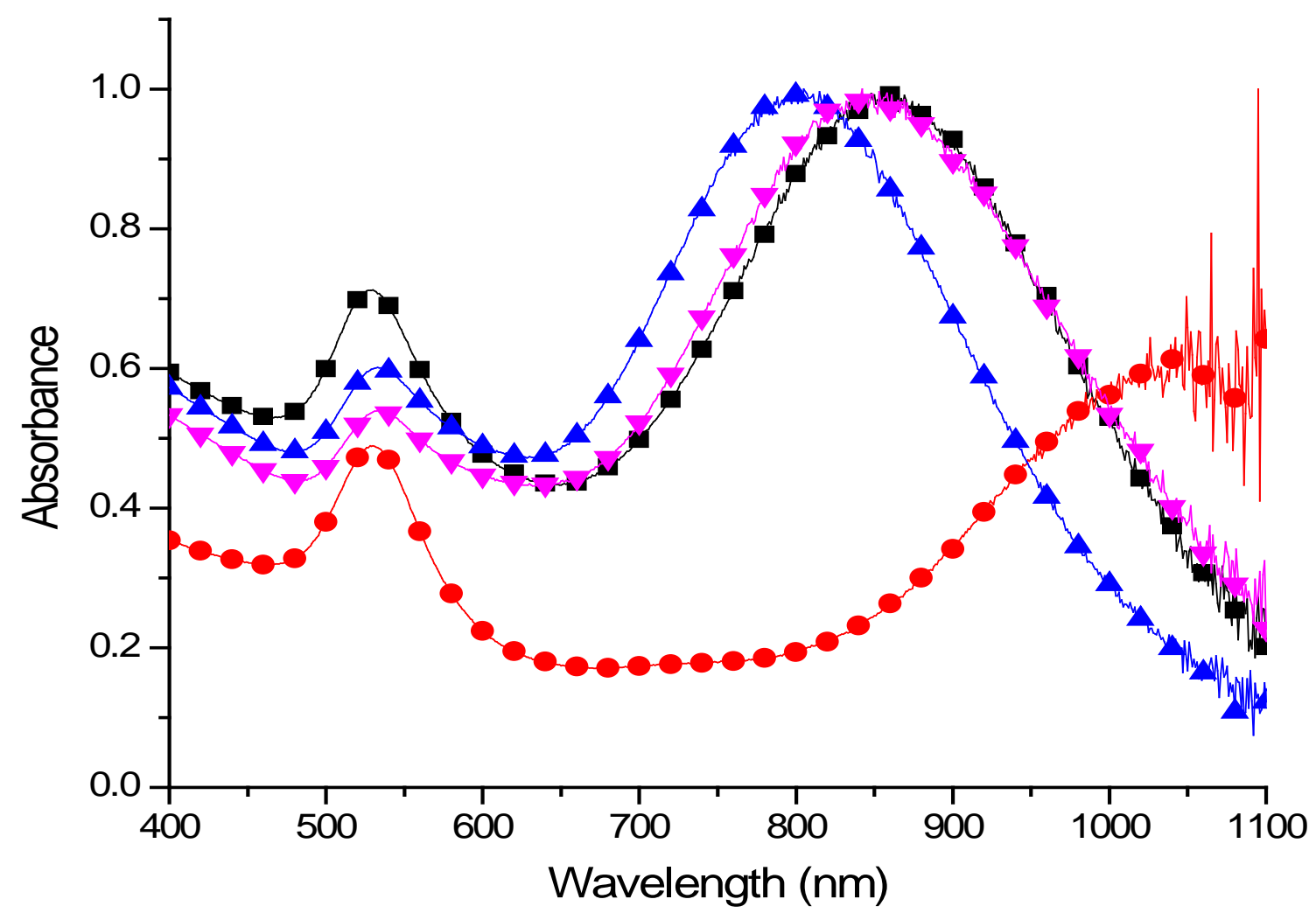

Figure 24: Normalized absorbance and spectral profile of GGS nanoparticles synthesized using DiaSynth method with one-step (Sample 1, blue-triangle line), two-step (Pink-triangle-down line), and Non-dialyzed samples, one step (Sample 3 , black-square line) and two-step (red-circle line). The nIR peak and ratio are reported in Table 2. 


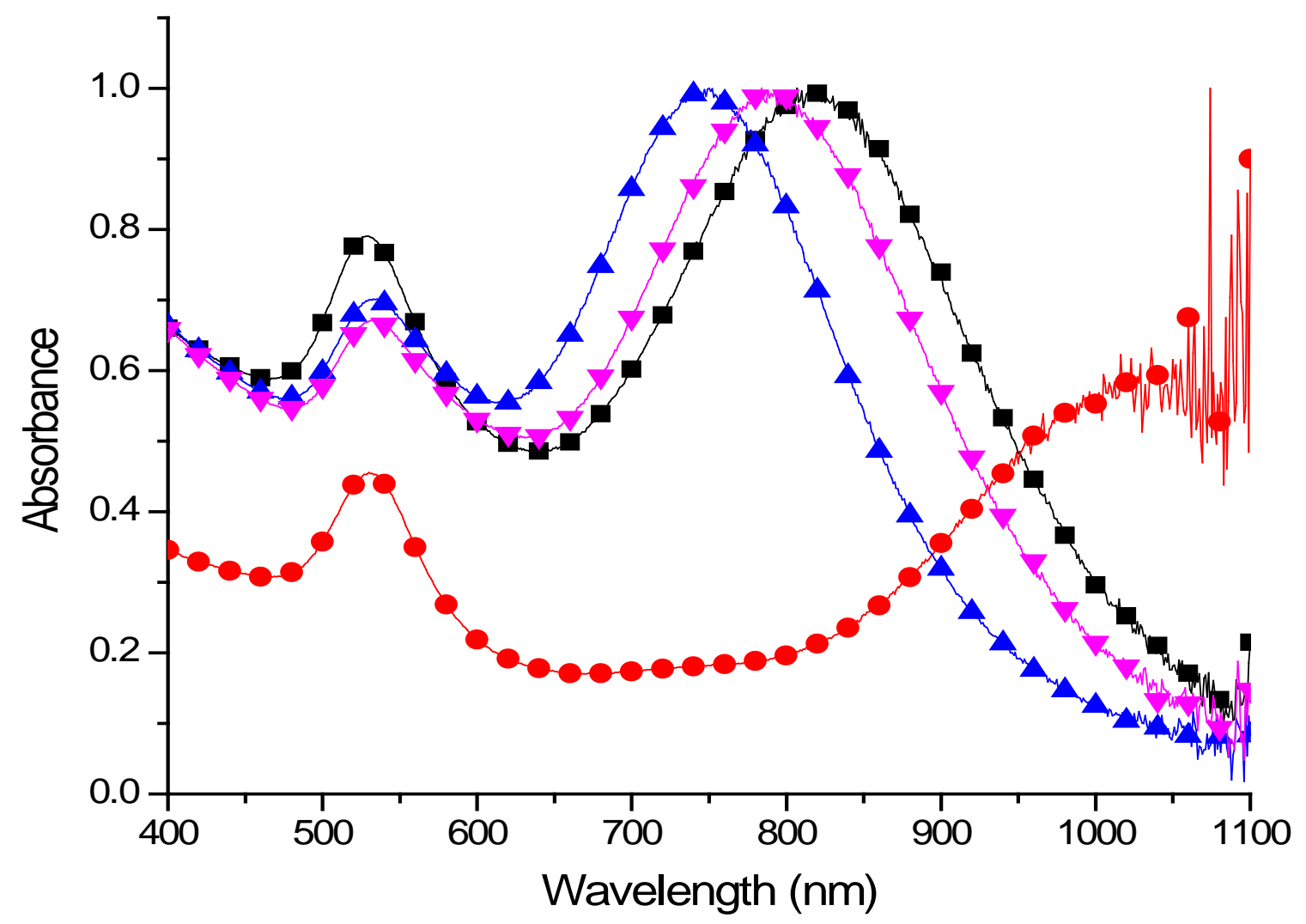

Figure 25: Normalized absorbance and spectral profile of GGS nanoparticles synthesized using DiaSynth method with one-step (Sample 1, blue-triangle line), two-step (Pink-triangle-down line), and Non-dialyzed samples, one step (Sample 3 , black-square line) and two-step (red-circle line), after adding in the CS overnight. The nIR peak and quality ratio are reported in Table 2. 


\begin{tabular}{|l|l|l|l|}
\hline & Controls & nIR Peak & Ratio \\
\hline & Sample 1 & 805 & 1.66 \\
\hline Before CS & Sample 2 & 842 & 1.85 \\
\hline & Sample 3 & 856 & 1.40 \\
\hline & Sample 4 & 1095 & 2.04 \\
\hline & Sample 1 & 750 & 1.43 \\
\hline \multirow{2}{*}{ After CS } & Sample 2 & 784 & 1.49 \\
\hline & Sample 3 & 807 & 1.27 \\
\hline & Sample 4 & 1074 & 2.20 \\
\hline
\end{tabular}

Table 6: nIR peak and the ratios of each sample before and after adding the CS.

\subsubsection{Conclusion}

Using the DiaSynth method, compared to traditional method including 2step method, the results show that DiaSynth method has high quality ratio. The ratios and the nIR peak of the different parameters are provided in Table 7 . Next, in order to stabilize the AuNPs, CS was added to them over night and spectral profile was measured the following day which show there was no significant changes; therefore the particles are more stable. 


\subsubsection{DiaSynth - repeat of Section 2.4.10}

The experiment in Section 2.4.10 is being repeated after washing the dialysis membrane very carefully. The purpose of this experiment is to synthesize a batch of AuNPs with $\mathrm{HAuCl}_{4}$ and $\mathrm{Na}_{2} \mathrm{~S}_{2} \mathrm{O}_{3}$ using the DiaSynth method, dialyzed against DI water at room temperature. However, from the previous studies, Section $2.3 \& 2.4$, samples with $11 \mathrm{~mL}$ of $2 \mathrm{mM} \mathrm{HAuCl}{ }_{4}$ mixed with 3 $\mathrm{mL}$ of $3 \mathrm{mM} \mathrm{Na}_{2} \mathrm{~S}_{2} \mathrm{O}_{3}$ in a 3500 Da MWCO Dialysis membrane showed the best result. The experiment will use the sample initial ratio $(11+3)$ as well as $11+2$, while extending the dialysis time to 4 hrs and using a 2000 Da MWCO Dialysis membrane with non-dialysis controls.

\subsubsection{Protocol}

Fill $6-8$ L bucket with $7.5-8$ L of DI water and place stir bar inside. Next, using 3 of the 6 - 8 L buckets, add, in three separate 3500 Da MWCO Dialysis membrane, a mixture of $11 \mathrm{~mL}$ of $2 \mathrm{mM} \mathrm{HAuCl}_{4}$ (first in the bag) and 3 $\mathrm{mL}$ of $3 \mathrm{mM} \mathrm{Na}_{2} \mathrm{~S}_{2} \mathrm{O}_{3}$ (second after the gold solution had been added), and let the sample dialyze for 1, 2, and 4 hours in separate buckets (Sample 1, 2, and 3, respectively). Repeat everything from using the other three $8 \mathrm{~L}$ bucket, except using 2000 Da MWCO Dialysis membrane for 1, 2, and 4 hours in separate buckets (Sample 4, 5, and 6, respectively). Then for a non-dialysis sample, $11 \mathrm{~mL}$ of $2 \mathrm{mM} \mathrm{HAuCl}_{4}$ and 2 (Sample 7) or 3 (Sample 8) $\mathrm{mL}$ of $3 \mathrm{mM} \mathrm{Na} \mathrm{S}_{2} \mathrm{O}_{3}$ are mixed in a $50 \mathrm{~mL}$ tubes and reacted for $1 \mathrm{hr}$. Next, spectral scans were obtained after an hour of the self-assembly synthesis at room temperature (RT), using a 
UV/Vis spectrophotometer (Carey 50 Varian). A Malvern Zetasizer (ZS90) and TEM (FEI Tecnai F20) were used to characterize the GGS nanoparticles surface charge, size, and morphology.

\subsubsection{Data/Analysis}

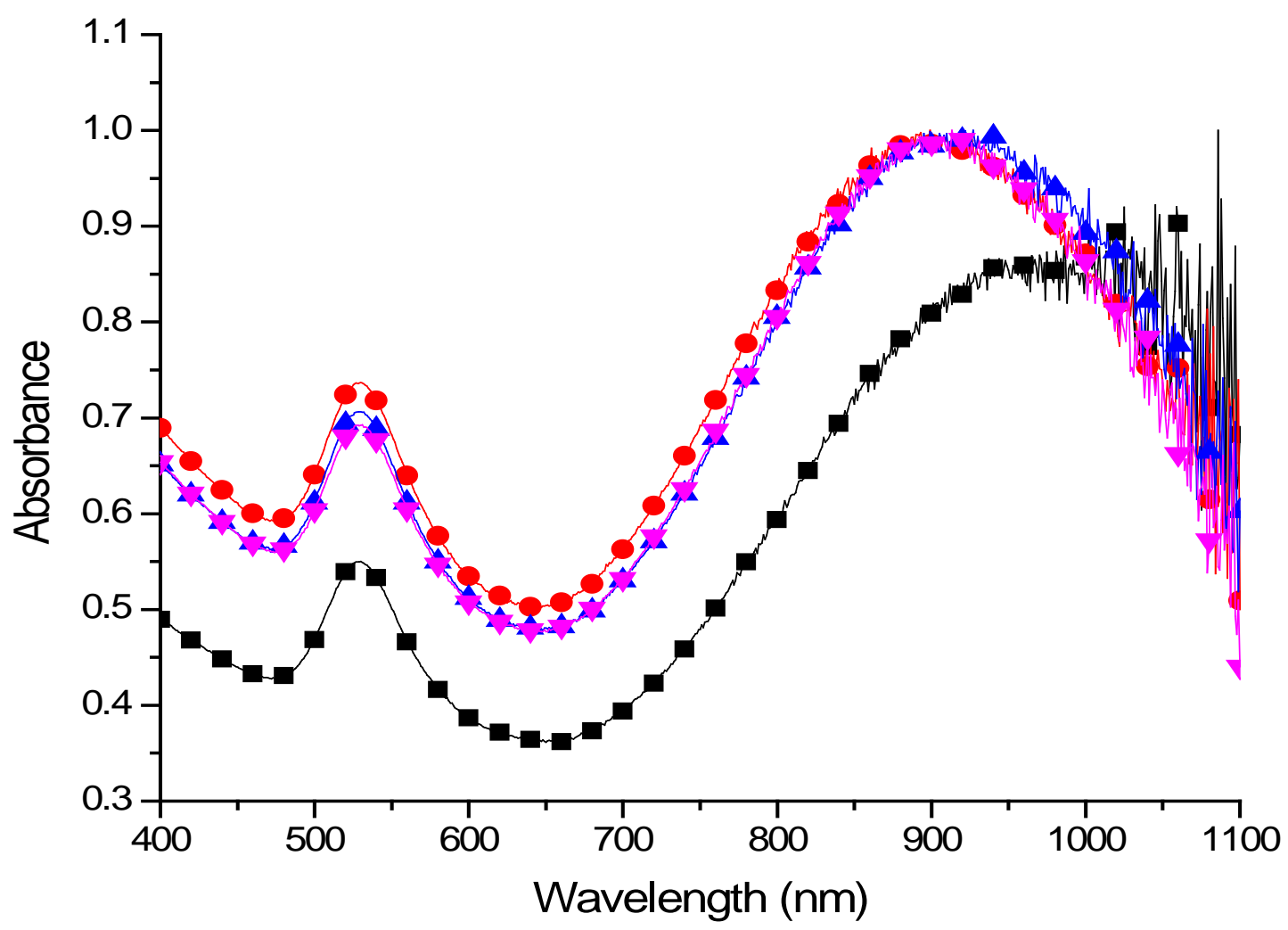

Figure 26: Normalized absorbance and spectral profile of GGS nanoparticles synthesized using DiaSynth method with 2000 MWCO Dialysis membrane, a mixture of $11 \mathrm{~mL}$ of $2 \mathrm{mM} \mathrm{HAuCl}_{4}$ and $3 \mathrm{~mL}$ of $3 \mathrm{mM} \mathrm{Na} 2 \mathrm{~S}_{2} \mathrm{O}_{3}$ is added. The sample were dialyze for 1 (red-circle line), 2 (blue-triangle line), and 4 (pinktriangle-down line). Non-dialyzed sample using $11 \mathrm{~mL}$ of $2 \mathrm{mM} \mathrm{HAuCl}_{4}$ mixed with $3 \mathrm{~mL}$ of $3 \mathrm{mM} \mathrm{Na} \mathrm{S}_{2} \mathrm{O}_{3}$ is used as a control (black-square line). nIR peak and quality ratio are reported in Table 8. 


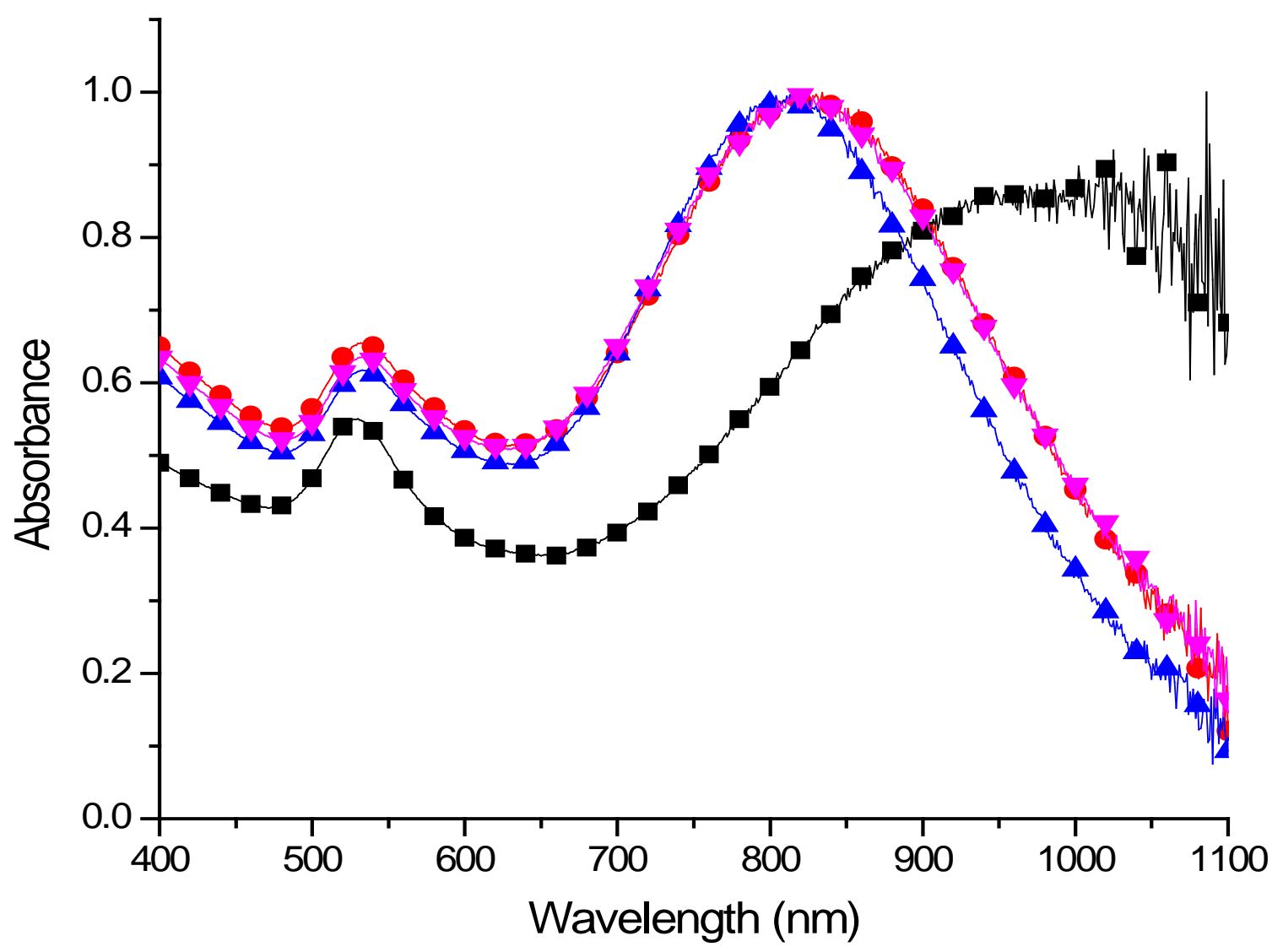

Figure 27: Normalized absorbance and spectral profile of GGS nanoparticles synthesized using DiaSynth method with 3500 MWCO Dialysis membrane, a mixture of $11 \mathrm{~mL}$ of $2 \mathrm{mM} \mathrm{HAuCl}_{4}$ and $3 \mathrm{~mL}$ of $3 \mathrm{mM} \mathrm{Na} \mathrm{S}_{2} \mathrm{O}_{3}$ is added. The sample were dialyze for 1 (red-circle line), 2 (blue-triangle line), and 4 (pinktriangle-down line). Non-dialyzed sample using $11 \mathrm{~mL}$ of $2 \mathrm{mM} \mathrm{HAuCl}_{4}$ mixed with $3 \mathrm{~mL}$ of $3 \mathrm{mM} \mathrm{Na} \mathrm{S}_{2} \mathrm{O}_{3}$ is used as a control (black-square line). nIR peak and quality ratio are reported in Table 8. 


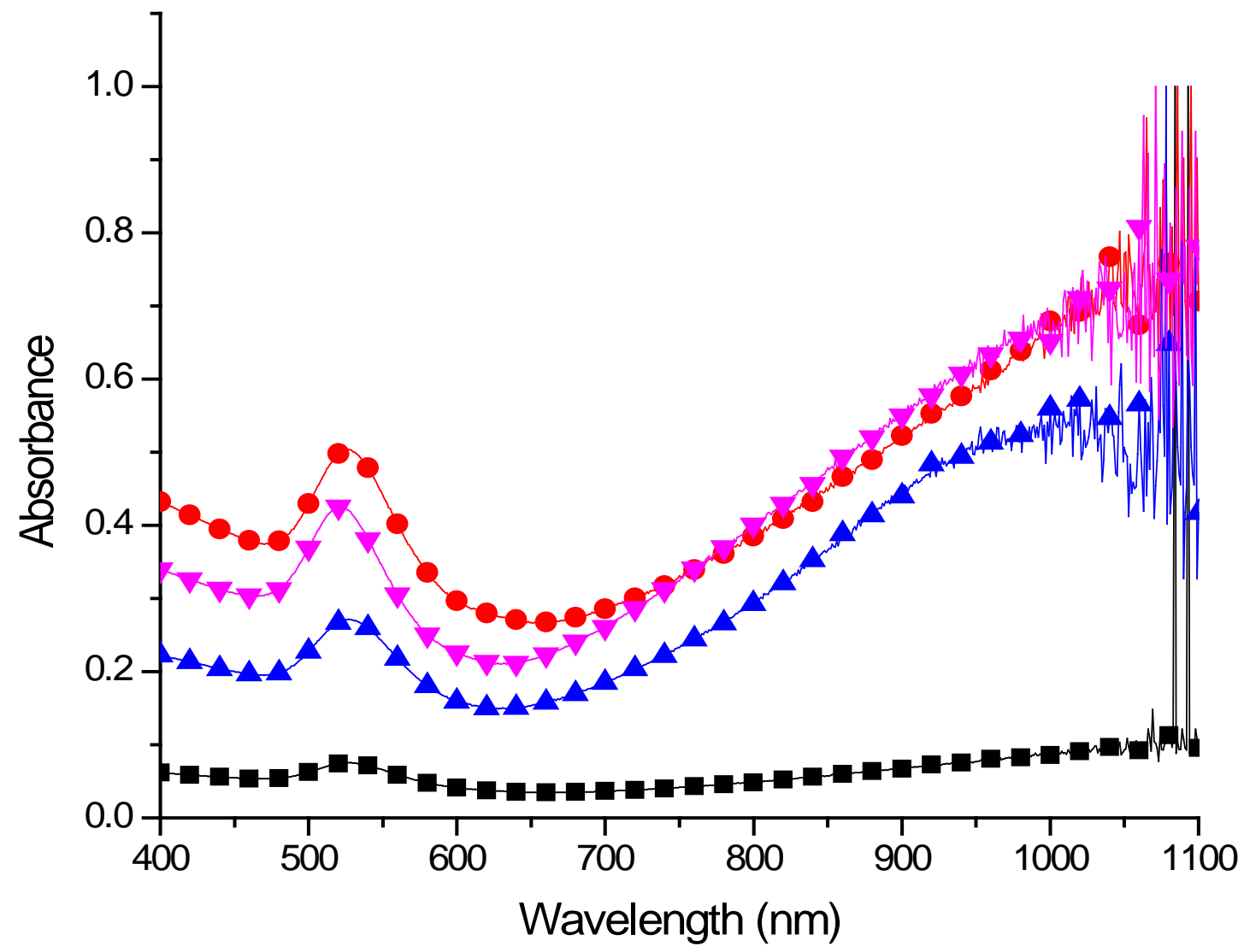

Figure 28: Normalized absorbance and spectral profile of GGS nanoparticles synthesized using DiaSynth method with 2000 MWCO Dialysis membrane, a mixture of $11 \mathrm{~mL}$ of $2 \mathrm{mM} \mathrm{HAuCl}{ }_{4}$ and $2 \mathrm{~mL}$ of $3 \mathrm{mM} \mathrm{Na} \mathrm{S}_{2} \mathrm{O}_{3}$ is added. The sample were dialyze for 1 (red-circle line), 2 (blue-triangle line), and 4 (pinktriangle-down line). Non-dialyzed sample using $11 \mathrm{~mL}$ of $2 \mathrm{mM} \mathrm{HAuCl}_{4}$ mixed with $2 \mathrm{~mL}$ of $3 \mathrm{mM} \mathrm{Na} \mathrm{S}_{2} \mathrm{O}_{3}$ is used as a control (black-square line). nIR peak and quality ratio are reported in Table 9. 


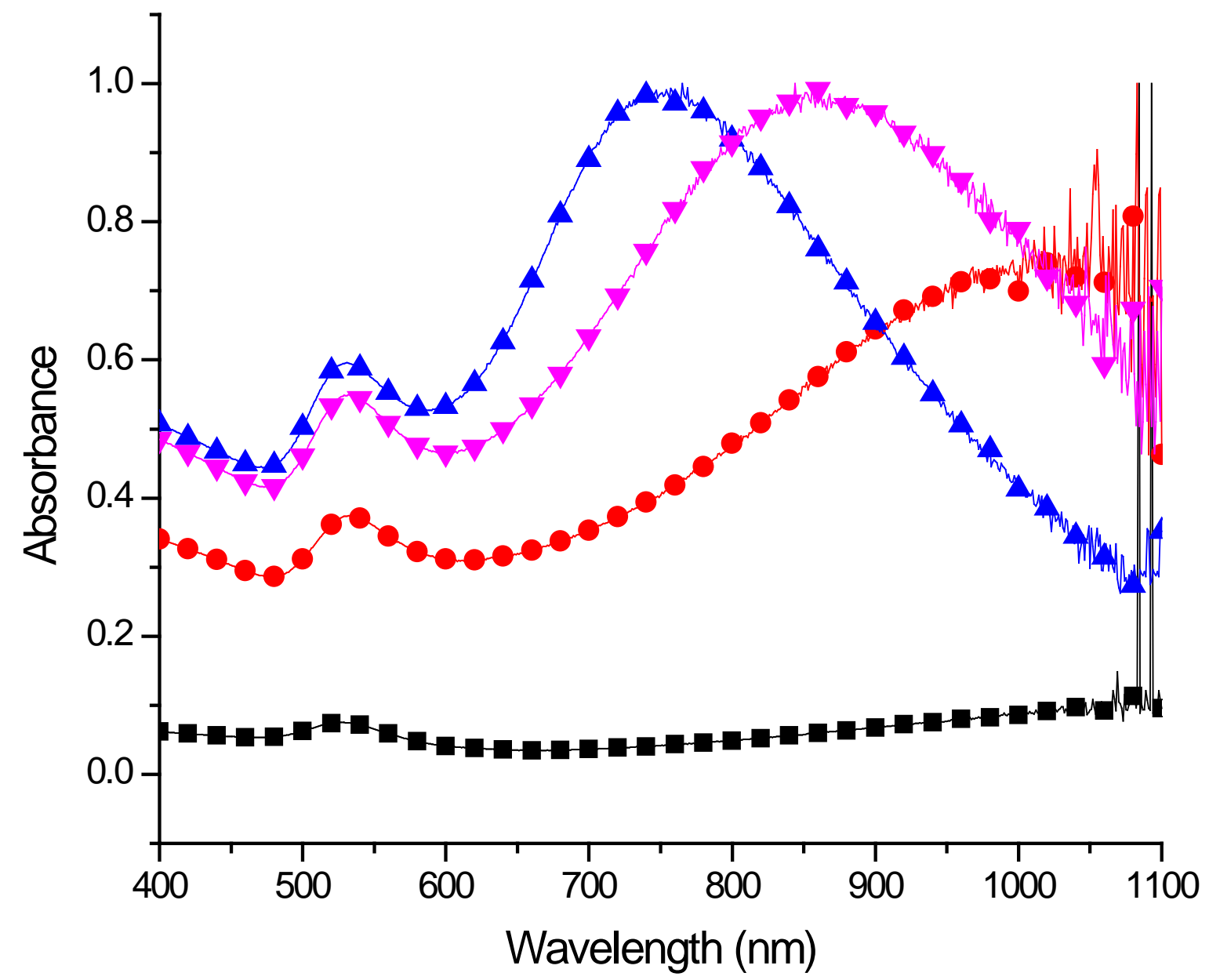

Figure 29: Normalized absorbance and spectral profile of GGS nanoparticles synthesized using DiaSynth method with 3500 MWCO Dialysis membrane, a mixture of $11 \mathrm{~mL}$ of $2 \mathrm{mM} \mathrm{HAuCl}$ and $2 \mathrm{~mL}$ of $3 \mathrm{mM} \mathrm{Na} \mathrm{S}_{2} \mathrm{O}_{3}$ is added. The sample were dialyze for 1 (red-circle line), 2 (blue-triangle line), and 4 (pinktriangle-down line). Non-dialyzed sample using $11 \mathrm{~mL}$ of $2 \mathrm{mM} \mathrm{HAuCl} \mathrm{Hixed}_{4}$ with $2 \mathrm{~mL}$ of $3 \mathrm{mM} \mathrm{Na} \mathrm{S}_{2} \mathrm{O}_{3}$ is used as a control (black-square line). nIR peak and quality ratio are reported in Table 9. 


\begin{tabular}{|c|c|c|c|}
\hline & Samples $(11+3)$ & $\begin{array}{c}\text { nIR Wavelength Peak } \\
\text { (nm) }\end{array}$ & Quality Ratio \\
\hline Non-Dialysis & $1 \mathrm{hr}$ & 959 & 1.539 \\
\hline \multirow{3}{*}{$\begin{array}{c}2000 \text { Da } \\
\text { MWCO Dialysis }\end{array}$} & $1 \mathrm{hr}$ & 899 & 1.357 \\
\hline & $2 \mathrm{hr}$ & 926 & 1.416 \\
\hline & $4 \mathrm{hr}$ & 930 & 1.444 \\
\hline \multirow{3}{*}{$\begin{array}{c}3500 \text { Da } \\
\text { MWCO Dialysis }\end{array}$} & $1 \mathrm{hr}$ & 816 & 1.527 \\
\hline & $2 \mathrm{hr}$ & 815 & 1.620 \\
\hline & $4 \mathrm{hr}$ & 819 & 1.573 \\
\hline
\end{tabular}

Table 7: nIR peak and the quality ratios of each sample from Figure 26 and 27.

\begin{tabular}{|c|c|c|c|}
\hline & Samples (11+2) & $\begin{array}{c}\text { nIR Wavelength } \\
\text { Peak (nm) }\end{array}$ & Quality Ratio \\
\hline Non-Dialysis & $\mathbf{1 ~ h r}$ & N/A & N/A \\
\hline $\begin{array}{c}\mathbf{2 0 0 0} \text { Da MWCO } \\
\text { Dialysis }\end{array}$ & $\mathbf{1 ~ h r}$ & N/A & N/A \\
\hline $\mathbf{4 5 0 0}$ Da MWCO & $\mathbf{4 h}$ & N/A & N/A \\
\hline Dialysis & $\mathbf{2 ~ h r}$ & N/A & N/A \\
\hline & $\mathbf{4 h r}$ & 1027 & 2.005 \\
\hline
\end{tabular}

Table 9: nIR peak and the quality ratios of each sample from Figure 28 and 29. 


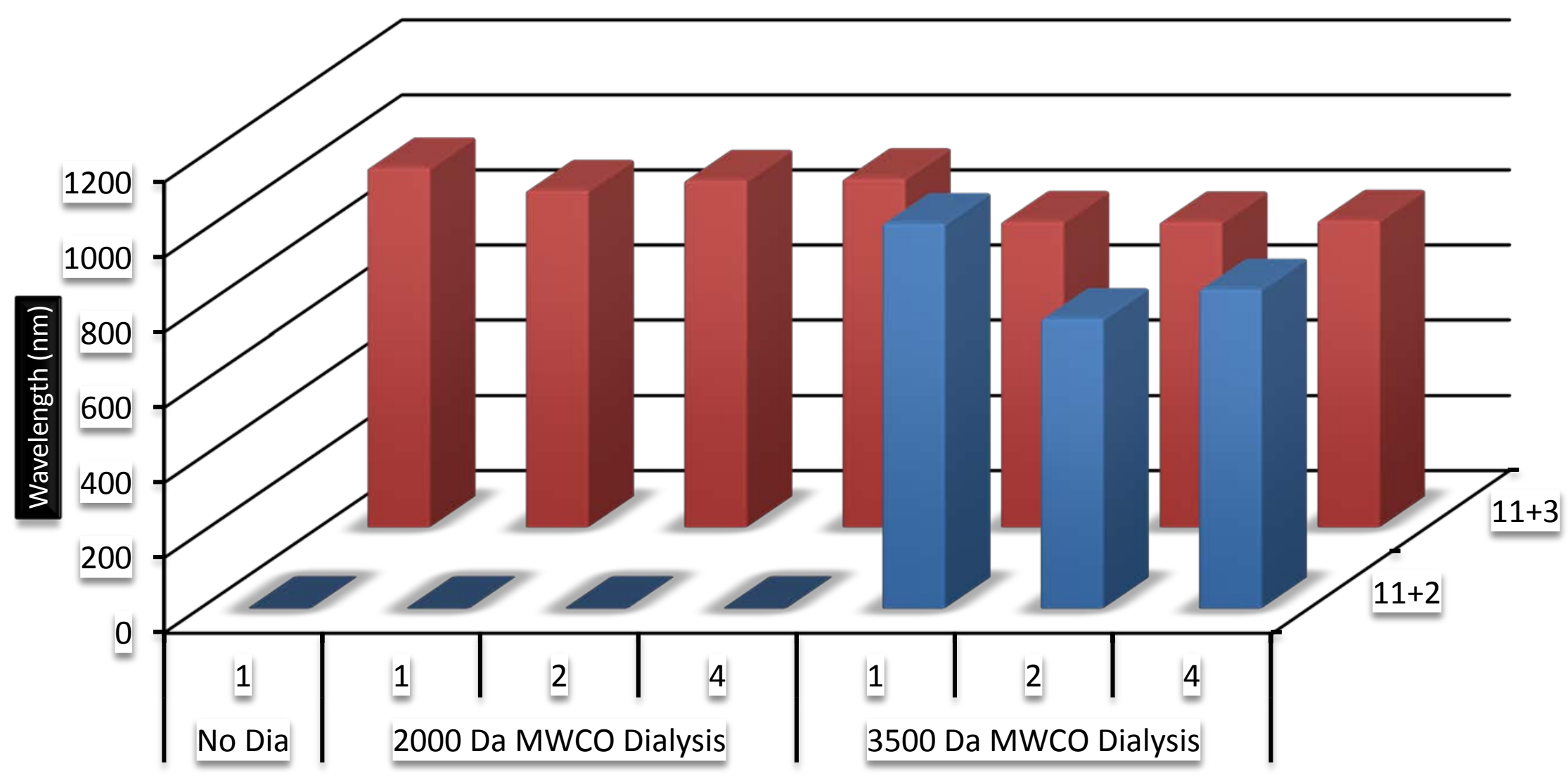

Figure 29: Graph of the nIR peak of samples from Tables 8 \& 9, X-axis is dialysis time (in hrs) for each control, Y-Axis is the initial ratio used to synthesize the AuNPs, and Z-axis nIR peak of the AuNPs after the synthesis. 


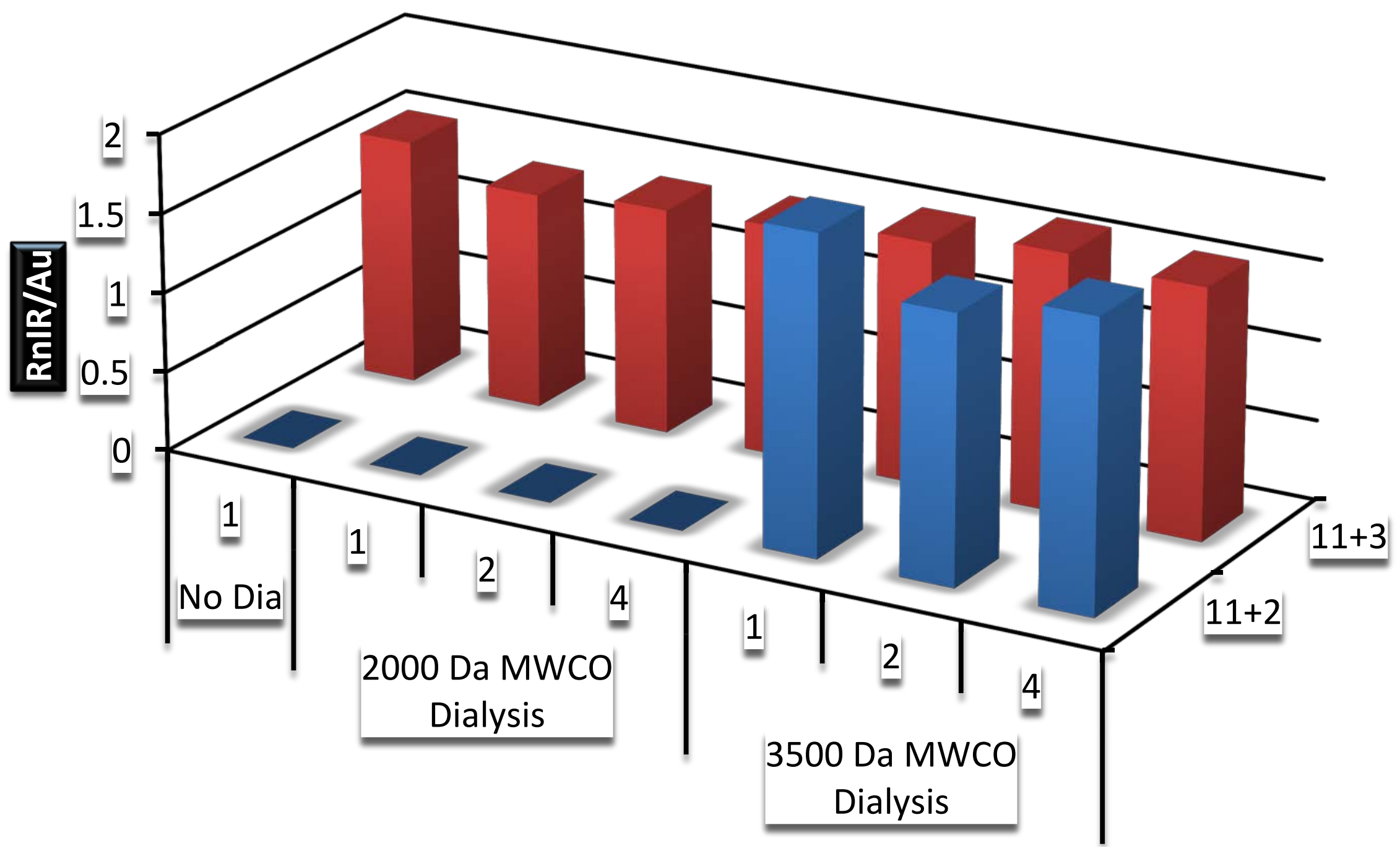

Figure 30: Graph of the quality ratio of samples from Tables 8 \& 9, X-axis is dialysis time (in hrs) for each control, Y-Axis is the initial ratio used to synthesize the AuNPs, and Z-axis quality ratio of the AuNPs after the synthesis.. 


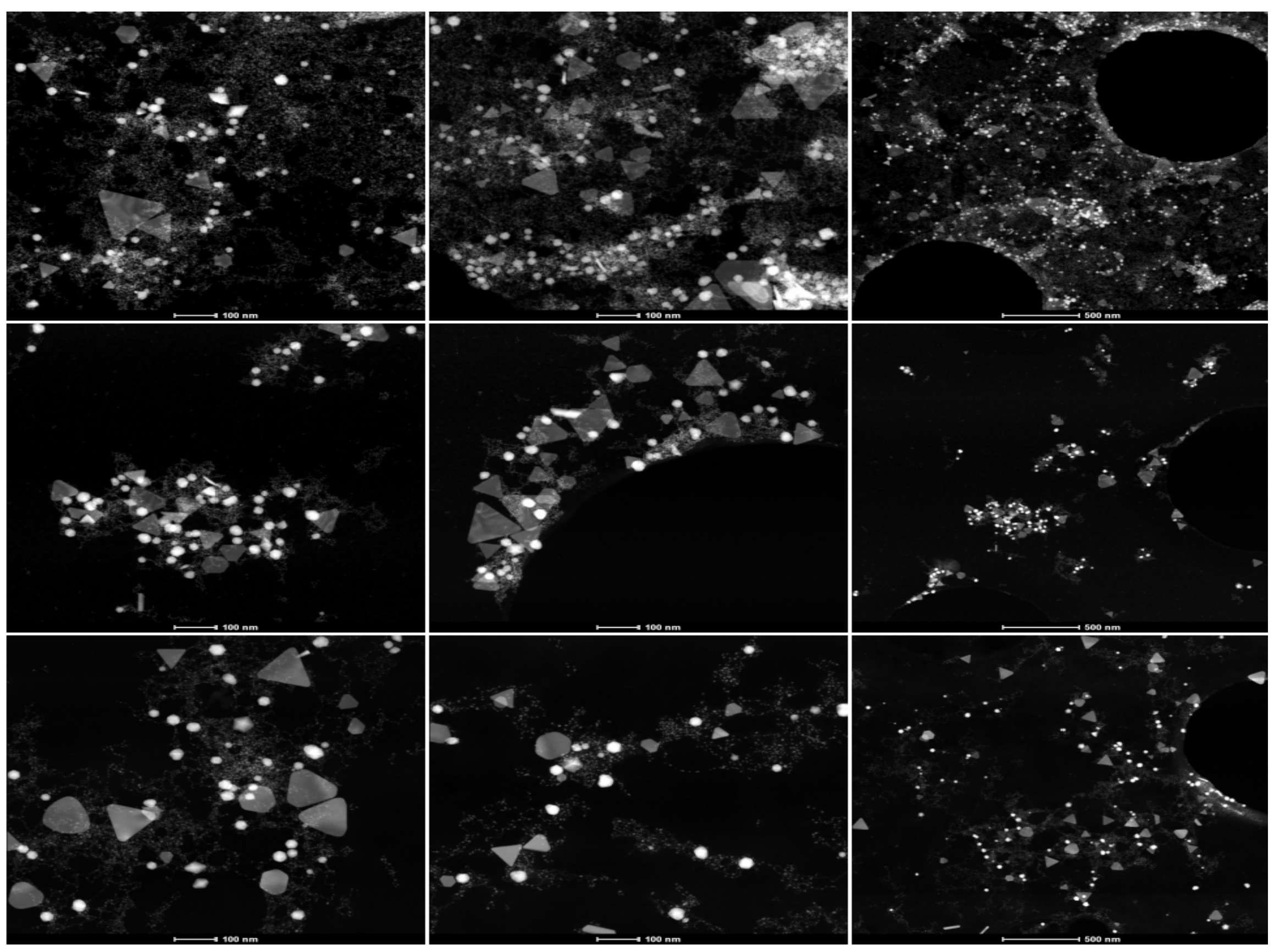

Figure 31: TEM images of Dialyzed and non-dialyzed samples. Top row - Non-dialysis sample, Middle row DiaSynth using 2000 MWCO Dialysis membrane, and Bottom row DiaSynth using 3500 MWCO Dialysis membrane. For column $1 \& 2$ samples are at $100 \mathrm{X}$, while column 3 samples are at $500 \mathrm{X}$. 


\subsubsection{Conclusion}

After noticing that dialysis membrane are soaked a preservative called sodium azide, which could potentially be the cause of the aggregation, the dialysis membrane are thoroughly washed with DI water, and then placed in the DI water with the $\mathrm{HAuCl}_{4}$ and $\mathrm{Na}_{2} \mathrm{~S}_{2} \mathrm{O}_{3}$. This experiment was repeated from Section 2.5, using DiaSynth along with the controls shown in Tables $8 \&$ 9. The data shows that using the 3500 Da MWCO Dialysis membrane with a mixture of $11 \mathrm{~mL}$ of 2 $\mathrm{mM} \mathrm{HAuCl}_{4}$ and $3 \mathrm{~mL}$ of $3 \mathrm{mM} \mathrm{Na}_{2} \mathrm{~S}_{2} \mathrm{O}_{3}$ dialyzed for 1 , 2, or 4 hrs, has the best $\mathrm{R}^{\mathrm{nIR} / \mathrm{Au}}=1.57,1.62$, and 1.57 , respectfully. The TEM samples were prepared using the $1 \mathrm{hr}$ samples for each control on 11+3 (non-dialysis and 2000 \& 3500 Da MWCO Dialysis membrane). From the TEM images, it should that there is less production of the colloidal particles when using the DiaSynth method. 


\subsubsection{DiaSynth Sweep}

The purpose of this experiment is to run a sweep on GGS nanoparticle synthesis with DiaSynth method, using $11 \mathrm{~mL}$ of $2 \mathrm{mM} \mathrm{HAuCl}_{4}$ mixed with various "X mL" of $3 \mathrm{mM} \mathrm{Na} \mathrm{S}_{2} \mathrm{O}_{3}$ in 2000 and 3500 Da MWCO Dialysis membrane to show the best quality ratio.

\subsubsection{Protocol}

Fill an 8 L bucket with 7.5 - 8 L of DI water and place stir bar inside. Next, in a 3500 Da MWCO Dialysis membrane, a mixture of $11 \mathrm{~mL}$ of $2 \mathrm{mM}$ $\mathrm{HAuCl}_{4}$ (first in the bag) and $2.5 \mathrm{~mL}$ to $5 \mathrm{~mL}$ in $0.5 \mathrm{~mL}$ increments $\mathrm{mL}$ of $3 \mathrm{mM}$ $\mathrm{Na}_{2} \mathrm{~S}_{2} \mathrm{O}_{3}$ (second after the gold solution had been added), and let the sample dialyze for 1 hr. Repeat the experiment, except using 2000 Da MWCO Dialysis membrane. Then for a non-dialysis sample, $11 \mathrm{~mL}$ of $2 \mathrm{mM} \mathrm{HAuCl}_{4}$ and $2.5 \mathrm{~mL}$ to $5 \mathrm{~mL}$ in $0.5 \mathrm{~mL}$ increments of $3 \mathrm{mM} \mathrm{Na} \mathrm{S}_{2} \mathrm{O}_{3}$ are mixed in a $50 \mathrm{~mL}$ tubes and reacted for $1 \mathrm{hr}$ (Table 10 shows the list of the controls used in this experiment). In 6 separate $50 \mathrm{~mL}$ centrifugation tubes, add $11 \mathrm{~mL}$ of $2 \mathrm{mM} \mathrm{HAuCl}_{4}$ and $3 \mathrm{mM}$ $\mathrm{Na}_{2} \mathrm{~S}_{2} \mathrm{O}_{3}$ ranging from $2.5 \mathrm{~mL}$ to $5 \mathrm{~mL}$ in $0.5 \mathrm{~mL}$ increments in each tube separately. Next, spectral scans were obtained after an hour of the self-assembly synthesis at room temperature (RT), using a UV/Vis spectrophotometer (Carey 50 Varian). A Malvern Zetasizer (ZS90) was used to characterize the GGS nanoparticles surface charge and size. 


\begin{tabular}{|c|c|c|}
\hline Samples & Samples (Au + Na2S2O3) & Int Ratios (Au/Na2S2O3) \\
\hline \multirow{6}{*}{ Non-Dialysis } & $11+2.5$ & 4.40 \\
\hline & $11+3$ & 3.67 \\
\hline & $11+3.5$ & 3.14 \\
\hline & $11+4$ & 2.75 \\
\hline & $11+4.5$ & 2.44 \\
\hline & $11+5$ & 2.20 \\
\hline \multirow{6}{*}{2000 Da MWCO Dialysis } & $11+2.5$ & 4.40 \\
\hline & $11+3$ & 3.67 \\
\hline & $11+3.5$ & 3.14 \\
\hline & $11+4$ & 2.75 \\
\hline & $11+4.5$ & 2.44 \\
\hline & $11+5$ & 2.20 \\
\hline \multirow{6}{*}{3500 Da MWCO Dialysis } & $11+2.5$ & 4.40 \\
\hline & $11+3$ & 3.67 \\
\hline & $11+3.5$ & 3.14 \\
\hline & $11+4$ & 2.75 \\
\hline & $11+4.5$ & 2.44 \\
\hline & $11+5$ & 2.20 \\
\hline
\end{tabular}

Table 10: Represents the controls that will be used in the following experiment. 


\subsubsection{Data/Analysis}

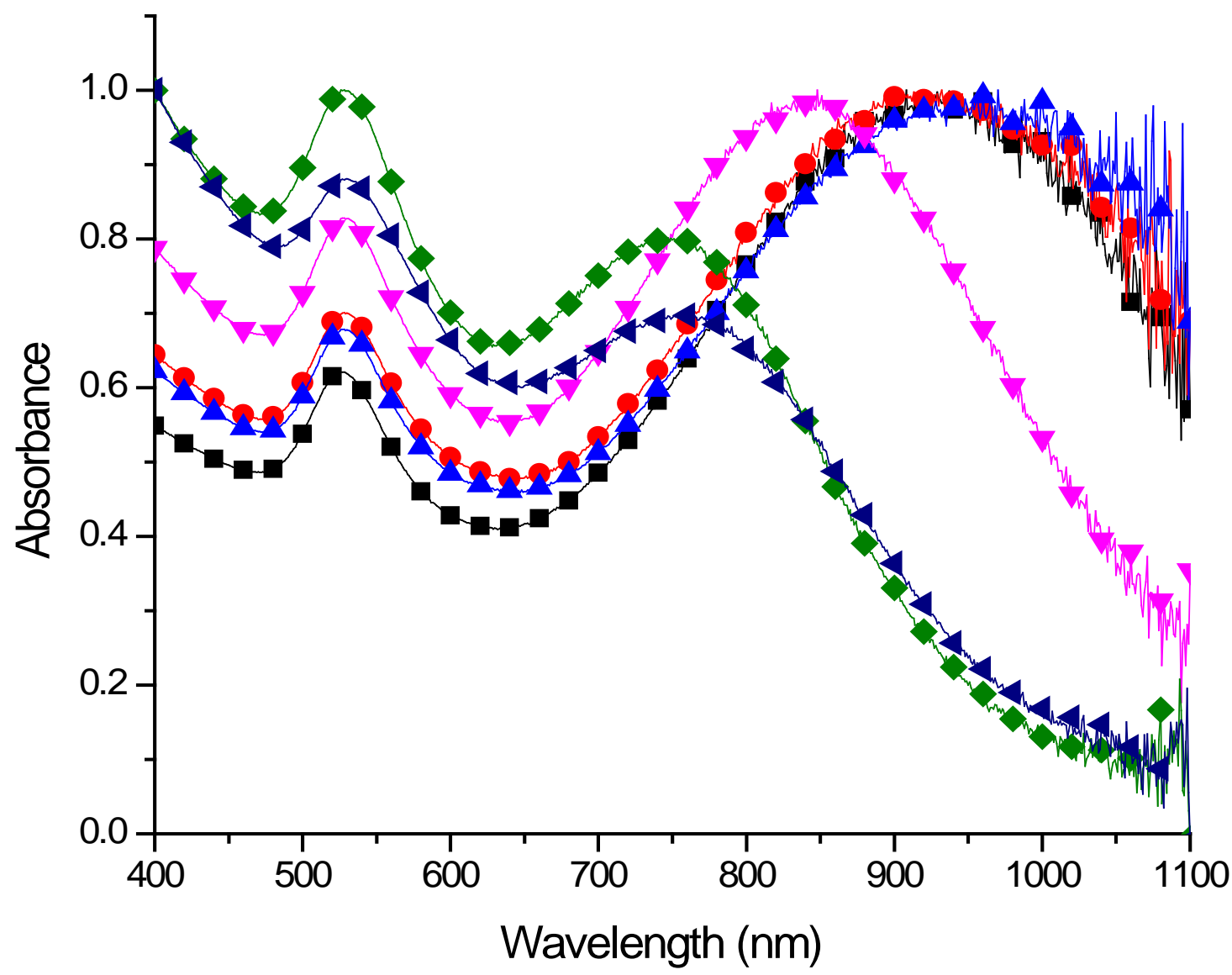

Figure 32: GGS nanoparticle sweep with DiaSynth method using $11 \mathrm{~mL}$ of $2 \mathrm{mM}$ $\mathrm{HAuCl}_{4}+\mathrm{X} \mathrm{mL}$ of $3 \mathrm{mM} \mathrm{Na} \mathrm{S}_{2} \mathrm{O}_{3}$ in $0.5 \mathrm{~mL}$ increments (from 2.5-5) in a 2000 MWCO Dialysis membrane. The Black-square, Red-circle, Blue-triangle, Pinktriangle-down, Green-square, and Purple-triangle-side line represents the spectral profile of the samples with $2.5,3,3.5,4,4.5$, and $5 \mathrm{~mL}$ of $3 \mathrm{mM} \mathrm{Na} \mathrm{S}_{2} \mathrm{O}_{3}$. The nIR peak and quality ratio is reported in Table 11. 


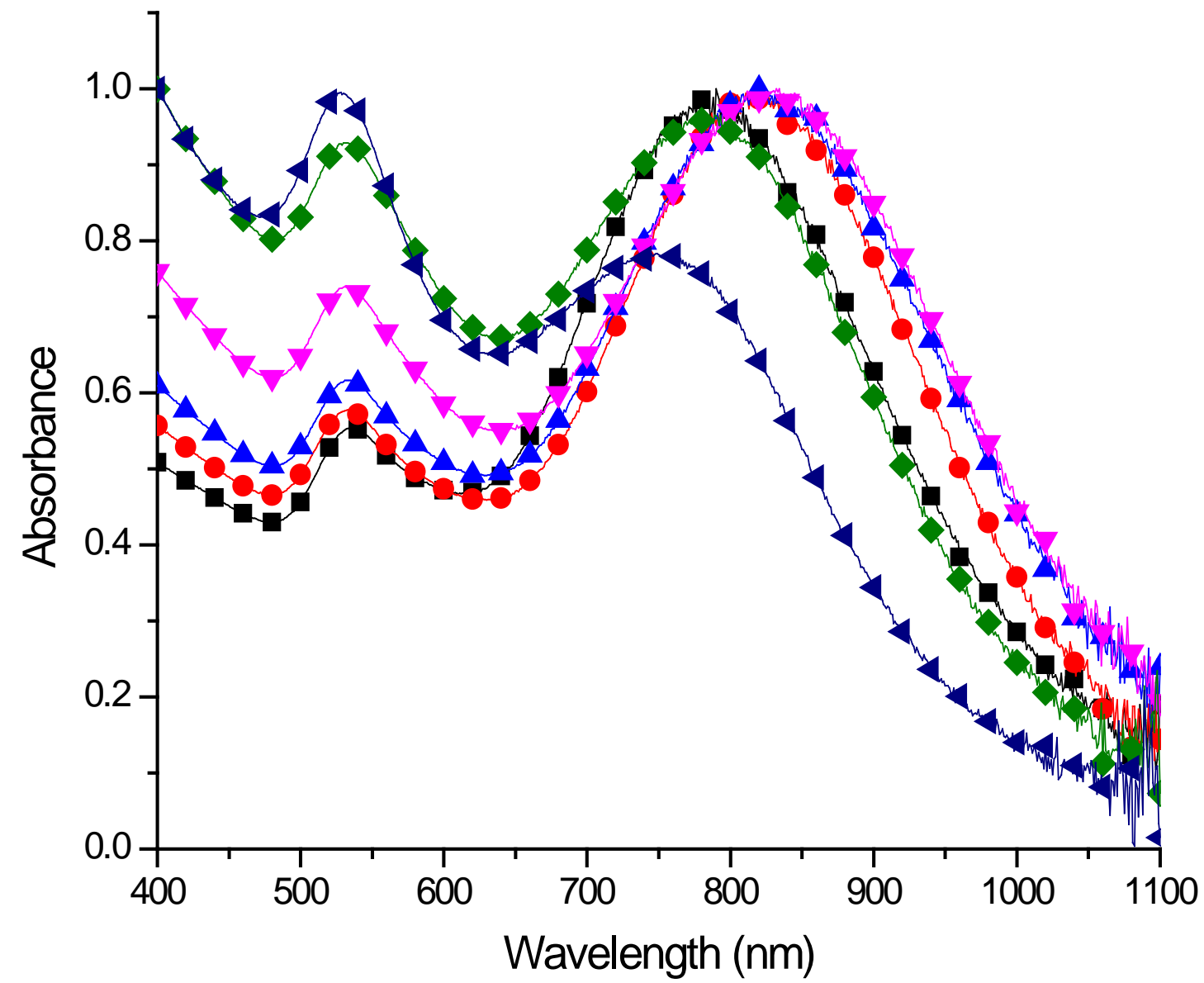

Figure 33: GGS nanoparticle sweep with DiaSynth method using $11 \mathrm{~mL}$ of 2 $\mathrm{mM} \mathrm{HAuCl}_{4}+\mathrm{X} \mathrm{mL}$ of $3 \mathrm{mM} \mathrm{Na}_{2} \mathrm{~S}_{2} \mathrm{O}_{3}$ in $0.5 \mathrm{~mL}$ increments (from 2.5-5) in a 3500 MWCO Dialysis membrane. The Black-square, Red-circle, Blue-triangle, Pink-triangle-down, Green-square, and Purple-triangle-side line represents the spectral profile of the samples with $2.5,3,3.5,4,4.5$, and $5 \mathrm{~mL}$ of $3 \mathrm{mM}$ $\mathrm{Na}_{2} \mathrm{~S}_{2} \mathrm{O}_{3}$. The nIR peak and quality ratio is reported in Table 11. 


\begin{tabular}{|c|c|c|c|}
\hline & $\begin{array}{c}\text { Int Ratios } \\
\text { (HAuCl4/Na2S2O3) }\end{array}$ & $\begin{array}{l}\text { nIR Wavelength } \\
\text { Peak (nm) }\end{array}$ & Quality Ratio \\
\hline \multirow{6}{*}{ Non-Dialysis } & 4.40 & N/A & N/A \\
\hline & 3.67 & 995 & 1.675 \\
\hline & 3.14 & 901 & 1.398 \\
\hline & 2.75 & 852 & 1.126 \\
\hline & 2.44 & 807 & 0.895 \\
\hline & 2.20 & 779 & 0.730 \\
\hline \multirow{6}{*}{$\begin{array}{c}2000 \text { Da MWCO } \\
\text { Dialysis }\end{array}$} & 4.40 & 931 & 1.588 \\
\hline & 3.67 & 928 & 1.421 \\
\hline & 3.14 & 950 & 1.436 \\
\hline & 2.75 & 848 & 1.209 \\
\hline & 2.44 & 771 & 0.783 \\
\hline & 2.20 & 771 & 0.787 \\
\hline \multirow{6}{*}{$\begin{array}{c}3500 \text { Da MWCO } \\
\text { Dialysis }\end{array}$} & 4.40 & 789 & 1.804 \\
\hline & 3.67 & 816 & 1.731 \\
\hline & 3.14 & 820 & 1.621 \\
\hline & 2.75 & 834 & 1.352 \\
\hline & 2.44 & 789 & 1.038 \\
\hline & 2.20 & 747 & 0.787 \\
\hline
\end{tabular}

Table 11: nIR peak and the quality ratios of each sample from Figure $33 \& 34$. 


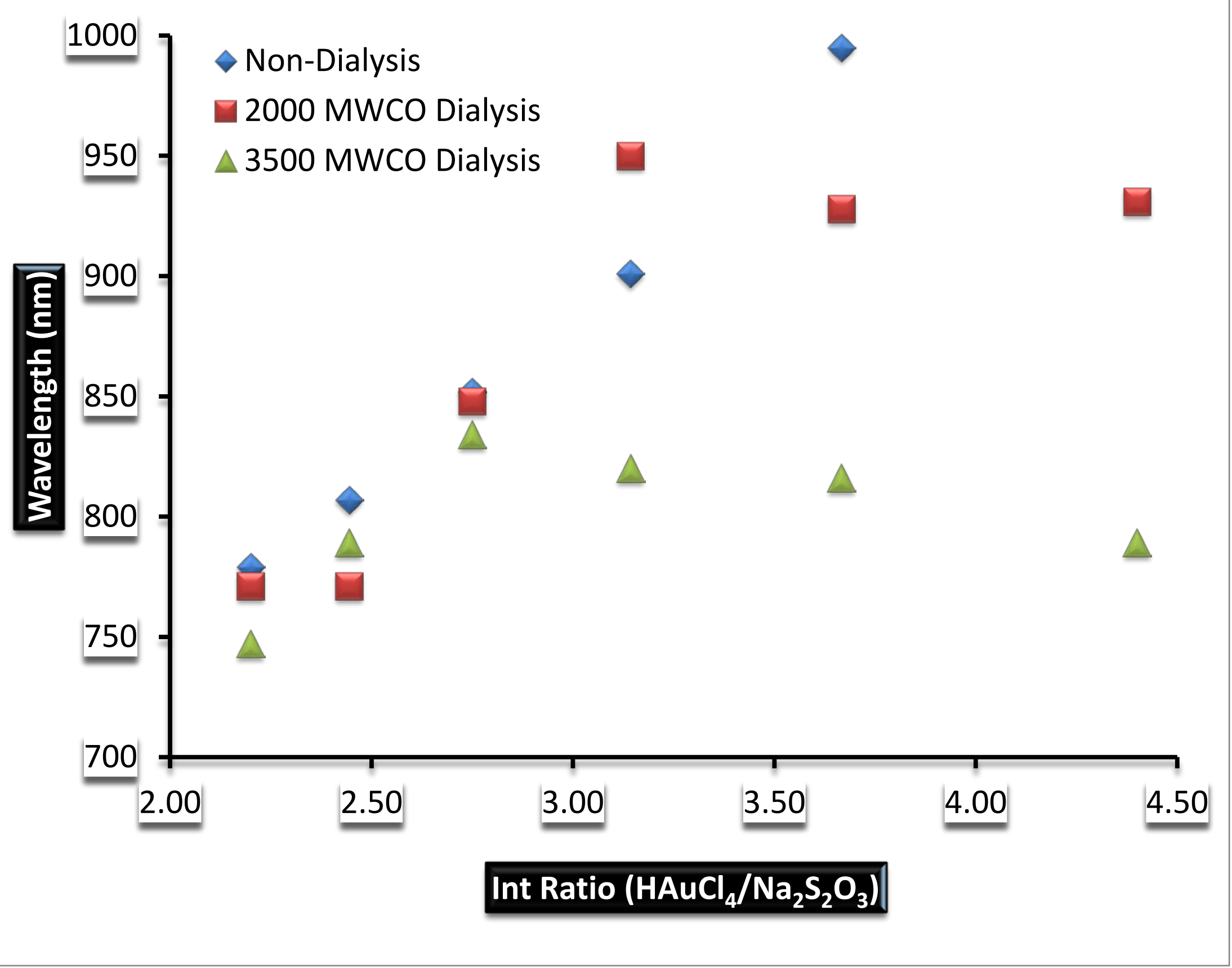

Figure 34: Scatter plot (data from Table 11) of the initial ratio $\left(\mathrm{HAuCl}_{4}: \mathrm{Na}_{2} \mathrm{~S}_{2} \mathrm{O}_{3}\right)$ used vs the nIR peak at the end of the reaction is the given three controls. 


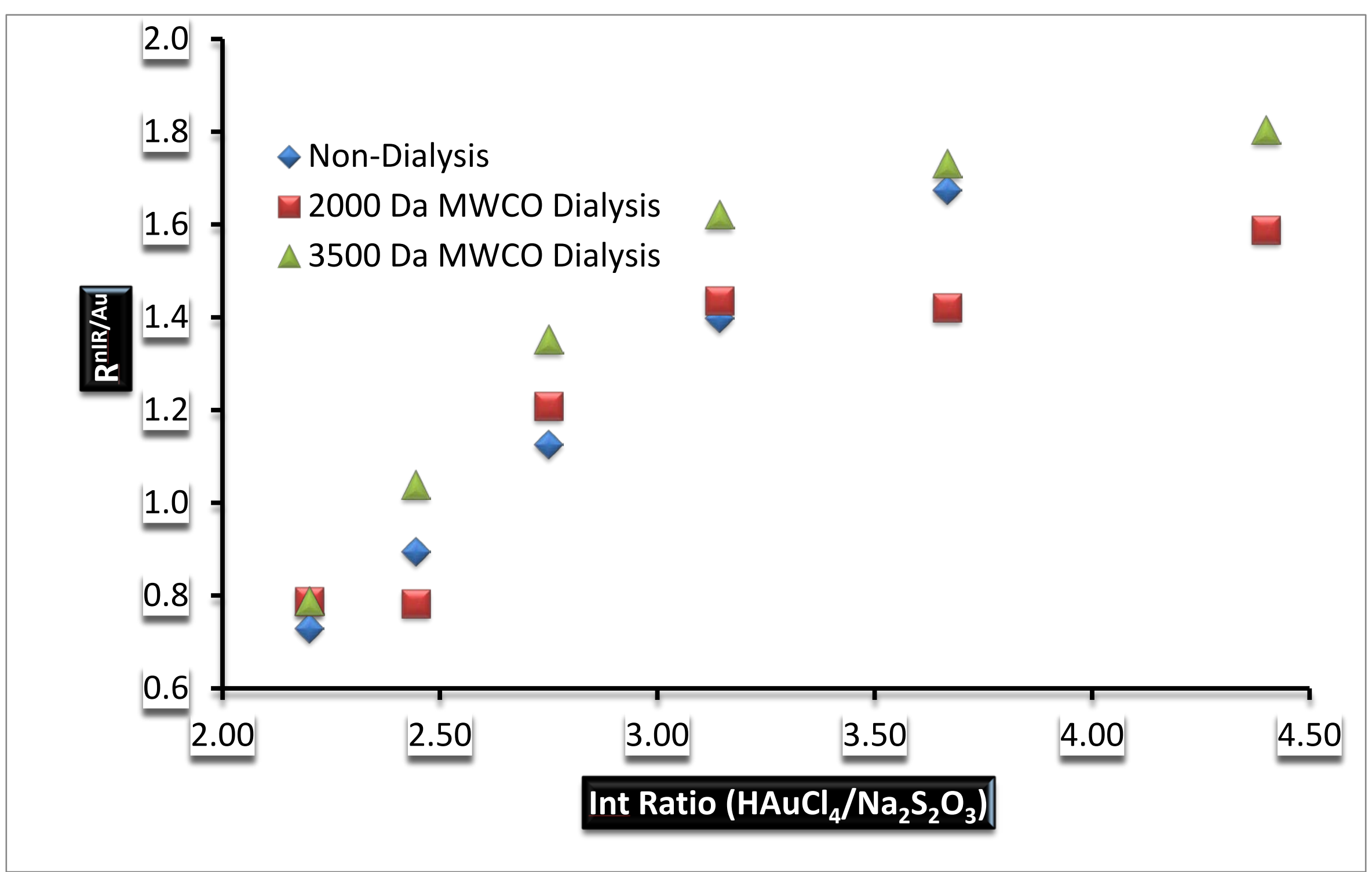

Figure 35: Scatter plot (data from Table 11) of the initial ratio $\left(\mathrm{HAuCl}_{4}: \mathrm{Na}_{2} \mathrm{~S}_{2} \mathrm{O}_{3}\right)$ used vs the $\mathrm{R}^{\mathrm{nIR} / \mathrm{Au}}$ at the end of the reaction is the given three controls. 


\subsubsection{Conclusion}

From the given data, the sample with $11 \mathrm{~mL}$ of $2 \mathrm{mM} \mathrm{HAuCl}_{4}$ mixed with $2.5 \mathrm{~mL}$ of $3 \mathrm{mM} \mathrm{Na}_{2} \mathrm{~S}_{2} \mathrm{O}_{3}$ in a 3500 Da MWCO Dialysis membrane, dialyzed against DI water, has the best $\mathrm{nIR} \mathrm{R}^{\mathrm{nIR} / \mathrm{Au}}=1.8$; while the $2000 \mathrm{Da}$ MWCO Dialysis membrane and non-dialyzed sample has $\mathrm{R}^{\mathrm{nIR} / \mathrm{Au}}=1.58$ and $\mathrm{N} / \mathrm{A}$, respectfully. Future studies will focus on using the $11 \mathrm{~mL}$ of $2 \mathrm{mM} \mathrm{HAuCl}_{4}$ mixed with $2.5 \mathrm{~mL}$ of $3 \mathrm{mM} \mathrm{Na} 2 \mathrm{~S}_{2} \mathrm{O}_{3}(11+2.5$, 4.4 Initial ratio) ratio. 


\subsubsection{DiaSynth - using higher MWCO bags}

The purpose of this experiment is to synthesize a batch of AuNPs with $\mathrm{HAuCl}_{4}$ and $\mathrm{Na}_{2} \mathrm{~S}_{2} \mathrm{O}_{3}$ using the DiaSynth method, dialyzed against DI water at room temperature. However, this experiment will use 4 different dialysis membrane, 2000 Da MWCO, 3500 Da MWCO, 6000 - 8000 Da MWCO, and 12000 Da MWCO dialysis membranes.

\subsubsection{Protocol}

Fill 4 - 8 L bucket with 7.5 - 8 L of DI water and place stir bar inside. Next, prepare 4 mixtures of $11 \mathrm{~mL}$ of $2 \mathrm{mM} \mathrm{HAuCl}_{4}$ (first in the bag) and $2.5 \mathrm{~mL}$ of $3 \mathrm{mM} \mathrm{Na} \mathrm{S}_{2} \mathrm{O}_{3}$ (second after the gold solution had been added) is added to 2000 Da MWCO, 3500 Da MWCO, 6000 - 8000 Da MWCO, and 12000 Da MWCO dialysis membrane separately, and let the samples dialyze for 1 . Then for a non-dialysis sample, $11 \mathrm{~mL}$ of $2 \mathrm{mM} \mathrm{HAuCl}_{4}$ and $2.5 \mathrm{~mL}$ of $3 \mathrm{mM} \mathrm{Na}_{2} \mathrm{~S}_{2} \mathrm{O}_{3}$ is mixed in a $50 \mathrm{~mL}$ tubes and reacted for $1 \mathrm{hr}$. Next, spectral scans were obtained after an hour of the self-assembly synthesis at room temperature (RT), using a UV/Vis spectrophotometer (Carey 50 Varian). 


\subsubsection{Data/Analysis}

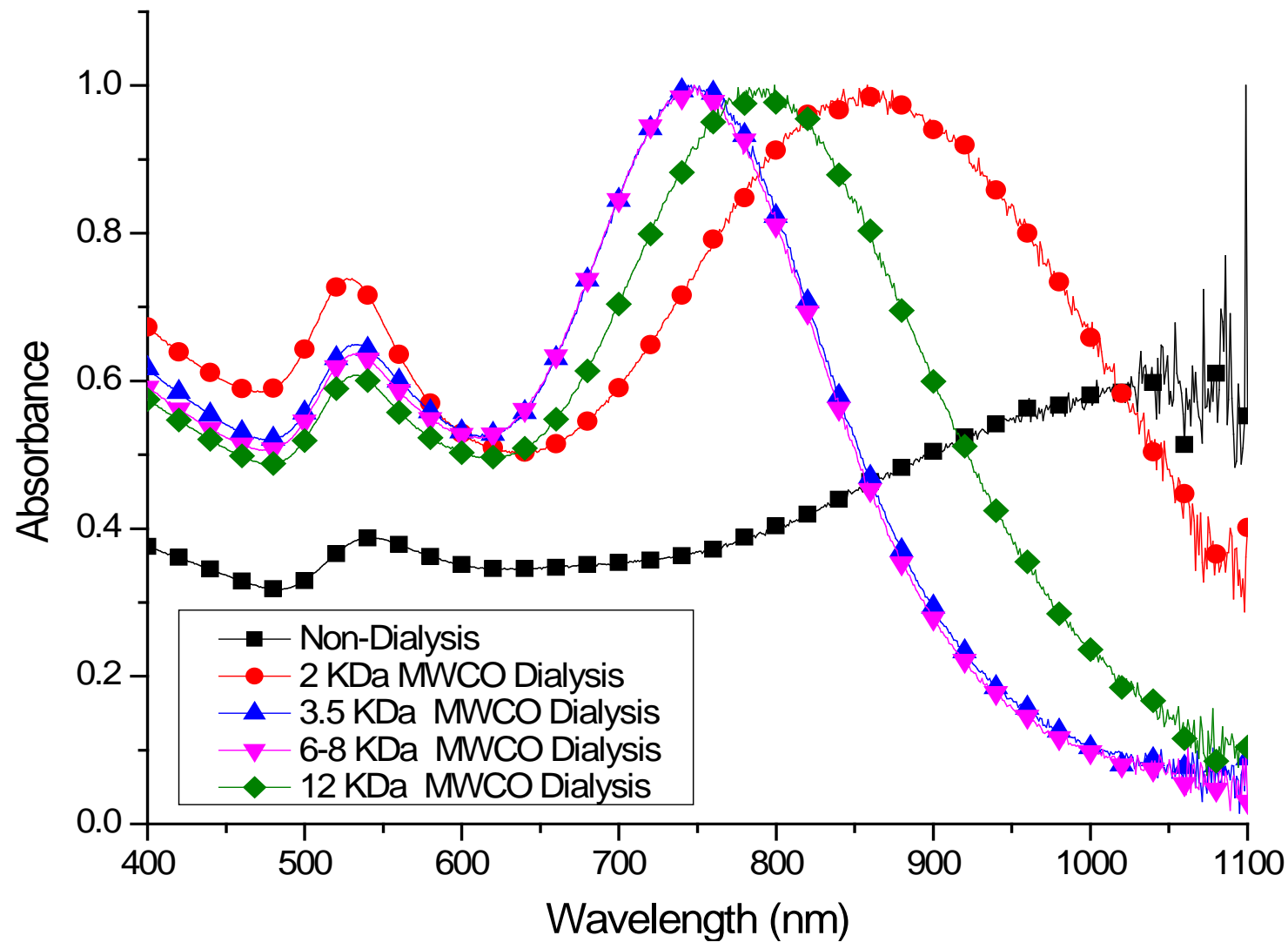

Figure 36: Normalized spectral profile of AuNPs synthesized using the DiaSynth method with 4 different MWCO bags. 


\begin{tabular}{|c|c|c|}
\hline Samples & $\begin{array}{c}\text { nIR Wavelength Peak } \\
(\mathrm{nm})\end{array}$ & Quality Ratio \\
\hline Non-Dialysis & 1098 & 2.58 \\
\hline 2KDa MWCO Dialysis & 858 & 1.35 \\
\hline 3.5KDa MWCO Dialysis & 748 & 1.54 \\
\hline 6-8KDa MWCO Dialysis & 744 & 1.57 \\
\hline 12KDa MWCO Dialysis & 799 & 1.65 \\
\hline
\end{tabular}

Table 12: nIR peak and the quality ratios of each sample from Figure 37.

\begin{tabular}{|c|c|c|c|c|}
\hline & $\begin{array}{c}\text { 2 Kda } \\
\text { MWCO } \\
\text { Dialysis }\end{array}$ & $\begin{array}{c}3.5 \text { Kda } \\
\text { MWCO } \\
\text { Dialysis }\end{array}$ & $\begin{array}{c}\text { 6-8 Kda } \\
\text { MWCO } \\
\text { Dialysis }\end{array}$ & $\begin{array}{r}12 \text { Kda } \\
\text { MWCO } \\
\text { Dialysis }\end{array}$ \\
\hline Size (nm) & 43.64 & 38.94 & 41.22 & 42.25 \\
\hline $\begin{array}{c}\text { Zeta Potential } \\
(\mathbf{m V})\end{array}$ & -26.4 & -35.2 & -29.95 & -30.25 \\
\hline
\end{tabular}

Table 13: Size and zeta measurements of the samples.

\subsubsection{Conclusion}

From the given data (Figure $37 \&$ Table 12), the sample with $11 \mathrm{~mL}$ of 2 mM HAuCl${ }_{4}$ mixed with $2.5 \mathrm{~mL}$ of $3 \mathrm{mM} \mathrm{Na}_{2} \mathrm{~S}_{2} \mathrm{O}_{3}$ in a 12000 Da MWCO Dialysis membrane, dialyzed against DI water, has the best $\mathrm{nIR} \mathrm{R}^{\mathrm{nIR} / \mathrm{Au}}=1.7$; while the other MWCO Dialysis membrane has a lower $\mathrm{R}^{\mathrm{nIR} / \mathrm{Au}}$. Future studies will focus on using the $11 \mathrm{~mL}$ of $2 \mathrm{mM} \mathrm{HAuCl}_{4}$ mixed with $2.5 \mathrm{~mL}$ of $3 \mathrm{mM}$ $\mathrm{Na}_{2} \mathrm{~S}_{2} \mathrm{O}_{3}$ (11+2.5, 4.4 Initial ratio) ratio with 12000 Da MWCO Dialysis membrane. 


\subsubsection{DiaSynth - 12 KDa MWCO Sweep}

The purpose of this experiment is to run a sweep on GGS nanoparticle synthesis with DiaSynth method, using $11 \mathrm{~mL}$ of $2 \mathrm{mM} \mathrm{HAuCl}_{4}$ mixed with various "X mL" of $3 \mathrm{mM} \mathrm{Na}{ }_{2} \mathrm{~S}_{2} \mathrm{O}_{3}$ in 12000 Da MWCO Dialysis membrane to show the best quality ratio.

\subsubsection{Protocol}

Fill an 8 L bucket with 7.5 - 8 L of DI water and place stir bar inside. Next, in a 12000 Da MWCO Dialysis membrane, a mixture of $11 \mathrm{~mL}$ of $2 \mathrm{mM}$ $\mathrm{HAuCl} 4$ (first in the bag) and $2.5 \mathrm{~mL}$ to $3.5 \mathrm{~mL}$ in $0.5 \mathrm{~mL}$ increments $\mathrm{mL}$ of 3 mM Na2S2O3 (second after the gold solution had been added), and let the sample dialyze for 1 . Next, spectral scans were obtained after an hour of the selfassembly synthesis at room temperature (RT), using a UV/Vis spectrophotometer (Carey 50 Varian). A Malvern Zetasizer (ZS90) was used to characterize the GGS nanoparticles surface charge and size. 


\subsubsection{Data/Analysis}

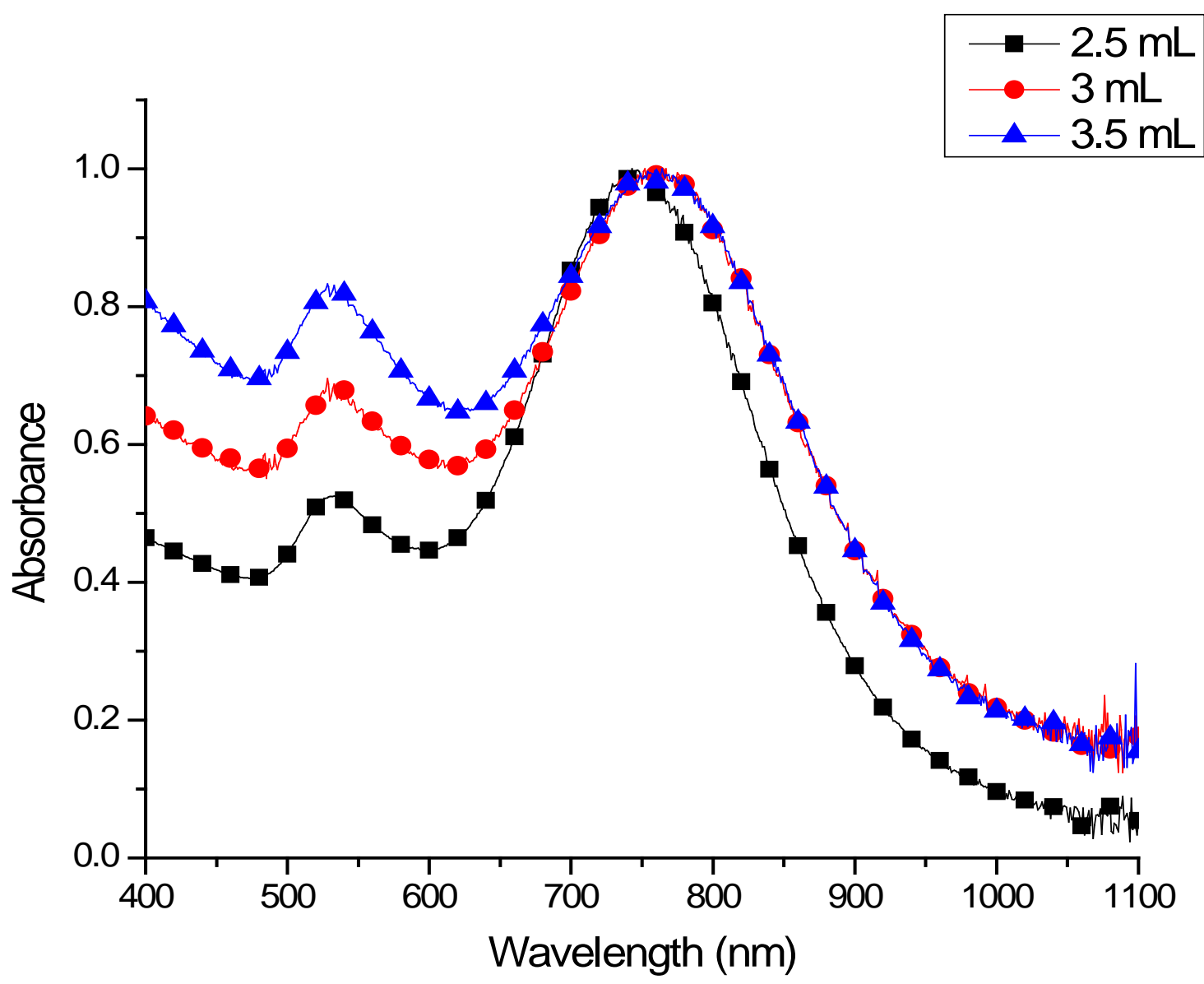

Figure 37: Normalized spectral profile of AuNPs synthesized using DiaSynth method in a 12000 Da MWCO Dialysis membrane, using $11 \mathrm{~mL}$ of $2 \mathrm{mM}$ HAuCl4 and various amount of $3 \mathrm{mM} \operatorname{Na2S} 2 \mathrm{O} 3(2.5,3$, and $3.5 \mathrm{~mL})$.

\begin{tabular}{|c|c|c|}
\hline Samples & nIR Wavelength Peak (nm) & Quality Ratio \\
\hline $2.5 \mathrm{~mL}$ & 746 & 1.904 \\
\hline $3 \mathrm{~mL}$ & 760 & 1.458 \\
\hline $3.5 \mathrm{~mL}$ & 763 & 1.199 \\
\hline
\end{tabular}

Table 14: nIR peak and the quality ratios of each sample from Figure 38. 


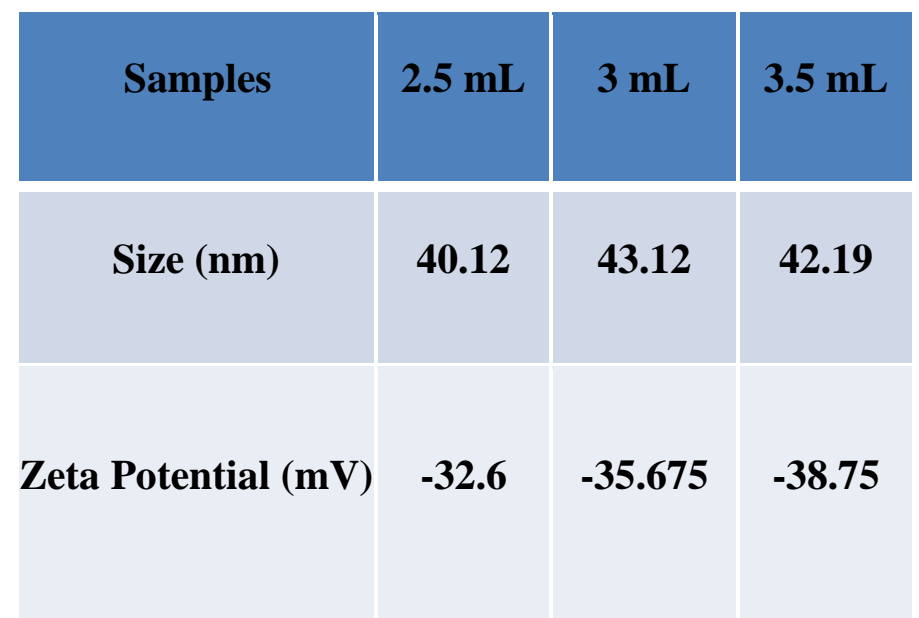

Table 15: Size and zeta measurements of the samples.

\subsubsection{Conclusion}

Instead of running the dialysis for $1 \mathrm{hr}$, it was accidently left running for 1.5 hrs. From the given data (Figure 38 \& Table 14), the sample with $11 \mathrm{~mL}$ of 2 mM HAuCl${ }_{4}$ mixed with $2.5 \mathrm{~mL}$ of $3 \mathrm{mM} \mathrm{Na}_{2} \mathrm{~S}_{2} \mathrm{O}_{3}$ in a 12000 Da MWCO Dialysis membrane, dialyzed against $\mathrm{DI}$ water, has the best $\mathrm{nIR} \mathrm{R}^{\mathrm{nIR} / \mathrm{Au}}=1.9$; while the other samples with 3 and $3.5 \mathrm{~mL}$ of $3 \mathrm{mM} \mathrm{Na}_{2} \mathrm{~S}_{2} \mathrm{O}_{3}$ has a lower $\mathrm{R}^{\mathrm{nIR} / \mathrm{Au}}$. 


\subsubsection{DiaSynth - Dialysate}

Using the DiaSynth method, samples are being dialyzed with a known MWCO dialysis membrane. However, it is unclear if the colloidal nanoparticles are forming on the outside or whether they get dialyzed out. The purpose of this experiment is to synthesize a bath of AuNPs using the DiaSynth method, and using rotary evaporator (rotovap) on the dialysate, concentrate the sample down, and measure the it for further analyze the sample. The purpose of the rotovap is to gently remove any solvents in the sample, water, by evaporation.

\subsubsection{Protocol}

Fill a 1 L beaker with 800 mL of DI water and place stir bar inside. Next, in a 12000 Da MWCO Dialysis membrane, a mixture of $11 \mathrm{~mL}$ of $2 \mathrm{mM} \mathrm{HAuCl} 4$ (first in the bag) and $2.5 \mathrm{~mL}$ of $3 \mathrm{mM} \mathrm{Na2S2O3} \mathrm{(second} \mathrm{after} \mathrm{the} \mathrm{gold} \mathrm{solution}$ had been added), and let the sample dialyze for $1 \mathrm{hr}$. Once the dialysis is finished, removed the dialysate, and rotovap the sample until only $20 \mathrm{mLs}$ of it is left. Then for a non-dialysis sample, $11 \mathrm{~mL}$ of $2 \mathrm{mM} \mathrm{HAuCl} 4$ and $2.5 \mathrm{~mL}$ of $3 \mathrm{mM}$ Na2S2O3 is mixed in a $50 \mathrm{~mL}$ tubes and reacted for $1 \mathrm{hr}$. Next, spectral scans were obtained after an hour of the self-assembly synthesis at room temperature (RT), using a UV/Vis spectrophotometer (Carey 50 Varian). A Malvern Zetasizer (ZS90) and TEM (FEI Tecnai F20) were used to characterize the GGS nanoparticles surface charge, size, and morphology. 


\subsubsection{Data/Analysis}

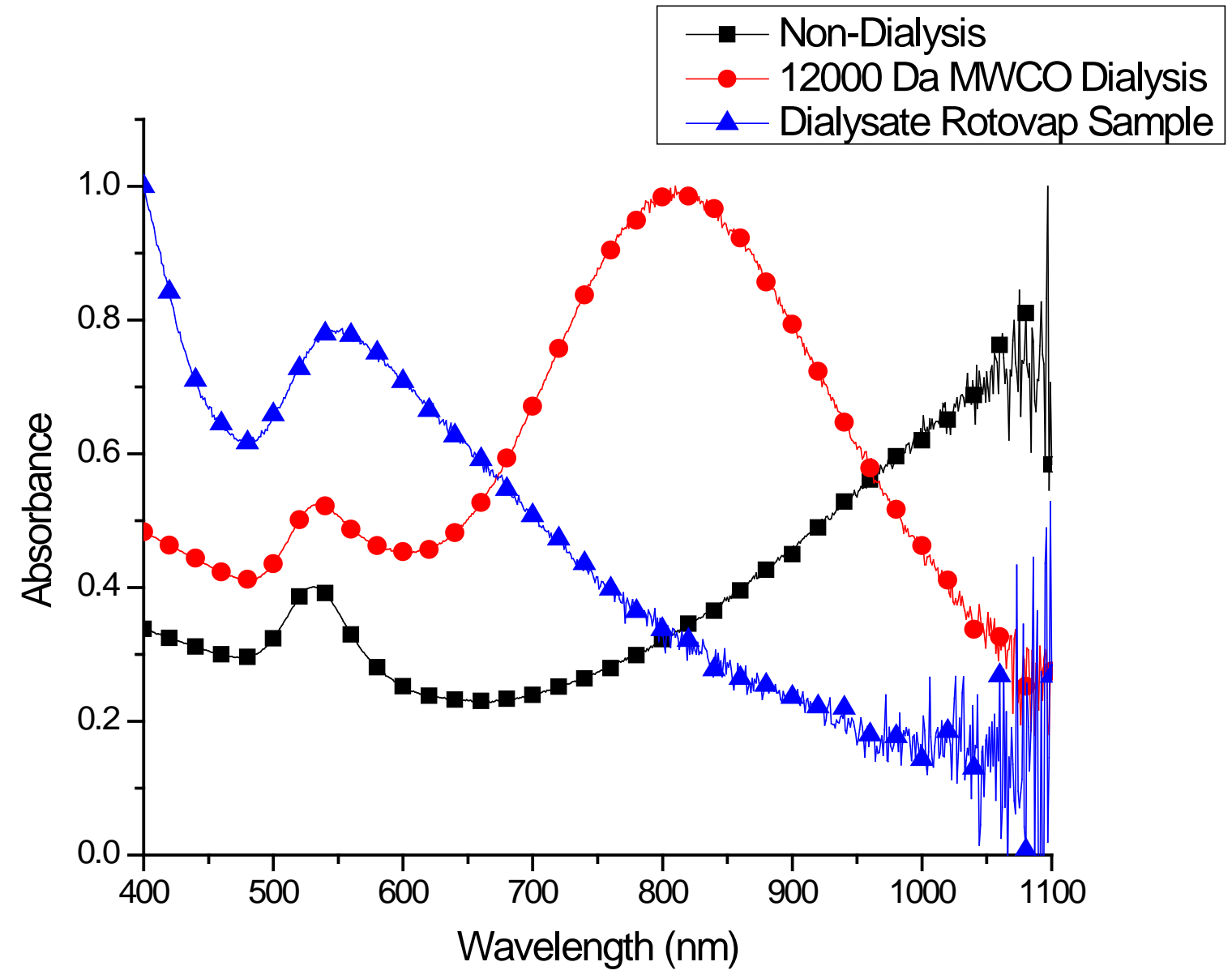

Figure 38: Normalized spectral profile of Non-Dialyzed, 12000 Da MWCO Dialysis membrane, and the rotovap sample. 

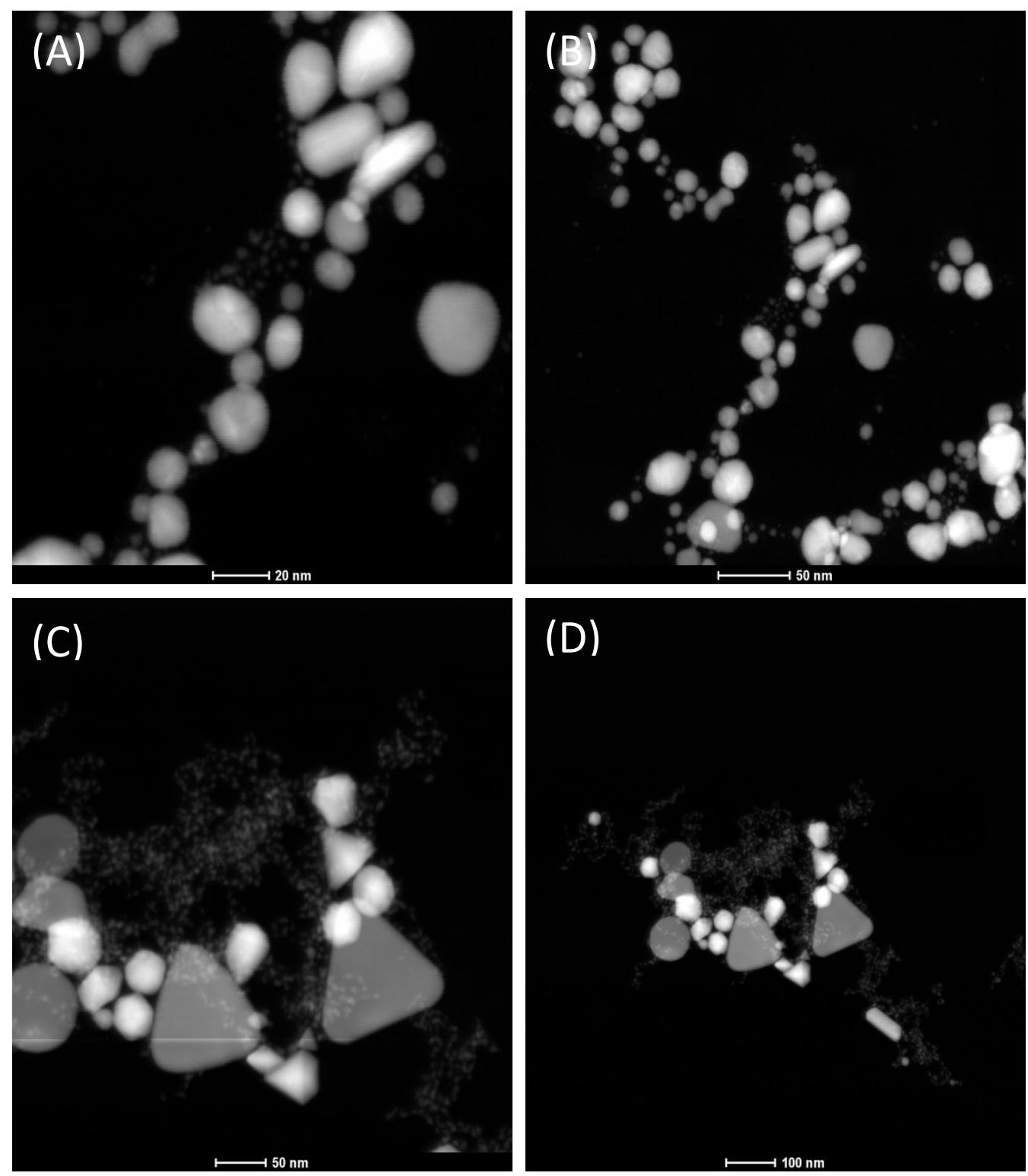

Figure 40: (A) \& (B) are the rotovap sample, while (C) \& (D) are the 12000 Da MWCO Dialysis product samples. 


\begin{tabular}{|l|c|c|c|}
\hline Sample & $\begin{array}{c}\text { Non- } \\
\text { Dialysis }\end{array}$ & $\begin{array}{c}12000 \text { Da MWCO } \\
\text { Dialysis }\end{array}$ & $\begin{array}{c}\text { Dialysate Rotovap } \\
\text { Sample }\end{array}$ \\
\hline Size (nm) & $\sim \mathbf{4 0}$ & $\sim 40$ & $2, \mathbf{7 8 , 1 8 8 , ~ \& ~ 5 0 0 +}$ \\
\hline $\begin{array}{l}\text { Zeta } \\
\text { (mV) }\end{array}$ & $-\mathbf{3 8}$ & -33 & -23 \\
\hline $\begin{array}{l}\text { Peak } \\
\text { (nm) }\end{array}$ & - & $\mathbf{8 1 1}$ & $\mathbf{5 3 0}$ \\
\hline Ratio & - & $\mathbf{1 . 9}$ & \\
\hline
\end{tabular}

\subsubsection{Conclusion}

Using the DiaSynth method, AuNPs have been synthesized at a high purity. From this experiment, a 12000 Da MWCO Dialysis membrane was used to mix $11 \mathrm{~mL}$ of $2 \mathrm{mM}$ HAuCl4 with $2.5 \mathrm{~mL}$ of $3 \mathrm{mM} \mathrm{Na2S2O3.} \mathrm{Once} \mathrm{the} \mathrm{dialysis}$ is finished, the dialysate was removed and rotovapped until only $20 \mathrm{mLs}$ of it is left. From Table 11, in the Dialysate Rotovap sample, there are multiple sized particles; this could be due to the fact that particles colliding and forming large aggregations (Figure 39). Next, the Dialysate Rotovap sample has an absorbance peak at $530 \mathrm{~nm}$, which is the same peak as the colloidal particles mentioned in the Introduction section. This confirms that the colloidal particles are indeed dialyzing out of the back and forcing ion exchange, which the ultimately effects the quality ratio to form the nIR favoring particles. 


\subsubsection{DiaSynth - Scale up}

Using the DiaSynth method, AuNPs have been synthesized at a high purity; however from a manufacturing standpoint, the process must be able to scale up in order to create a large bath of AuNPs with high purity and minimal processing. This experiment focuses on synthesizing AuNPs with the DiaSynth method with double the volume.

\subsubsection{Protocol}

Fill an 8 L bucket with 7.5 - 8 L of DI water and place stir bar inside. Next, in a 12000 Da MWCO Dialysis membrane, a mixture of $22 \mathrm{~mL}$ of $2 \mathrm{mM}$ HAuCl4 (first in the bag) and $5 \mathrm{~mL}$ of $3 \mathrm{mM} \mathrm{Na2S2O3} \mathrm{(second} \mathrm{after} \mathrm{the} \mathrm{gold}$ solution had been added), and let the sample dialyze for 1 . The experiment was repeated, except a mixture of $44 \mathrm{~mL}$ of $2 \mathrm{mM} \mathrm{HAuCl} 4$ (first in the bag) and 10 $\mathrm{mL}$ of $3 \mathrm{mM} \mathrm{Na2S2O3} \mathrm{(second} \mathrm{after} \mathrm{the} \mathrm{gold} \mathrm{solution} \mathrm{had} \mathrm{been} \mathrm{added),} \mathrm{and}$ sample being dialyzed for 2 hrs (explained in the conclusion of this section). Next, spectral scans were obtained after an hour of the self-assembly synthesis at room temperature (RT), using a UV/Vis spectrophotometer (Carey 50 Varian). A Malvern Zetasizer (ZS90) and TEM (FEI Tecnai F20) were used to characterize the GGS nanoparticles surface charge, size, and morphology. 


\subsubsection{Data/Analysis}

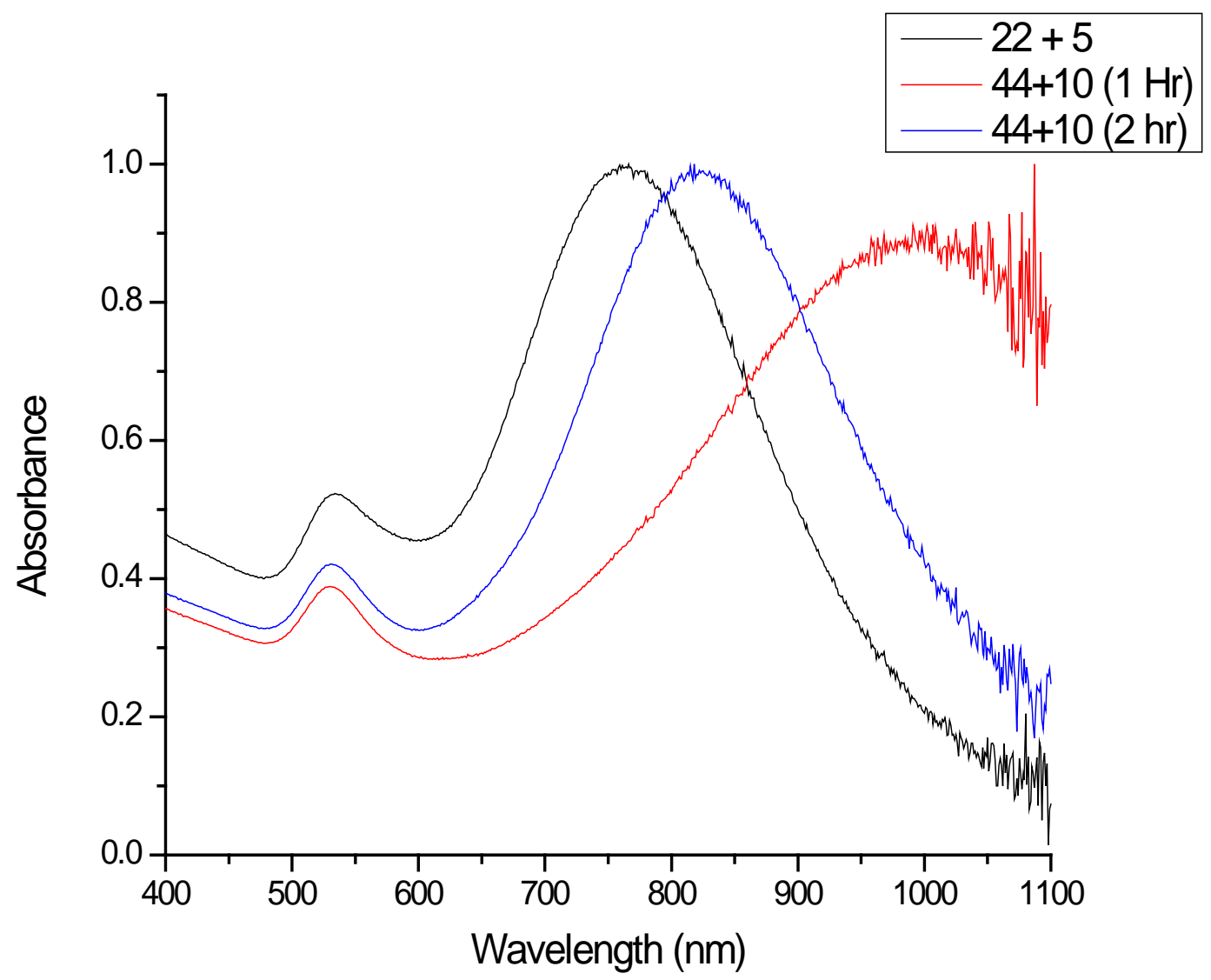

Figure 39: Normalized spectral profile of the two different scale ups.

\begin{tabular}{|c|c|c|c|c|}
\hline Sample & Peak (nm) & Ratio & $\begin{array}{c}\text { Size } \\
(\mathbf{n m})\end{array}$ & $\begin{array}{c}\text { Zeta } \\
(\mathbf{m V})\end{array}$ \\
\hline $22+5(1 \mathrm{hr})$ & 766 & 1.92 & 42.1 & -35.9 \\
\hline $44+10(1 \mathrm{hr})$ & 988 & 2.25 & 42.7 & -37.3 \\
\hline $44+10(2 \mathrm{hr})$ & 818 & 2.38 & 41 & -37.8 \\
\hline
\end{tabular}

Table 17: nIR spectral peak, quality ratio, size, and zeta measurements of the scale up samples. 


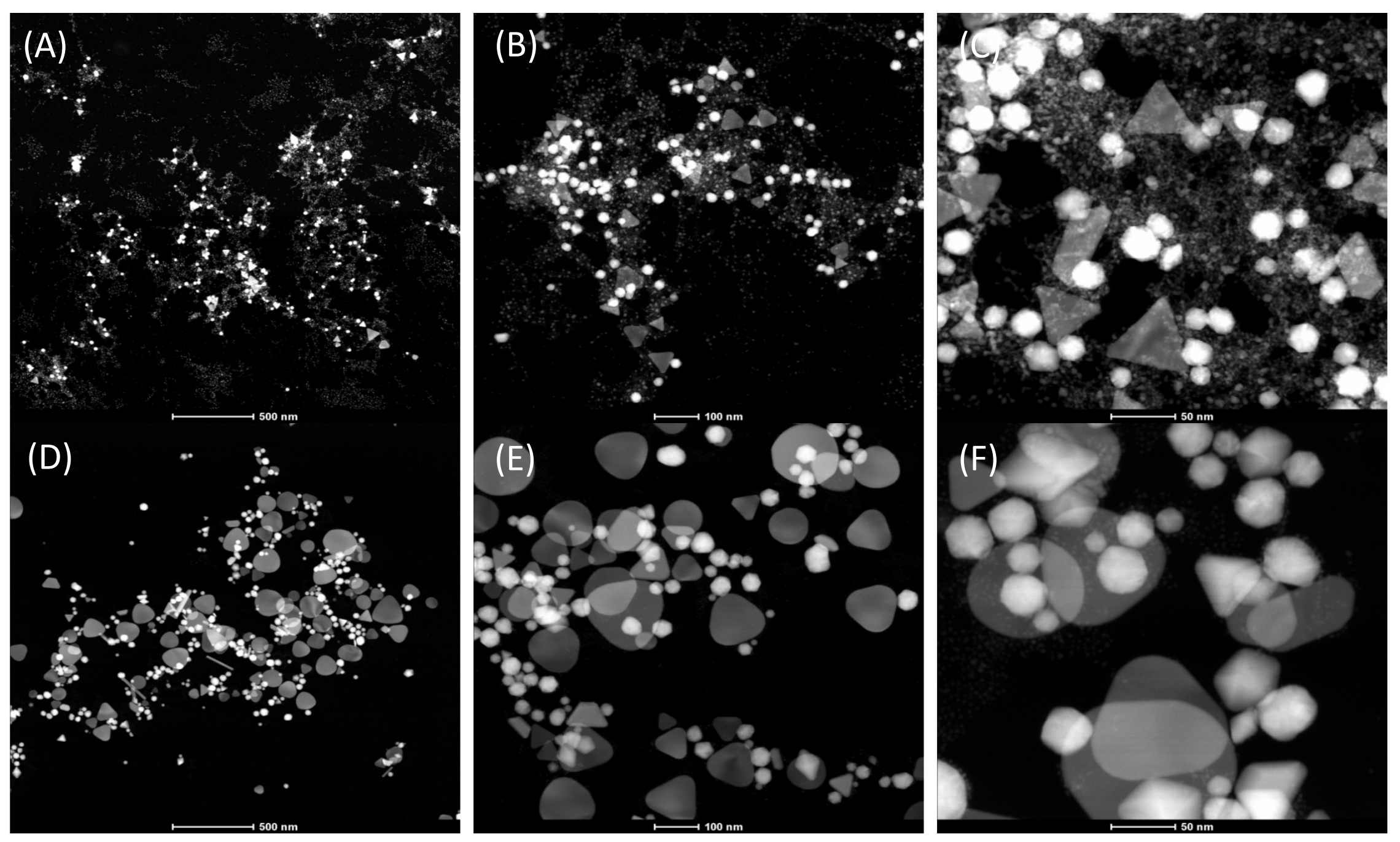

Figure 40: (A), (B), and (C) are non-dialyzed samples, while (D), (E), and (F) are from the 44+10 scale up. 


\subsubsection{Conclusion}

Using the DiaSynth method, AuNPs has been synthesized at a high purity, as mentioned and reported previously. From this experiment, a 12000 Da MWCO Dialysis membrane was used to mix $22 \mathrm{~mL}$ of $2 \mathrm{mM} \mathrm{HAuCl} 4$ with $5 \mathrm{~mL}$ of $3 \mathrm{mM}$ Na2S2O3, and a mix $44 \mathrm{~mL}$ of $2 \mathrm{mM} \mathrm{HAuCl} 4$ with $10 \mathrm{~mL}$ of $3 \mathrm{mM} \mathrm{Na2S2O3.}$ Once the dialysis is finished, spectral profile, size, zeta, and TEM measurements were taking. For the $44+10$ sample, the experiment reported here is the same as $1 \mathrm{hr}$ test, on that one 2 hrs was not an option. The 44+11 samples shows little to no colloidal formation (see Figure 42).

\section{CHAPTER 3 - DISCUSSION AND CONCLUSION}




\subsection{AuNPs}

Gold nanoparticles (AuNPs) has attracted enormous attention in the field of nanotechnology for applications such as, immunoassays, drug delivery, contrast enhancement, ex/in-vivo imaging, in-vitro assays, and cancer therapy (theranostic applications) (Section 1.2). These nanoparticles have a large surface-to-volume ratio; not only does this give a possibility of interaction between the gold nanoparticles and biomolecules, but opens the field to various medical applications. Specifically, gold/gold sulfide (GGS) nanoparticles have been introduced for many applications in addition to gold nanoshells and nanorods, for their smaller size, higher absorptive properties, and ease of fabrication. Theranostic applications have emerged as a technique to combine diagnosis, treatment, and imaging in cancer research. The ideal theranostic approach for cancer therapy has several tunable factors, mostly imaging and treatment, with a display of specifically targeting cancer cells.

In order to use GGS nanoparticles for therapeutic applications, the smaller goldcolloid contaminants formed during the self-assembly process must be removed. Traditionally, colloidal gold particles are removed via multi-step (3X) centrifugation (Section 2.2 \& 2.4.1), which is not only time consuming but inefficient. The removal of colloidal gold will reduce the total number of particles delivered to the body and reduce the impact on the reticulo-endothelial system (RES). Once the GGS particles have been synthesized, using $2 \mathrm{mM} \mathrm{HAuCl} 4 * 3 \mathrm{H} 2 \mathrm{O}$ and $3 \mathrm{mM} \mathrm{Na2S2O}$, they undergo a multistep centrifugation, Figure 4 shows the spectra of the samples, "as made" and after "3X centrifugation". There is a significant increase in the quality ratio, as seen in Figure 4, for the "as made" product the $\mathrm{R}^{\mathrm{nIR} / \mathrm{Au}}=0.83$; while the particles after multi-step 
centrifugation has an $\mathrm{R}^{\mathrm{nIR} / \mathrm{Au}}=1.95$, as expected the $\mathrm{R}^{\mathrm{nIR} / \mathrm{Au}}$ is increased due to the removal of the colloidal nanoparticles.

The use of $\mathrm{Na}_{2} \mathrm{~S}_{2} \mathrm{O}_{3}$ as an alternative to $\mathrm{Na}_{2} \mathrm{~S}$ has allowed a robust process to be developed where the nIR absorbing peak can be precisely controlled. By varying the volumes of reactants, this nIR peak can be reproduced time and again with great accuracy and precision $(+/-5 \mathrm{~nm})$, in direct contrast with the method used where the aging of $\mathrm{Na}_{2} \mathrm{~S}$ had to be within a precise range, and still resulted in particles with nIR peaks that could vary as much as $+/$ - $50 \mathrm{~nm}$ each time. In addition, the centrifugation process selects various components of the population, thus resulting in a shift of the peak absorbance wavelength of the final product may be away from the desired peak for the application. Detailed analysis of the dialysate and product is performed to understand the exact mechanism leading to increased yields, high quality ratio. However, this process represents a dramatic shift in production and scale up strategy, which could enable wider use of these nIR absorbing particles in a variety of applications.

\subsection{Temperature Effects}

From basic chemistry, the chemical kinetics deals with reaction rates; and the reaction rates is contributed by concentration of reactants, physical state of the reactants, temperature at which the reaction takes occurs, and the use of a catalyst. Under a "given" set of conditions, each reaction has its own rate, but can be influenced. For this thesis two main influencing factors were used: concentration and temperature. The concentration of the sample can affect the frequency of the collisions between reactant molecules; in this case it is $2 \mathrm{mM} \mathrm{HAuCl}_{4}$ and $3 \mathrm{mM} \mathrm{Na}_{2} \mathrm{~S}_{2} \mathrm{O}_{3}$. The temperature can 
affect the rate by two factors: (1) influencing the frequency and, (2) the energy of the reactant collision.

By adding in these conditions, change in temperature and concentration, prior to or during the synthesis of the AuNPs, the equilibrium has shift to favor the formation of nIR particles and the quality ratio in several experiments was greater than 1.6. However, this ratio was not close to the multi-step centrifugation method. In order to use these particles or therapeutic applications it is essential to increase the quality ratio to 2 or higher. Other experiments, not reported here, were also done including a modification of the two-step method. The two-step method reported by Zhou et al was modified, instead of adding in the $\mathrm{Na}_{2} \mathrm{~S}_{2} \mathrm{O}_{3}$ as the secondary addition, the gold solution was added to "coat" or for a "shell" on to the GGS particles that are forming. This also resulted in $\mathrm{R}^{\mathrm{nIR} / \mathrm{Au}}>1.5$, but less than 1.8 .

\subsection{DiaSynth}

Using dialysis during the production of GGS nanoparticles not only forcing ionexchange (by removing reactants or products), but as a consequence the equilibrium of the reaction can be shifted to favor the formation of nIR absorbing particles within the dialysis tubing and formation of gold colloid outside. Several dialysis MWCO membranes were used including: 2KDa, 3.5KDa, 6-8KDa, and $12 \mathrm{KDa}$, samples were then reacted for $1 \mathrm{hr}$ in $8 \mathrm{~L}$ of DI water at RT. From the spectral profile, given in Figure 37, dialysis with a $12 \mathrm{KDa}$ MWCO dialysis membrane shows the highest quality ratio. Next, the experiment was repeated using a 12 MWCO dialysis membrane, varying the amount of $\mathrm{Na}_{2} \mathrm{~S}_{2} \mathrm{O}_{3}$ added. As evidenced in Figure 38 \& Table 14, using the $2.5 \mathrm{~mL}$ of 
$\mathrm{Na}_{2} \mathrm{~S}_{2} \mathrm{O}_{3}$, further improved the quality ratio. The experiment was repeated using only the $2.5 \mathrm{~mL}$ of $\mathrm{Na}_{2} \mathrm{~S}_{2} \mathrm{O}_{3}$ for statistical analysis.

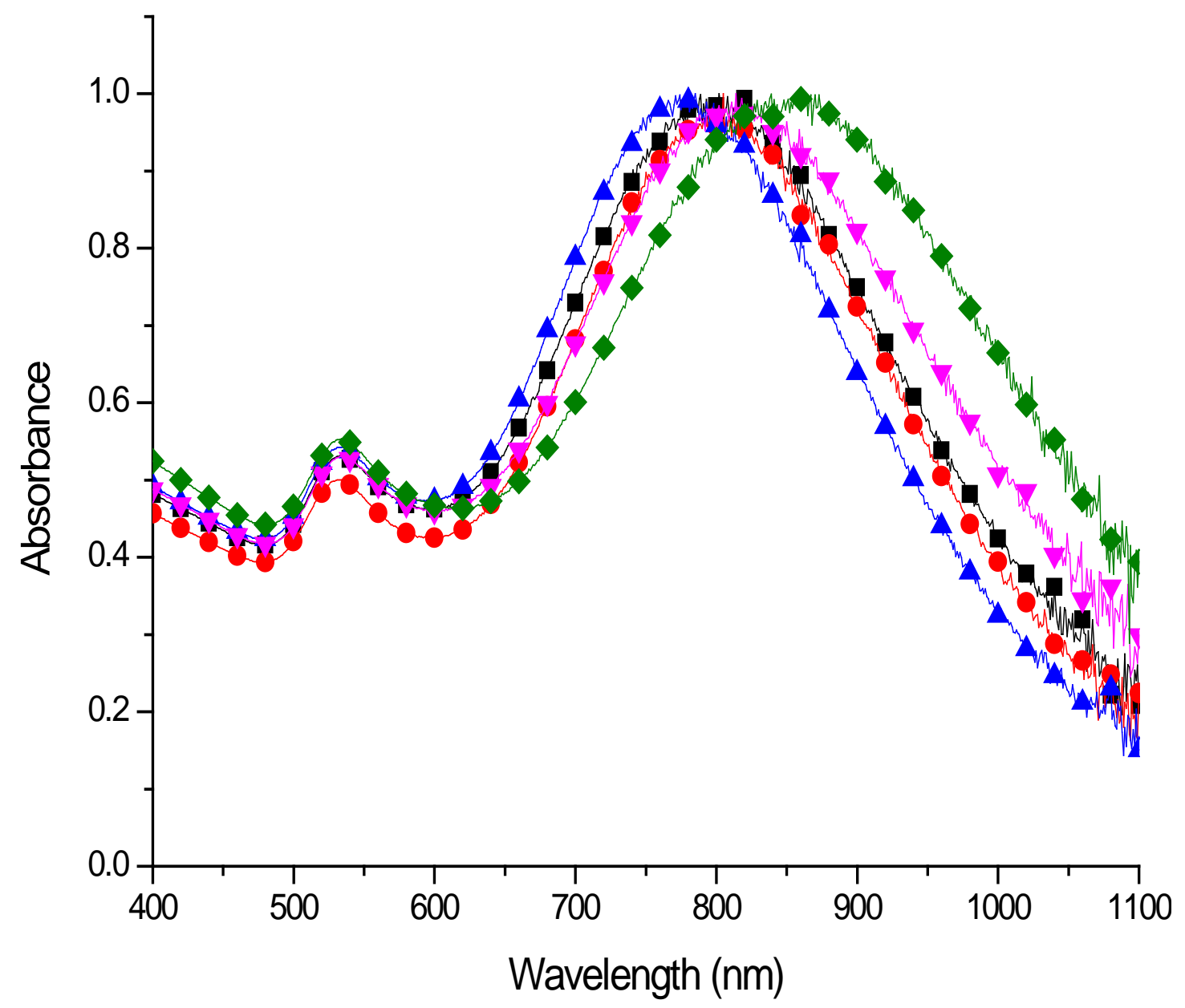

Figure 41: Spectral profile of GGS nanoparticles synthesized using the ratio $11+2.5$, the experiment was repeated with $n=5$. 


\begin{tabular}{|c|c|c|c|c|}
\hline Sample & $\begin{array}{c}\text { nIR Wavelength Peak } \\
(\mathbf{n m})\end{array}$ & Quality Ratio & Size (nm) & Zeta (mV) \\
\hline & 802 & 1.88 & 33.72 & -35.9 \\
\hline $\mathbf{1 1 + 2 . 5}$ & 805 & 2.00 & 33.46 & -33.8 \\
\hline & 785 & 1.84 & 32.98 & -34.4 \\
\hline & 814 & 1.88 & 34.23 & -34.4 \\
\hline
\end{tabular}

Table 18: nIR spectral peak, quality ratio, size, and zeta measurements of sample from Figure 41. The average $\mathrm{nIR}$ peak is $813 \mathrm{~nm} \pm 27 \mathrm{~nm}$, and the average quality ratio is $1.88 \mathrm{~nm} \pm 0.07$.

These results indicate the larger pore sizes of the membrane facilitate the diffusion and removal of certain species, during the reaction, which favors the production of nIR absorbing particles within the membrane. Additionally, increasing $\mathrm{HAuCl}_{4} / \mathrm{Na}_{2} \mathrm{~S}_{2} \mathrm{O}_{3}$ ratio shows an increase in purity at a fixed pore size. To allow formation of high ratio nIR absorbing nanoparticles compared to gold colloid which are a contaminant, in the DiaSynth process samples are dialyzed during the reaction. By dialyzing the samples, it allows us to change the kinetics and therefore shifting the equilibrium of the reaction. Our assumptions are based on the following system equations (2) and (4) shown above. Dialyzing samples at various time points we are having ions exchanging, which allows us to control the bandwidth and peak of the particles, ultimately help reduce the colloids and remove ions from the solution. This effect significantly decreases the gold colloid production, giving us a higher ratio of AuNPS nanoparticles compared to colloidal gold. The order to compare the over yield of the scale up process, a batch close to the nIR peak with the same volume was made 
(Table 19). From Table 19, DiaSynth (left side) are GGS particles as made, while the right side is the particles as made and with multi-step centrifugation.

\begin{tabular}{|c|c|c|}
\hline & DiaSynth & Non-Dialysis \\
\hline As made & $7.5 \mathrm{OD}, 55 \mathrm{mLs}$ & $2.5 \mathrm{OD}, 55 \mathrm{mLs}$ \\
\hline After multistep centrifugation & - & $117 \mathrm{OD}, .340 \mathrm{~mL}$ \\
\hline Final Yield & 412.5 & 28.9 \\
\hline Quality Ratio & 2.36 & 2.38 \\
\hline
\end{tabular}

Table 19: Results from the Non-Dialysis and DiaSynth method.

The results show that DiaSynth method has a significantly higher final yield ( 7.5 OD x 55 $\mathrm{mL}$, compared to $117 \mathrm{OD} \times 0.34 \mathrm{~mL}$ ) than as made GGS particles after multistep centrifugation. In the end, the DiaSynth method as proven to be an effective method on synthesizing nIR particles with little to no modification in the GGS synthesis compared to as made GGS particles and doing a multi-step centrifugation.

\subsection{Future Direction}

The use of AuNPs in biomedical field has endless applications. Using the DiaSynth method, quality of nIR GGS particles has improved tremendously. It is not clear whether the particles formed using the DiaSynth method and the RT method are the same "species" being formed. Both syntheses allow the formation of the nIR GGS nanoparticles; further characterization of the both types of synthesis is required.

To clarify the reaction mechanism a technique known as $\mathrm{x}$-ray photoelectron spectroscopy can be used to understand the oxidization states of the $\mathrm{HAuCl}_{4}$ and $\mathrm{Na}_{2} \mathrm{~S}_{2} \mathrm{O}_{3}$ and compared to as made product. Other techniques are also recommended such as X-ray diffraction patterning to understand the final products of the synthesis; furthermore, for detailed characterization Inductively coupled plasma mass spectrometry (ICPMS) and Energy-dispersive X-ray spectroscopy (EDAX). 
Lastly, further scaling up the DiaSynth is very important, not only from the manufacturing perspective but from a medical stand point as well. The GGS particles formed must be synthesized for large clinical studies and/or any other application that require a large batch of particles. Future scale up models should consider with using an automated process and larger volumes. A provisional patent has been filed on the DiaSynth process on the unique process, not only is the DiaSynth process more efficient but has a higher yield than current processes. Furthermore, this process may be applicable to other types of self-assembled one-pot synthesis procedures such as quantum dots if the correct membranes and temperature regimes are adhered. 


\section{REFERENCES:}

Weissleder, R. A clearer vision for in vivo imaging. Nat. Biotechnol. 19:316-317, 2001. Agbenyega, J. (2008). "Water soluble gold: Biomaterials." Materials Today 11(12): 13.

Averitt, R. D., D. Sarkar, et al. (1997). "Plasmon resonance shifts of Au-coated Au2S nanoshells: Insight into multicomponent nanoparticle growth." Physical Review Letters 78(22): 4217-4220.

Azzazy, H. M. E. and M. M. H. Mansour (2009). "In vitro diagnostic prospects of nanoparticles." Clinica Chimica Acta 403(1-2): 1-8.

Brown, S. D., P. Nativo, et al. (2010). "Gold Nanoparticles for the Improved Anticancer Drug Delivery of the Active Component of Oxaliplatin." Journal of the American Chemical Society 132(13): 4678-4684.

Chen, J., J. M. McLellan, et al. (2006). "Facile Synthesis of Gold-Silver Nanocages with Controllable Pores on the Surface." Journal of the American Chemical Society 128(46): 14776-14777.

Conners, K. H. (1990). Chemical Kinetics: The Study of Reaction Rates in Solution. New York, New York, VCH Publisher.

Day, E. S., L. R. Bickford, et al. (2010). "Antibody-conjugated gold-gold sulfide nanoparticles as multifunctional agents for imaging and therapy of breast cancer." Int J Nanomedicine 5: 445-454.

Diao, J. J. and G. D. Chen (2001). "Electromagnetic cavity resonant absorption of the gold nanoshell." Journal of Physics D-Applied Physics 34(14): L79-L82.

Diao, J. J. and H. Chen (2006). "Near infrared surface plasmon resonance of gold tabular nanostructures in the HAuCl4-Na2S reaction." J Chem Phys 124(11): 116103.

Erickson, T. A. and J. W. Tunnell (2007). Gold Nanoshells in Biomedical Applications. Nanotechnologies for the Life Sciences, Wiley-VCH Verlag GmbH \& Co. KGaA.

Ghosh, S., S. Dutta, et al. (2009). "Increased Heating Efficiency and Selective Thermal Ablation of Malignant Tissue with DNA-Encased Multiwalled Carbon Nanotubes." ACS Nano 3(9): 2667-2673.

Gobin, A. M., M. H. Lee, et al. (2007). "Near-Infrared Resonant Nanoshells for Combined Optical Imaging and Photothermal Cancer Therapy." Nano Letters 7(7): 1929-1934.

Gobin, A. M., E. M. Watkins, et al. (2010). "Near-Infrared-Resonant Gold/Gold Sulfide Nanoparticles as a Photothermal Cancer Therapeutic Agent." Small 6(6): 745-752.

Hirsch, L. R., J. B. Jackson, et al. (2003). "A Whole Blood Immunoassay Using Gold Nanoshells." Analytical Chemistry 75(10): 2377-2381.

Huang, X., I. H. El-Sayed, et al. (2006). "Cancer Cell Imaging and Photothermal Therapy in the Near-Infrared Region by Using Gold Nanorods." Journal of the American Chemical Society 128(6): 2115-2120.

Huang, X., P. K. Jain, et al. (2007). "Gold nanoparticles: interesting optical properties and recent applications in cancer diagnostics and therapy." Nanomedicine (Lond) 2(5): 681-693.

Huo, Q. (2007). "A perspective on bioconjugated nanoparticles and quantum dots." Colloids Surf B Biointerfaces 59(1): 1-10. 
Jelveh, S. and D. B. Chithrani (2011). "Gold Nanostructures as a Platform for Combinational Therapy in Future Cancer Therapeutics." Cancers 3(1): 1081-1110.

Kim, C.-k., P. Ghosh, et al. (2009). "Multimodal drug delivery using gold nanoparticles." Nanoscale 1(1): 61-67.

Lapotko, D. (2011). "Plasmonic Nanobubbles as Tunable Cellular Probes for Cancer Theranostics." Cancers (Basel) 3(1): 802-840.

Likhatskii, M. and Y. Mikhlin (2007). "Influence of sulfide ions on the formation and properties of gold nanoparticles in aqueous solutions." Glass Physics and Chemistry 33(4): 422-425.

Lowery, A. R., A. M. Gobin, et al. (2006). "Immunonanoshells for targeted photothermal ablation of tumor cells." Int J Nanomedicine 1(2): 149-154.

Lukianova-Hleb, E. Y., I. I. Koneva, et al. (2011). "Selective and Self-Guided Micro-Ablation of Tissue with Plasmonic Nanobubbles." Journal of Surgical Research 166(1): e3e13.

Majimel, J., D. Bacinello, et al. (2008). "Synthesis of hybrid gold-gold sulfide colloidal particles." Langmuir 24(8): 4289-4294.

Melancon, M. P., M. Zhou, et al. (2011). "Cancer Theranostics with Near-Infrared LightActivatable Multimodal Nanoparticles." Accounts of Chemical Research 44(10): 947-956.

Oldenburg, S. J., R. D. Averitt, et al. (1998). "Nanoengineering of optical resonances." Chemical Physics Letters 288(2-4): 243-247.

Park, H., J. Yang, et al. (2008). "Multifunctional nanoparticles for photothermally controlled drug delivery and magnetic resonance imaging enhancement." Small 4(2): 192-196.

Pérez-Juste, J., I. Pastoriza-Santos, et al. (2005). "Gold nanorods: Synthesis, characterization and applications." Coordination Chemistry Reviews 249(17-18): 1870-1901.

Prodan, E., P. Nordlander, et al. (2003). "Electronic Structure and Optical Properties of Gold Nanoshells." Nano Letters 3(10): 1411-1415.

Rai, M. (2011). Metal Nanoparticles in Microbiology. Berlin Heidelberg, Springer.

Raschke, G., S. Brogl, et al. (2004). "Gold nanoshells improve single nanoparticle molecular sensors." Nano Letters 4(10): 1853-1857.

Ren, L. and G. M. Chow (2003). "Synthesis of nir-sensitive Au-Au2S nanocolloids for drug delivery." Materials Science and Engineering: C 23(1-2): 113-116.

Schwartzberg, A. M., C. D. Grant, et al. (2007). "Reduction of $\mathrm{HAuCl}(4)$ by $\mathrm{Na}(2) \mathrm{S}$ revisited: The case for $\mathrm{Au}$ nanoparticle aggregates and against Au(2)S/Au Core/Shell particles." Journal of Physical Chemistry C 111(25): 8892-8901.

Shah, M. A. and G. K. Schwartz (2001). "Cell cycle-mediated drug resistance: an emerging concept in cancer therapy." Clin Cancer Res 7(8): 2168-2181.

Silberberg, M. S. (2006). Chemistry: The Molecular Nature of Matter and Change. New York, New York, The McGraw HIII Companies.

Song, Q., R. Risco, et al. (2008). "Selective targeting of pigmented retinal pigment epithelial (RPE) cells by a single pulsed laser irradiation: an in vitro study." Opt. Express 16(14): 10518-10528. 
Stone, J., S. Jackson, et al. (2011). "Biological applications of gold nanorods." Wiley Interdisciplinary Reviews: Nanomedicine and Nanobiotechnology 3(1): 100-109.

Sun, I. C., D. K. Eun, et al. (2011). "Tumor-Targeting Gold Particles for Dual Computed Tomography/Optical Cancer Imaging." Angewandte Chemie-International Edition 50(40): 9348-9351.

Sun, X., G. Zhang, et al. (2012). "Targeted Cancer Therapy by Immunoconjugated GoldGold Sulfide Nanoparticles Using Protein G as a Cofactor." Ann Biomed Eng.

Vladimir P. Zharov, V. G., Mark Viegas (2003). "Photothermal detection of local thermal effects during selective nanophotothermolysis " Appl. Phys. Lett. 83: 4897.

W. Cai, T. G., H. Hong J. Sun (2008). "Applications of gold nanoparticles in cancer nanotechnology " Nanotechnology, Science and Applications 1(1): 17-32

Xia, Y., W. Li, et al. (2011). "Gold Nanocages: From Synthesis to Theranostic Applications." Accounts of Chemical Research 44(10): 914-924.

Xie, X. N., X. Gao, et al. (2009). "Chemically Linked AuNP-Alkane Network for Enhanced Photoemission and Field Emission." ACS Nano 3(9): 2722-2730.

Yavuz, M. S., Y. Cheng, et al. (2009). "Gold nanocages covered by smart polymers for controlled release with near-infrared light." Nat Mater 8(12): 935-939.

Young, J. K., E. R. Figueroa, et al. (2012). "Tunable nanostructures as photothermal theranostic agents." Ann Biomed Eng 40(2): 438-459.

Yu, C. and J. Irudayaraj (2006). "Multiplex Biosensor Using Gold Nanorods." Analytical Chemistry 79(2): 572-579.

Zhou, H. S., I. I. Honma, et al. (1994). "Controlled synthesis and quantum-size effect in gold-coated nanoparticles." Phys Rev B Condens Matter 50(16): 12052-12056. 
Appendix I - Provisional Patent Application

IN THE UNITED STATES PATENT AND TRADEMARK OFFICE

UNITED STATES PROVISIONAL PATENT APPLICATION

FOR

METHOD FOR SYNTHESIZING SELF-ASSEMBLING NANOPARTICLES

OF

ANDRÉ M. GOBIN, DHRUVINKUMAR PATEL, KURTIS JAMES, AND GUANDONG

ZHANG 


\section{BACKGROUND OF THE INVENTION}

\section{(a) Field of the Invention}

[0001] Embodiments disclosed herein relate to a method for synthesizing selfassembling nanoparticles with defined plasmon resonances. More particularly, certain embodiments disclosed herein relate to an improved method for synthesizing selfassembling gold / gold sulfide nanoparticles by dialyzing samples during the self-assembly process.

\section{(b) Description of the Prior Art}

[0002] U.S. Application Nos. 12/807,792 and 12/807,793, incorporated herein by reference in their entireties, disclose gold / gold sulfide (“GGS”) nanoparticles within a chitosan matrix, and methods for synthesizing and using the same. These references disclose forming GGS nanoparticles by self-assembly of a sulfide source, such as sodium thiosulfate, and a gold source, such as cholorauric acid. GGS nanoparticles have absorbance peaks in the near infra-red ("NIR") region, which are tunable by varying the self-assembly conditions. During self-assembly of GGS nanoparticles, gold colloid is simultaneously formed as a byproduct.

\section{SUMMARY OF THE INVENTION}

[0003] Embodiments disclosed herein relate to a method for synthesizing selfassembling nanoparticles. More particularly, certain embodiments disclosed herein relate to an improved method for synthesizing self-assembling GGS nanoparticles by dialyzing samples during the self-assembly process. In some embodiments, an improved method for synthesizing GGS nanoparticles disclosed herein provides a higher ratio of GGS nanoparticles to gold colloid as compared to the method cited in U.S. Application Nos. 12/807,792 and 12/807,793.

[0004] In one embodiment, a method for synthesizing nanoparticles comprises blending gold source and a sulfide source within a first chamber, the first chamber being separated from a second chamber by a dialysis membrane. 
[0005] This summary is provided to introduce a selection of the concepts that are described in further detail in the detailed description and drawings contained herein. This summary is not intended to identify any primary or essential features of the claimed subject matter. Each embodiment described herein is not intended to address every object described herein, and each embodiment does not necessarily include each feature described. Other forms, embodiments, objects, advantages, benefits, features, and aspects of the present invention will become apparent to one of skill in the art from the detailed description and drawings contained herein.

\section{BRIEF DESCRIPTION OF THE DRAWINGS}

[0006] A better understanding of the present invention will be had upon reference to the following description in conjunction with the accompanying drawings, wherein:

[0007] Fig. 1 is a TEM image of a sample including GGS nanoparticles and gold colloid;

[0008] Fig. 2 is a TEM image of a sample including GGS nanoparticles;

[0009] Fig. 3 is an image showing the spectra scan of samples from Example 1;

[0010] Fig. 4 is an image showing the spectra scan of samples from Example 2;

[0011] Figs. 5A-5B are images showing the spectra scan of samples from Example 3 ;

[0012] Fig. 6 is an image showing the spectra scan of samples from Example 4;

[0013] Fig. 7 is an image showing the spectra scan of samples from Example 5;

[0014] Figs. 8A-8C are images showing spectra of samples from Example 6;

[0015] Fig. 9 is an image showing the spectra scan of samples from Example 7;

[0016] Fig. 10 is an image showing the spectra scan of samples from Example 8;

[0017] Figs. 11A-11B are images showing spectra of samples from Example 9;

[0018] Fig. 12 is an image showing the spectra scan of samples from Example 10; and 
[0019] Figs. 13A-B are images showing spectra of samples from Example 11, and Figs. 13C-D are charts showing the relationship between peak wavelength and Int ratio (defined below), and between quality ratio and Int ratio.

\section{DETAILED DESCRIPTION OF THE PREFERRED EMBODIMENT}

[0020] For purposes of promoting an understanding of the principles of the invention, reference will now be made to one or more selected embodiments illustrated in the drawings and specific language will be used to describe the same. It will nevertheless be understood that no limitation of the scope of the invention is thereby intended; any alterations and further modifications of the described or illustrated embodiments, and any further applications of the principles of the invention as illustrated herein are contemplated as would normally occur to one skilled in the art to which the invention relates. One embodiment of the invention is shown in great detail, although it will be apparent to those skilled in the relevant art that some features or some combinations of features may not be shown for the sake of clarity.

[0021] GGS nanoparticles are preferably created by the self-assembly of a sulfide source and a gold source. In some embodiments, the sulfide source is a sulfide salt. In certain embodiments, the sulfide source is sodium thiosulfate $\left(\mathrm{Na}_{2} \mathrm{~S}_{2} \mathrm{O}_{3}\right)$, sodium sulfide $\left(\mathrm{Na}_{2} \mathrm{~S}\right)$, or other suitable sulfur-containing chemical or mixture of chemicals. In some embodiments, the gold source is a gold salt. In some embodiments, the gold source is chloroauric acid $\left(\mathrm{HAuCl}_{4}\right)$, sodium tetrachloroaurate(III) dehydrate $\left(\mathrm{NaAuCl}_{4}\right)$, or other suitable gold-containing chemical or mixture of chemicals. The absorbance peak of GGS nanoparticles can be controlled by cooperatively adjusting the ratio of sodium thiolsulfate and chloroauric acid solutions used to create the GGS nanoparticles. In addition, the concentration of each component may also affect the absorbance peak. Using manufacturing methods disclosed herein, stable GGS nanoparticles may be produced with absorbance peaks between about $600 \mathrm{~nm}$ and about $1000 \mathrm{~nm}$. In certain embodiments, GGS nanoparticles are selectively manufactured to have an absorbance peak substantially identical to the wavelength of the laser used to excite the GGS nanoparticles to maximize the energy absorbed by the GGS nanoparticles. 
[0022] Referring now to Fig. 1, gold colloid is a byproduct of GGS nanoparticle self-assembly. Gold colloid has an absorbance peak at $530+/-20 \mathrm{~nm}$. In the methods disclosed in the referenced applications, gold colloid is removed through centrifugation. GGS nanoparticles are separated from gold colloid by centrifugation. An example separation process is centrifugation at $1000 \mathrm{~g}$ for 20 minutes. Additional centrifugation steps may be used to increase purity.

[0023] Referring now to Fig. 2, GGS nanoparticles are formed in a several shapes, including rods, generally triangular plates, and generally spherical bodies. The term "GGS nanoparticles" is not shape specific and includes particles of particular shapes and mixtures of shapes. The shape of individual GGS nanoparticles within a sample affects the overall absorbance spectrum of the sample. Rod-shaped particles, when oriented on end, provide an absorbance peak at about $530 \mathrm{~nm}$. Therefore, even when substantially all gold colloid is removed from a sample, a measure of absorbance at about $530 \mathrm{~nm}$ may still be present.

[0024] In some embodiments, a sample contains a gold source and a sulfide source which self-assemble into GGS nanoparticles and gold colloid. The sample is dialyzed against deionized ("DI") water during the self-assembly process. In certain embodiments, the gold source and sulfide source are blended in a bag-shaped dialysis membrane. In other embodiments, the gold source and sulfide source are blended together for a specific length of time then transferred into a bag-shaped dialysis membrane. In certain embodiments, the gold source and sulfide source are blended in a first chamber, the first chamber being separate from a second chamber by a dialysis membrane. In certain embodiments, the second chamber may be a re-circulating or purged flow water bath. In certain embodiments, the first chamber may be a flow-through dialysis cell.

[0025] As shown in the examples below, variation in the dialysis time, the molecular weight cut off ("MWCO") of the dialysis membrane, and the ratio of gold source to sulfide source modifies the quality ratio of the resulting product and the wavelength of the absorbance peak. Without being bound by theory, it is hypothesized that dialysis performed during the self-assembly process forces ion-exchange across the membrane, providing a change in reaction kinetics. This hypothesized change in kinetics results in a shift in the equilibrium of the self-assembly reaction which favors GGS nanoparticle 
production within the dialysis membrane and gold colloid production outside the membrane.

[0026] A "quality ratio" is the ratio of the absorbance of synthesized particles in the NIR region (700 nm to $900 \mathrm{~nm}$, for the purposes of this calculation), which corresponds to absorbance characteristics of GGS nanoparticles, relative to absorbance at 530 +/- $20 \mathrm{~nm}$, which corresponds to the absorbance characteristics of gold colloid. Earlier GGS synthesis methods provided quality ratios in the range of $0.4-0.8$ prior to any separation steps, such as centrifugation. The method disclosed herein has provided quality ratios above 1.8, above 2.0, and above 2.3, prior to separation steps, indicating a significantly higher yield of GGS nanoparticles.

[0027] The examples herein disclose the use of dialysis membranes to improve the yield of self-assembled GGS nanoparticles. However, dialysis membranes may be used to improve the yield of other self-assembling nanoparticles as well. In further embodiments, a first chemical species and a second chemical species are blended in a first chamber, the first chamber being separated from a second chamber by a dialysis membrane, wherein the first chemical species and the second chemical species self-assemble into a nanoparticle. In certain embodiments, the first chemical species is a gold source and the second chemical species is a sulfide source. In other embodiments, the first chemical species is a silver source and the second chemical species is a nitride source. In some embodiments, the first chamber is a dialysis membrane shaped to form a bag and the second chamber is a liquidfilled beaker, vial, vat, bucket, or other container in which the first chamber is submerged. In other embodiments, a first chemical species may be dialyzed against the second chemical species to form self-assembling nanoparticles. In these embodiments, a first chemical species is added into a first chamber and a second chemical species is added into a second chamber, the first chamber and second chamber being separated by a dialysis membrane.

[0028] The following examples are provided to illustrate certain specific features of working embodiments and general protocols. The scope of the present invention is not limited to those features exemplified by the following examples. Spectral scans disclosed in the examples were obtained using a UV/Vis spectrophotometer (Carey 50 Varian), and all 
disclosed wavelengths are in nanometer units. Nanometer-scale images were obtained using a tunneling electron microscope (“TEM”) (200 kV FEI Tecnai F20).

\section{EXAMPLE 1}

[0029] Fill a $1 \mathrm{~L}$ beaker with $800 \mathrm{~mL}$ of DI water and include a stir bar. Add a mixture of $11 \mathrm{~mL}$ of $2 \mathrm{mM} \mathrm{HAuCl}_{4}$ and $3 \mathrm{~mL}$ of $3 \mathrm{mM} \mathrm{Na}_{2} \mathrm{~S}_{2} \mathrm{O}_{3}$ in a 3500 Molecular Weight Cut Off (“MWCO”) dialysis membrane for 1 hour (sample 1). For a non-dialysis control sample, $11 \mathrm{~mL}$ of $2 \mathrm{mM} \mathrm{HAuCl}_{4}$ and $3 \mathrm{~mL}$ of $3 \mathrm{mM} \mathrm{Na}_{2} \mathrm{~S}_{2} \mathrm{O}_{3}$ are mixed in a $50 \mathrm{~mL}$ tube and reacted for 1 hour (sample 2). Fill a second $1 \mathrm{~L}$ beaker with $3 \mathrm{mM} \mathrm{Na}_{2} \mathrm{~S}_{2} \mathrm{O}_{3}$. Add $25 \mathrm{~mL}$ of $2 \mathrm{mM} \mathrm{HAuCl}_{4}$ in a $3500 \mathrm{MWCO}$ dialysis membrane to the second beaker and let it react for 1 hour (sample 3).

[0030] Spectral scans of the samples are shown in Fig 3. Sample 1 has a peak at attributable to gold colloid and a strong, distinct peak in the NIR range attributable to GGS nanoparticles. Sample 2 has a peak attributable to gold colloid and strong absorbance NIR range and extending into longer wavelengths. Sample 3 has a peak absorbance at about 530 $\mathrm{nm}$ and no peak in the $700-900 \mathrm{~nm}$ range, indicating the formation only of gold colloid.

\section{EXAMPLE 2}

[0031] Fill a $1 \mathrm{~L}$ beaker with $800 \mathrm{~mL}$ of DI water and include a stir bar. Add a mixture of $11 \mathrm{~mL}$ of $2 \mathrm{mM} \mathrm{HAuCl}_{4}$ and $3 \mathrm{~mL}$ of $3 \mathrm{mM} \mathrm{Na}_{2} \mathrm{~S}_{2} \mathrm{O}_{3}$ in a $3500 \mathrm{MWCO}$ dialysis membrane to the beaker for 1 hour (sample 1). For a non-dialysis sample (sample 2), 11 $\mathrm{mL}$ of $2 \mathrm{mM} \mathrm{HAuCl}_{4}$ and $3 \mathrm{~mL}$ of $3 \mathrm{mM} \mathrm{Na}_{2} \mathrm{~S}_{2} \mathrm{O}_{3}$ are mixed in a $50 \mathrm{~mL}$ tube and reacted for 1 hour. Separately, fill two 1L beakers with $3 \mathrm{mM} \mathrm{Na}_{2} \mathrm{~S}_{2} \mathrm{O}_{3}$. To each beaker, add 25 $\mathrm{mL}$ of $2 \mathrm{mM} \mathrm{HAuCl}_{4}$ in a $3500 \mathrm{MWCO}$ dialysis membrane and let them react for 2.5 and 5 hours, respectively.

[0032] Spectral scans of the samples are shown in Fig. 4. As shown, samples 3 and 4 have negligible GGS nanoparticle formation.

\section{EXAMPLE 3}

[0033] Fill four $1 \mathrm{~L}$ beakers with $800 \mathrm{~mL}$ of DI water and stir bar. Place a mixture of $11 \mathrm{~mL}$ of $2 \mathrm{mM} \mathrm{HAuCl}_{4}$ and $2 \mathrm{~mL}$ of $3 \mathrm{mM} \mathrm{Na}_{2} \mathrm{~S}_{2} \mathrm{O}_{3}$ in a $3500 \mathrm{MWCO}$ dialysis membrane into two beakers for 1 and 2 hours, respectively (samples 2 and 3 of Fig. 5A). 
Place a mixture of $11 \mathrm{~mL}$ of $2 \mathrm{mM} \mathrm{HAuCl}_{4}$ and $3 \mathrm{~mL}$ of $3 \mathrm{mM} \mathrm{Na}_{2} \mathrm{~S}_{2} \mathrm{O}_{3}$ in a $3500 \mathrm{MWCO}$ dialysis membrane into two beakers for 1 and 2 hours (samples 2 and 3 of Fig. 5B). For a non-dialysis sample (sample 1 of Figs. 5A and 5B), $11 \mathrm{~mL}$ of $2 \mathrm{mM} \mathrm{HAuCl}_{4}$ and 2 or $3 \mathrm{~mL}$ of $3 \mathrm{mM} \mathrm{Na} \mathrm{S}_{2} \mathrm{O}_{3}$ are mixed in a $50 \mathrm{~mL}$ tube and reacted for $1 \mathrm{hr}$.

[0034] Spectral scans of the samples are shown in Figs. 5A and 5B. As shown, the sample of $11 \mathrm{~mL}$ of $2 \mathrm{mM} \mathrm{HAuCl}_{4}$ and $2 \mathrm{~mL}$ of $3 \mathrm{mM} \mathrm{Na}_{2} \mathrm{~S}_{2} \mathrm{O}_{3}$ dialyzed in a $3500 \mathrm{MWCO}$ dialysis membrane produces the largest peak shift in the NIR range.

\section{EXAMPLE 4}

[0035] Fill two $1 \mathrm{~L}$ beakers with $800 \mathrm{~mL}$ of DI water and stir bar. Maintain a water temperature of about $100^{\circ} \mathrm{C}$. Add a mixture of $11 \mathrm{~mL}$ of $2 \mathrm{mM} \mathrm{HAuCl}_{4}$ and 3 of $3 \mathrm{mM}$ $\mathrm{Na}_{2} \mathrm{~S}_{2} \mathrm{O}_{3}$ in a 3500 MWCO dialysis membrane for a 5 minute soak (sample 1). Add a mixture of $11 \mathrm{~mL}$ of $2 \mathrm{mM} \mathrm{HAuCl}_{4}$ and $2 \mathrm{~mL}$ of $3 \mathrm{mM} \mathrm{Na}_{2} \mathrm{~S}_{2} \mathrm{O}_{3}$ in a 3500 MWCO dialysis membrane for a 15 minute soak (sample 2).

[0036] As shown in Fig. 6, neither sample produced a peak in the NIR range.

\section{EXAMPLE 5}

[0037] Fill an 8 L bucket with DI water and stir bar. In a 1-step method, a mixture of $11 \mathrm{~mL}$ of $2 \mathrm{mM} \mathrm{HAuCl}_{4}$ and $3 \mathrm{~mL}$ of $3 \mathrm{mM} \mathrm{Na}_{2} \mathrm{~S}_{2} \mathrm{O}_{3}$ in a $3500 \mathrm{MWCO}$ dialysis membrane is added for 1 hour (sample 2). Next for a 2-step method, $4 \mathrm{~mL}$ of $2 \mathrm{mM}$ $\mathrm{HAuCl}_{4}$ and $3 \mathrm{~mL}$ of $3 \mathrm{mM} \mathrm{Na}_{2} \mathrm{~S}_{2} \mathrm{O}_{3}$ are reacted for 30 seconds in a $50 \mathrm{~mL}$ tube, then added into a $3500 \mathrm{MWCO}$ dialysis membrane with an additional $7 \mathrm{~mL}$ of $2 \mathrm{mM} \mathrm{HAuCl}_{4}$ to react for an hour (sample 3). For a non-dialysis sample, $11 \mathrm{~mL}$ of $2 \mathrm{mM} \mathrm{HAuCl}_{4}$ and $3 \mathrm{~mL}$ of 3 $\mathrm{mM} \mathrm{Na} \mathrm{S}_{2} \mathrm{O}_{3}$ are mixed in a $50 \mathrm{~mL}$ tube and reacted for 1 hour (sample 1 ).

[0038] Spectral scans of the samples are shown in Fig. 7. As shown, the two step method of mixing the gold source and sulfide source shortly before insertion into the dialysis membrane resulted in a higher quality ratio, but a lower peak shift, than the one step method.

\section{EXAMPLE 6}

[0039] Fill an $8 \mathrm{~L}$ bucket with DI water and stir bar. Combine samples of $11 \mathrm{~mL}$ of $2 \mathrm{mM} \mathrm{HAuCl}_{4}$ and $3 \mathrm{~mL}$ of $3 \mathrm{mM} \mathrm{Na}_{2} \mathrm{~S}_{2} \mathrm{O}_{3}$ in $3.5 \mathrm{KDa}$ and $12 \mathrm{KDa} \mathrm{MWCO}$ dialysis 
membranes, and allow each to react for an hour (samples 2 and 3 of Fig. 8A). For a 2-step method, react samples of $4 \mathrm{~mL}$ of $2 \mathrm{mM} \mathrm{HAuCl}_{4}$ and $3 \mathrm{~mL}$ of $3 \mathrm{mM} \mathrm{Na}_{2} \mathrm{~S}_{2} \mathrm{O}_{3}$ for 30 seconds, then add $7 \mathrm{~mL}$ of $2 \mathrm{mM} \mathrm{HAuCl}_{4}$ and place in 3.5 and $12 \mathrm{KDa}$ MWCO dialysis membranes to allow further reaction for an hour (samples 2 and 3 of Fig. 8B). For a nondialysis sample, $11 \mathrm{~mL}$ of $2 \mathrm{mM} \mathrm{HAuCl}_{4}$ and $3 \mathrm{~mL}$ of $3 \mathrm{mM} \mathrm{Na}_{2} \mathrm{~S}_{2} \mathrm{O}_{3}$ are mixed in a $50 \mathrm{~mL}$ tube and reacted for 1 hour (sample 1 of Figs. 8A, 8B and 8C). Additionally, the following controls were also synthesized: 2-step, react samples of $4 \mathrm{~mL}$ of $2 \mathrm{mM} \mathrm{HAuCl}_{4}$ and $3 \mathrm{~mL}$ of $3 \mathrm{mM} \mathrm{Na}_{2} \mathrm{~S}_{2} \mathrm{O}_{3}$ for 30 seconds, then add $7 \mathrm{~mL}$ of $2 \mathrm{mM} \mathrm{HAuCl}_{4}$ and allow to react for 1 hour (sample 2 of Fig. 8C); 1-step dialysis as above using a 12 KDa MWCO dialysis membrane (sample 3 of Fig. 8C); and 2-step dialysis as above using a 12 KDa MWCO dialysis membrane (sample 4 of Fig. 8C).

[0040] Spectral scans of the samples are shown in Figs. 8A - 8C. In both the 1-step process and 2-step process, dialysis provides a greatly increased quality ratio as compared to the non-dialysis sample, as shown by the relatively small gold colloid peaks. For the 1step process, Fig. 8A shows that using the 3.5 KDa MWCO dialysis membrane results in a greater peak shift and a higher quality ratio than the $12 \mathrm{KDa}$ MWCO dialysis membrane. In contrast, Fig. 8B shows that using a 3500 MWCO dialysis membrane results in the NIR absorbance peak shifting to a higher wavelength than the non-dialysis sample for the 2-step process. Fig. 8C shows that the two step process, used without dialysis, does not produce a significant fraction of NIR GGS nanoparticles.

\section{EXAMPLE 7}

[0041] Fill two $1 \mathrm{~L}$ beakers with $800 \mathrm{~mL}$ of DI water and stir bar. Maintain a water temperature of $65^{\circ} \mathrm{C}$ in one of the beakers, while the other is left at room temperature (RT). Add a mixture of $11 \mathrm{~mL}$ of $2 \mathrm{mM} \mathrm{HAuCl}_{4}$ and $3 \mathrm{~mL}$ of $3 \mathrm{mM} \mathrm{Na} \mathrm{S}_{2} \mathrm{O}_{3}$ in a $3500 \mathrm{MWCO}$ dialysis membrane to the RT beaker (sample 2) and the $65^{\circ} \mathrm{C}$ beaker (sample 3 ), each for 1 hour. For a non-dialysis sample, $11 \mathrm{~mL}$ of $2 \mathrm{mM} \mathrm{HAuCl}_{4}$ and $3 \mathrm{~mL}$ of $3 \mathrm{mM} \mathrm{Na} \mathrm{S}_{2} \mathrm{O}_{3}$ are mixed in a $50 \mathrm{~mL}$ tube and reacted for 1 hour (sample 1 ).

[0042] Spectral scans of the samples are shown in Fig. 9. As shown, the yield of GGS nanoparticles, as evidenced by the NIR peak, was significantly greater at RT than at the elevated temperature. 


\section{EXAMPLE 8}

[0043] Fill an $8 \mathrm{~L}$ bucket with DI water and stir bar. Add a mixture of $11 \mathrm{~mL}$ of 2 $\mathrm{mM} \mathrm{HAuCl}_{4}$ and $3 \mathrm{~mL}$ of $3 \mathrm{mM} \mathrm{Na}_{2} \mathrm{~S}_{2} \mathrm{O}_{3}$ in $2 \mathrm{KDa}$ and $3 \mathrm{KDa}$ MWCO dialysis membranes for 1 hour (samples 2 and 3). For a non-dialysis sample, $11 \mathrm{~mL}$ of $2 \mathrm{mM} \mathrm{HAuCl}_{4}$ and $3 \mathrm{~mL}$ of $3 \mathrm{mM} \mathrm{Na} 2 \mathrm{~S}_{2} \mathrm{O}_{3}$ are mixed in a $50 \mathrm{~mL}$ tube and reacted for 1 hour (sample 1).

[0044] Spectral scans of the samples are shown in Fig. 10. As shown, use of the 3.5 KDa MWCO dialysis membrane provides a significantly larger NIR peak shifts than the 2 KDa MWCO membrane. The following Table 1 is a summary of the absorbance peaks and quality ratios for each sample.

Table 1. Summary of Sample Properties in Example 8

\begin{tabular}{|l|c|c|}
\hline Samples & NIR Absorbance Peak (nm) & Quality Ratio \\
\hline Sample 1 / No dialysis & 928 & 1.473 \\
\hline Sample 2 / 2 KDa MWCO & 918 & 1.378 \\
\hline Sample 3 / 3.5 MWCO & 765 & 1.513 \\
\hline
\end{tabular}

\section{EXAMPLE 9}

[0045] Fill an $8 \mathrm{~L}$ bucket with DI water and stir bar. Add mixtures of $11 \mathrm{~mL}$ of 2 $\mathrm{mM} \mathrm{HAuCl}_{4}$ and $3 \mathrm{~mL}$ of $3 \mathrm{mM} \mathrm{Na}_{2} \mathrm{~S}_{2} \mathrm{O}_{3}$ in three separate $3.5 \mathrm{KDa}$ MWCO dialysis membranes for 1, 2, and 4 hour, respectively (samples 2, 3, and 4 of Fig. 11A). Fill a separate $8 \mathrm{~L}$ bucket with DI water and stir bar. Add mixtures of $11 \mathrm{~mL}$ of $2 \mathrm{mM} \mathrm{HAuCl}_{4}$ and $3 \mathrm{~mL}$ of $3 \mathrm{mM} \mathrm{Na}_{2} \mathrm{~S}_{2} \mathrm{O}_{3}$ in three separate $2 \mathrm{KDa}$ MWCO dialysis membranes for 1, 2, and 4 hours, respectively (samples 2, 3, and 4 of Fig. 11B). For a non-dialysis sample, 11 $\mathrm{mL}$ of $2 \mathrm{mM} \mathrm{HAuCl}_{4}$ and $3 \mathrm{~mL}$ of $3 \mathrm{mM} \mathrm{Na}_{2} \mathrm{~S}_{2} \mathrm{O}_{3}$ are mixed in a $50 \mathrm{~mL}$ tube and reacted for 1 hour (sample 1 of Figs. 11A and 11B). Spectral scans of the samples are shown in Figs. $11 \mathrm{~A}$ and $11 \mathrm{~B}$.

[0046] The following Table 2 is a summary of the absorbance peaks, extinction coefficients, and quality ratios of each sample. For the non-dialyzed "No Dia" control samples, the column "Dialysis Time" simply indicates the delay between mixing the gold and sulfide sources and acquiring the spectral data. 
Table 2. $\quad$ Summary of Sample Properties in Example 9

\begin{tabular}{|l|c|c|c|c|c|}
\hline Samples & $\begin{array}{c}\text { Dialysis } \\
\text { Time } \\
\text { (hours) }\end{array}$ & $\begin{array}{c}\text { NIR } \\
\text { Absorbance } \\
\text { Peak (nm) }\end{array}$ & $\begin{array}{c}\text { Colloid } \\
\text { Extinction } \\
\text { Coeff. }\end{array}$ & $\begin{array}{c}\text { NIR } \\
\text { Extinction } \\
\text { Coeff. }\end{array}$ & $\begin{array}{c}\text { Quality } \\
\text { Ratio }\end{array}$ \\
\hline $\begin{array}{l}\text { No Dia } \\
\text { (sample 1, Figs. } \\
\text { 11A and 11B) }\end{array}$ & 1 & 959 & 0.766 & 1.179 & 1.539 \\
\hline $\begin{array}{l}\text { 2K Dia } \\
\text { (sample 2, Fig. } \\
\text { 11B) }\end{array}$ & 1 & 899 & 0.605 & 0.821 & 1.357 \\
\hline $\begin{array}{l}\text { 2K Dia } \\
\text { (sample 3, Fig. } \\
\text { 11B) }\end{array}$ & 2 & 926 & 0.632 & 0.895 & 1.416 \\
\hline $\begin{array}{l}\text { 2K Dia } \\
\text { (sample 4, Fig. } \\
\text { 11B) }\end{array}$ & 4 & 930 & 0.616 & 0.889 & 1.444 \\
\hline $\begin{array}{l}\text { 3.5K Dia } \\
\text { (sample 2, Fig. } \\
\text { 11A) }\end{array}$ & 1 & 816 & 0.599 & 0.916 & 1.527 \\
\hline $\begin{array}{l}\text { 3.5K Dia } \\
\text { (sample 3, Fig. } \\
\text { 11A) }\end{array}$ & 2 & 815 & 0.622 & 1.007 & 1.620 \\
\hline $\begin{array}{l}\text { 3.5K Dia } \\
\text { (sample 4, Fig. } \\
\text { 11A) }\end{array}$ & 4 & 819 & 0.615 & 0.967 & 1.573 \\
\hline
\end{tabular}

\section{EXAMPLE 10}

[0047] Fill an $8 \mathrm{~L}$ bucket with DI water and stir bar. Add mixtures of $11 \mathrm{~mL}$ of 2 $\mathrm{mM} \mathrm{HAuCl}_{4}$ and $2 \mathrm{~mL}$ of $3 \mathrm{mM} \mathrm{Na}_{2} \mathrm{~S}_{2} \mathrm{O}_{3}$ in three separate $3.5 \mathrm{KDa}$ MWCO dialysis membranes for 1, 2, and 4 hour, respectively. Also, add mixtures of $11 \mathrm{~mL}$ of $2 \mathrm{mM}$ $\mathrm{HAuCl}_{4}$ and $2 \mathrm{~mL}$ of $3 \mathrm{mM} \mathrm{Na}_{2} \mathrm{~S}_{2} \mathrm{O}_{3}$ in three separate $2 \mathrm{KDa}$ MWCO dialysis membranes for 1, 2, and 4 hours. For a non-dialysis sample, $11 \mathrm{~mL}$ of $2 \mathrm{mM} \mathrm{HAuCl}_{4}$ and $2 \mathrm{~mL}$ of 3 $\mathrm{mM} \mathrm{Na} \mathrm{S}_{2} \mathrm{O}_{3}$ are mixed in a $50 \mathrm{~mL}$ tube and reacted for 1 hour.

[0048] Spectral scans of the samples are shown in Fig. 12. As shown, dialysis using 3.5 KDa MWCO dialysis membranes produced significant peak shifts. Dialysis using 2 KDa MWCO dialysis membranes did not result in distinct peaks in the NIR range.. 


\section{EXAMPLE 11}

[0049] Fill an $8 \mathrm{~L}$ bucket with DI water and stir bar. Add mixtures of $11 \mathrm{~mL}$ of 2 $\mathrm{mM} \mathrm{HAuCl}_{4}$ and 2.5, 3, 3.5, 4, 4.5, or $5 \mathrm{~mL}$ of $3 \mathrm{mM} \mathrm{Na}_{2} \mathrm{~S}_{2} \mathrm{O}_{3}$ in $50 \mathrm{~mL}$ tubes, or $2 \mathrm{KDa}$ or 3.5 KDa MWCO dialysis membranes for 1 hour. The following Table 3 is a summary of the samples, their Int ratios, NIR peaks, and quality ratios. An "Int ratio" is the ratio of the volume of gold source to the volume of sulfide source in a given sample, the concentrations of the gold source and sulfide source remaining constant between compared samples. For example, $11 \mathrm{~mL}$ of $2 \mathrm{mM} \mathrm{HAuCl}_{4}$ and $2.5 \mathrm{~mL}$ of $3 \mathrm{mM} \mathrm{Na}_{2} \mathrm{~S}_{2} \mathrm{O}_{3}$ provides an Int ratio of 11 / $2.5=4.40$. Non-dialyzed samples are identified herein as "RT" or room temperature, although all samples were maintained at room temperature throughout the experiment.

Table 3. S Summary of Sample Properties in Example 11

\begin{tabular}{|c|c|c|c|c|}
\hline $\begin{array}{c}\text { Dialysis } \\
\text { Method }\end{array}$ & $\begin{array}{c}\text { Sample (vol. gold source }+ \\
\text { vol. sulfide source) }\end{array}$ & Int Ratio & $\begin{array}{c}\text { NIR Absorbance } \\
\text { Peak (nm) }\end{array}$ & Quality Ratio \\
\hline RT & $11+2.5$ & 4.40 & none & N/A \\
\hline RT & $11+3$ & 3.67 & 995 & 1.675 \\
\hline RT & $11+3.5$ & 3.14 & 901 & 1.398 \\
\hline RT & $11+4$ & 2.75 & 852 & 1.126 \\
\hline RT & $11+4.5$ & 2.44 & 807 & 0.895 \\
\hline RT & $11+5$ & 2.20 & 779 & 0.730 \\
\hline $2 \mathrm{KDa}$ & $11+2.5$ & 4.40 & 931 & 1.588 \\
\hline $2 \mathrm{KDa}$ & $11+3$ & 3.67 & 928 & 1.421 \\
\hline $2 \mathrm{KDa}$ & $11+3.5$ & 3.14 & 950 & 1.436 \\
\hline $2 \mathrm{KDa}$ & $11+4$ & 2.75 & 848 & 1.209 \\
\hline $2 \mathrm{KDa}$ & $11+4.5$ & 2.44 & 771 & 0.783 \\
\hline $2 \mathrm{KDa}$ & $11+5$ & 2.20 & 771 & 0.787 \\
\hline $3.5 \mathrm{KDa}$ & $11+2.5$ & 4.40 & 789 & 1.804 \\
\hline $3.5 \mathrm{KDa}$ & $11+3$ & 3.67 & 816 & 1.731 \\
\hline $3.5 \mathrm{KDa}$ & $11+3.5$ & 3.14 & 820 & 1.621 \\
\hline $3.5 \mathrm{KDa}$ & $11+4$ & 2.75 & 834 & 1.352 \\
\hline $3.5 \mathrm{KDa}$ & $11+4.5$ & 2.44 & 789 & 1.038 \\
\hline $3.5 \mathrm{KDa}$ & $11+5$ & 2.20 & 747 & 0.787 \\
\hline
\end{tabular}

[0050] Spectral scans of selected samples from Table 3 are shown in Figs. 13A and 13B. More specifically, Fig. 13A includes spectral scans of samples dialyzed in 2 KDa MWCO dialysis membranes and Fig. 13B includes spectral scans of samples dialyzed in 3.5 KDa MWCO dialysis membranes. Fig. 13C depicts the correlation between NIR peak wavelength and Int ratio. Fig. 13D depicts the correlation between quality ratio and Int 
ratio. Note that in several places in Figs. 13C and 13D, a diamond symbol identifying a non-dialyzed sample is not visible as it is covered by a square symbol identifying a sample dialyzed in a 2 KDa MWCO dialysis membrane. Fig. 13C indicates that decreasing Int ratios generally correlate with NIR absorbance peaks at lower wavelengths. As shown in Fig. 13D, increasing Int ratios generally correlate with increasing quality ratios.

[0051] The foregoing detailed description is given primarily for clearness of understanding and no unnecessary limitations are to be understood therefrom for modifications can be made by those skilled in the art upon reading this disclosure and may be made without departing from the spirit of the invention. 


\begin{abstract}
OF THE DISCLOSURE
Embodiments disclosed herein relate to a method for synthesizing self-assembling nanoparticles with defined plasmon resonances. More particularly, certain embodiments disclosed herein relate to an improved method for synthesizing self-assembling gold / gold sulfide nanoparticles by dialyzing samples during the self-assembly process.
\end{abstract}




\section{APPENDIX II}

\section{APPOINTMENT OF MEMBERS OF THE EXAMINATION COMMITTEE}

\section{UNIVERSITY OF LOUISVILLE}

\section{J. B. SPEED SCHOOL OF ENGINEERING}

$$
\text { June } 5^{\text {th }}, 2012
$$

MEMO TO: Academic Affairs Office

J. B. Speed School of Engineering

FROM: $\quad$ Andre M. Gobin, Bioengineering

Thesis Director

SUBJECT: Appointment of Members of the Master of Engineering Examination Committee for DHRUVINKUMAR PATEL

THROUGH: Robert S. Keynton

\section{CONSTITUENCY OF EXAMINATION COMMITTEE}

It is recommended that the following individuals be officially designated as members of the Master of Engineering Examination Committee of subject M.Eng. candidate. Each of these persons has been contacted, and has agreed to serve on the Examination Committee (see page 1 for more detail on constituency of the committee):

(Name, Department)

1. Andre M. Gobin, Bioengineering

Thesis Director

2. Andrea S. Gobin, Bioengineering Member

3. Stuart J. Williams, Mechanical Engineering Member

4. Member

In addition to the foregoing membership of the Examination Committee, it is requested that the following committee representatives from outside Speed School, each of whom has agreed to serve, be appointed as Members of the Examination Committee:

1. External Member (Name)

(Mailing Address of External Member)

2. (Name)

External Member

(Mailing Address of External Member)

\section{M.ENG. PROJECT DESCRIPTION}

A brief description of the proposed M.Eng. Project is as follows:

This project is focused on the scale up of gold-gold sulfide (GGS) nanoparticles with desired near infrared peak (nIR) that can be used for therapeutic applications. By combining published the current methods for 1step self-assembly and an equilibrium shifting approach, the reaction is shifted to favor the formation of nIR absorbing particles. 


\section{APPENDIX II \\ (continued)}

A tentative title (10 words or less) of the proposed M.Eng. Thesis is:

A Novel High Yield Process for Gold Sulfide Nanoparticle Synthesis

(Signature of Thesis Director)

\section{III.APPROVAL BY DEPARTMENT CHAIR}

The Thesis Director has conferred with me relative to the investigation, thesis topic and committee membership of the indicated student, and I concur with the recommendations.

(Signature of Department Chair)

General Instructions:

The student in collaboration with the Thesis Director should prepare this form: original to the Department Chair, copy retained by the student, and one copy for the Thesis Director's file.

Full-time students must submit the project description and constituency of the Master of Engineering examination committee according to the specific dates in Appendix I.

Part-time students must submit the project description and constituency of a Master of Engineering examination committee not later than one calendar year prior to the student's expected date of graduation.

\section{Approval form to be distributed by Department Chair to M.Eng. candidate, thesis director, committee members, and Academic Affairs Office.}


APPENDIX III

\section{ORAL EXAMINATION REQUEST}

UNIVERSITY OF LOUISVILLE

\section{J. B. SPEED SCHOOL OF ENGINEERING}

$6 / 5 / 12$

(Date)

MEMO TO: Academic Affairs Office

FROM: $\quad$ (Insert name of M.Eng. Thesis Director)

SUBJECT: $\quad$ M.Eng. Oral Examination and Thesis Defense for (Name of Student)

1. The oral examination and thesis defense of subject degree candidate will be held on

Tuesday (Day of Week), June $5^{\text {th }}, 2012$ (Date), at 10:00 AM (Time) in Room

No. $\underline{306}$ of _ LUTZ HALL (Building).

2. The title of the M.Eng. Thesis is:

A NOVEL HIGH YIELD PROCESS FOR GOLD SULFIDE NANOPARTICLE SYNTHESIS VIA SHIFTING EQUILIBRIUM OF SELF-ASSEMBLY REACTION

(Signature of Thesis Director)

THE STUDENT IS RESPONSIBLE FOR DISTRIBUTION OF THESE COPIES

Copies to: 1) Department Chair

2) Thesis Director

3) Committee Member

4) Committee Member

5) Committee Member

6) Committee Member
Robert S. Keynton

Andre M. Gobin

Andrea S. Gobin

Stuart J. Williams 


\title{
APPENDIX III \\ ORAL EXAMINATION REQUEST \\ UNIVERSITY OF LOUISVILLE \\ J. B. SPEED SCHOOL OF ENGINEERING
}

\author{
MEMORANDUM TO: $\quad$ Academic Affairs Office \\ FROM: \\ (Insert name of Thesis Director) \\ SUBJECT: \\ M.Eng. Oral Examination and Thesis Defense For (Name of Student)
}

1. The oral examination and thesis defense of subject degree candidate will be held on

Tuesday (Day of Week), June 5 ${ }^{\text {th }}, 2012$ (Date), at 10:00 AM (Time) in Room

No. 306 of _ LUTZ HALL (Building).

2. The examination and defense began at 10:00 AM_ (Time) and was concluded at 11:30 AM (Time).

3. The candidate PASSED the oral examination and thesis defense.

4. Qualifications or clarifying statements considered to be important by the Thesis Director (Optional):

(Signature of Thesis Director)

Copy to: Department Chair 